UNIVERSIDADE DE SÃO PAULO

INSTITUTO DE FÍSICA DE SÃO CARLOS

DANILO OLZON DIONYSIO DE SOUZA

Propriedades optoeletrônicas de interfaces

híbridas metal/semicondutor orgânico preparadas por deposição assistida por feixe de íons (IBAD) 



\section{Propriedades optoeletrônicas de interfaces \\ híbridas metal/semicondutor orgânico preparadas por deposição assistida por feixe de íons (IBAD)}

Dissertação apresentada ao Programa de Pós Graduação em Física do Instituto de Física de São Carlos da Universidade de São Paulo, para obtenção do título de Mestre em Ciências.

Área de Concentração: Física Aplicada

Orientador: Prof. Dr. Francisco E. G. Guimarães

Versão Corrigida

(versão original disponível na Unidade que aloja o Programa)

São Carlos 
AUTORIZO A REPRODUÇÃO E DIVULGAÇÃO TOTAL OU PARCIAL DESTE TRABALHO, POR QUALQUER MEIO CONVENCIONAL OU ELETRÔNICO, PARA FINS DE ESTUDO E PESQUISA, DESDE QUE CITADA A FONTE.

Ficha catalográfica elaborada pelo Serviço de Biblioteca e Informação IFSC/USP

Souza,Danilo Olzon Dionysio de

Propriedades optoeletronicas de interfaces hibridas metal/semicondutor orgânico preparadas por deposição assistida por feixe de íons (IBAD)./Danilo Olzon Dionysio de Souza ; orientador Francisco Eduardo Gontijo Guimarães.--versão corrigida--São Carlos, 2011.

$132 p$.

Dissertação (Mestrado-Programa de Pós-Graduação em Ciências.Área de concentração:Física Aplicada ) - Instituto de Física de São Carlos,Universidade de São Paulo,2011.

1. Eletrônica orgânica. 2. Interface metal polímeros. 3. OLED. 4. IBAD. 5.Contatos elétricos. I.Título. 




\section{AGRADECIMENTOS}

À minha família, que sempre esteve ao meu lado me apoiando e dando a oportunidade de concluir este mestrado. Sem vocês nada faria sentido.

Ao meu orientador, Prof. Francisco Guimarães, pela oportunidade de trabalhar neste projeto e pela amizade.

Aos professores Chubaci e Masao, pela oportunidade de trabalharmos juntos e pela amizade.

Aos técnicos do IFSC: Débora, Aroldo, Carlão, Nibio, Bertho, Marcos, Carlinhos e outros tantos que me ajudaram.

Aos técnicos do IF - USP: João Terassi, Otávio, Celso, Vanda, Jorge e Márcio.

À secretaria da Pós Graduação (Silvio, Ricardo e Victor) e também ao Prof. Tito.

À biblioteca: Cris, Neusa, Natalina, Bethânia, Mara e todos os outros funcionários.

Aos meus colegas: Angelo, Tsuty, Luis,Regina, Mike, Nirton, Fernando, Gustavo, Victor, Haroldo, Alexandre, Douglas e outros, que, com certeza esqueci.

Ao Prof. Zanatta pela pronta ajuda com as medidas de Raman.

Ao CNPq pela bolsa concedida.

E por fim, ao IFSC, por ter me acolhido na graduação e no mestrado. 



\section{RESUMO}

OLZON-DIONYSIO, D. Propriedades optoeletrônicas de interfaces híbridas metal/semicondutor orgânico preparadas por deposição assistida por feixe de íons (IBAD). 2011. 132p. Dissertação (Mestrado em Ciências) - Instituto de Física de São Carlos, Universidade de São Paulo, São Carlos, 2011.

Neste trabalho foram estudadas as propriedades optoeletrônicas de dispositivos orgânicos emissores de luz (OLEDs) à base de polímeros conjugados possuindo catodos metálicos depositados por meio da técnica de deposição assistida por feixe de íons (IBAD). O principal objetivo do trabalho é produzir uma interface híbrida metal/polímero não abrupta e estudar os seus efeitos na injeção de elétrons. $O$ uso da técnica IBAD em eletrônica orgânica é incipiente, sendo este o primeiro trabalho no Brasil aplicando-a em eletrônica orgânica. Diversos experimentos exploratórios foram feitos para adequar o uso da técnica a esta nova aplicação. Os dispositivos OLEDs possuem estrutura vertical que consiste de um anodo transparente de óxido de estanho índio (ITO) depositado sobre substrato de vidro; de uma camada transportadora de buracos de Poli (3,4-etilenodioxitiofeno): Poli (estirenosulfonato) (PEDOT:PSS) e de uma camada ativa de polifluoreno (PFO). O catodo de alumínio foi depositado sobre o PFO, utilizando a técnica IBAD, utilizando íons de argônio com energia variando de 0 a $1000 \mathrm{eV}$. Simulações utilizando o código TRIM (Transport of Ions in Matter) foram feitas para avaliar a penetração do Al na camada polimérica, bem como o deslocamento atômico durante o processo IBAD. Medidas de microscopia de fluorescência, fotoluminescência (PL) e espectroscopia Raman foram utilizadas para caracterizar os efeitos dos íons sobre a camada polimérica. As propriedades da interface híbrida foram estudadas variando-se a espessura da camada ativa emissora de luz e introduzindo camadas espaçadoras de polieletrólitos inertes entre o catodo metálico e o PFO. Íons com energia maior que $400 \mathrm{eV}$ produzem a diminuição das propriedades luminescentes do polímero. Por fim, as propriedades de injeção eletrônica do catodo foram estudadas através de medidas de corrente e eletroluminescência em função da voltagem. Os resultados mostraram que houve um expressivo deslocamento da voltagem de injeção $\left(\mathrm{V}_{\text {on }}\right)$ para íons de argônio com energias variando entre 0 e $400 \mathrm{eV}$. As curvas de corrente versus voltagem são descritas pelo modelo 
Fowler- Nordheim e possuem características alteradas pelo processo IBAD. Medidas de luminescência e de corrente versus voltagem sugerem a formação de uma interface contendo nanopartículas metálicas isoladas espalhadoras de luz para energias dos íons de argônio entre 0 e $80 \mathrm{eV}$. Estas nanopartículas favorecem a injeção para campos elétricos menores. A melhora no contato entre o polímero e o catodo é observada e é consistente com a redução de caminhos preferenciais durante a injeção de elétrons, o que minimiza problemas relacionados à eficiência e durabilidade dos OLEDs.

Palavras-chave: Eletrônica orgânica. Interface metal polímero. OLED. IBAD. Contatos elétricos 


\begin{abstract}
OLZON-DIONYSIO, D. Optoelectronic properties of interfaces hybrid metal / organic semiconductor prepared by ion beam assisted deposition (IBAD). 2011.132p.. Dissertação (Mestrado em Ciências) - Instituto de Física de São Carlos, Universidade de São Paulo, São Carlos, 2011.
\end{abstract}

In this work, optoelectronic properties from organic light emitting devices (OLEDs), based on conjugated polymers with metallic cathode, which were deposited by ion beam assisted deposition technique (IBAD) were studied. The main objective of this work is to produce a hybrid non abrupt metal/polymer interface and to study its effects on electron injection. The use of this technique in organic electronics is incipient, being used in Brazil for the first time. Several exploratory experiments were made, to suit this technology to this new application. The OLEDs devices have a typical vertical-architecture, using Indium Tin Oxide (ITO) covered glass substrate as transparent anode; Poly [ethylene-dioxythiophene]: Poly [styrene sulfonic acid] (PEDOT:PSS) as hole transport layer and polifluorene (PFO) as emitting layer. The cathode layer were deposited over the PFO using IBAD with aluminum and Ar ions, with energies in the range from 0 to $1000 \mathrm{eV}$. Computer simulations using TRIM code (Transport of Ions in Matter) were done to evaluate the Al penetration into the polymer and the atomic displacement during IBAD process. Fluorescence microscopy, photoluminescence (PL) and Raman spectroscopy were used to study the effects of ions on the polymer layer. The hybrid interface properties were studied with the variation of the active layer thickness and introducing spacing layers of inert polyelectrolyte between the metallic cathode and the PFO. Ions with energy above $400 \mathrm{eV}$ decrease polymer electroluminescent properties. Finally, electron injection properties of the cathode were studied using Current - Voltage and Electroluminescent measurements. The results show that lower $\mathrm{Ar}^{+}$ion energies (between 0 and $400 \mathrm{eV}$ ) cause a significant shift on the injection voltage. The Current - Voltage curves, whose characteristics are modified by IBAD, are described by Fowler - Nordheim model. These measurements suggests that $\mathrm{Ar}^{+}$ion energies between 0 and $80 \mathrm{eV}$ promote the formation of an interface that contains isolated metallic nanoparticles, which may scatter the 
light. These nanoparticles ease the injection for lower electric fields. The enhancement of the contact between polymer and cathode is observed and is consistent with the reduction of preferred paths during electron injection, which minimizes the problems related to OLEDs efficiency and durability.

Keywords: Organic electronics. Polymer metal interface. OLED. IBAD. Electrical contacts. 


\section{LISTA DE FIGURAS}

Figura 1 Representação dos orbitais $\pi$ e $\sigma$ de uma molécula conjugada.

Figura 2 Diagrama esquemático dos níveis energéticos para um carbono, para $\quad 30$ dois carbonos ligados por uma dupla ligação e para infinitos segmentos deste, ligados consecutivamente.

Figura 3 - Diagrama de Jablonski ilustrando a excitação óptica e relaxação energética de um estado excitado através de diferentes processos intramoleculares.

Figura 4 - Dinâmica da migração de energia entre segmentos conjugados.

Figura 5 - Emissão (E1) e reflexão (E2) de um dipolo oscilante $(\mu)$ situado a uma distância d da superfície metálica.

Figura 6 - Eficiência da emissão (1-EF) em função da distancia entre a molécula emissora e a superfície metálica, considerando transferência ressonante Förster, onde r0 é o raio de Förster.

Figura 7 - Gráfico da razão entre IC e I0, em função da distância entre a molécula emissora e a superfície metálica, para superfícies com reflectâncias de 100,80, 60, 40, $2020 \%$. Na parte superior estão representadas as dimensões das amostras utilizadas neste trabalho, para visualização.

Figura 8 - (a) Esquema da estrutura básica de um OLED. (b) Diagrama esquemático das bandas de energia de um OLED.

Figura 9 Diagrama de bandas de energia para um dispositivo polarizado, destacando o processo de funcionamento. -

Figura 10 Diagrama esquemático das bandas de um OLED, com o uso de PEDOT: PSS, PFO e diferentes metais.

Figura 11 - Diagrama de energias para um dispositivo sob um campo elétrico. As setas em vermelho indicam a distância para o tunelamento que deve ser superada para a injeção através de cada barreira.

Figura 12 - Digrama esquemático das bandas de energia para um contato elétrico sem armadilhas profundas (a) e com armadilhas profundas(b).

Figura 13 - Desenho esquemático da formação da interface metal/polímero para polímeros reativos (a) e polímeros consideravelmente inertes (b). Figura retirada da referência23.

Figura 14 Esquema do processo de IBAD realizado (a). Esquema da interface 
formada por IBAD (b).

Figura 15 Etapas do processo de decapagem do substrato vidro/ITO. Visão de 53 cima (parte superior) e visão lateral (parte inferior).

Figura 16 Estrutura química dos polímeros (poli (3,4-etilenodioxitiofeno) (PEDOT) (a) e (poli (estirenosulfonato) (PSS) (b). Fonte: CLEVIOS

Figura 17 Método spin coating para obtenção de filme polimérico.. (a) Deposição 54 da solução de blenda por meio de uma pipeta sobre o substrato vidro/ITO. b) Centrifugação para eliminar o excesso de solução (c) Evaporação do solvente com formação do filme polimérico.

Figura 18 Estrutura química do ADS GE108. Fonte: ADS 55

Figura 19 (a) Espectro de emissão para o substrato quartzo/ADS GE108 e (b) 56 espectro de excitação para o substrato vidro/ADS GE108.

Figura 20 Estruturas químicas do poli(cloreto de dialildimetil amônia) (PDAC)(a) 57 e do poli(estireno sulfonado) (PSS) (b).

Figura 21 Esquema do sistema de IBAD.

Figura 22 Esquema da amostra: (a) vista de cima (à direita da amostra os polímeros foram removidos); (b) e (c) Cortes A e B, respectivamente, conforme indicado.

Figura 23 Esquema do porta amostras (fora de escala).

Figura 24 Esquema das amostras preparadas.

Figura 25 Esquema do sistema de PL utilizado na segunda série de amostras. $\quad 67$

Figura 26 Penetração média de um íon em função da energia, para alvos com duas densidades diferentes.

Figura 27 Número de átomos deslocados em função da profundidade, para íons de argônio com $200 \mathrm{eV}$ incidindo sobre PFO. Incidência de íons da esquerda para a direita.

Figura 28 Número de átomos de $\mathrm{Al}$ deslocados em função da profundidade para íns de argônio com $200 \mathrm{eV}$ incidindo sobre uma camada de $\mathrm{Al}$ (que varia de 5 a $30 \AA$ ) sobre PFO (a) e a soma de todos deslocamentos, demonstrando o processo IBAD(b). À esquerda da linha tracejada, tem-se o Al e à direita, o PFO. A incidência de íons se dá da esquerda para a direita. 
Figura 29 Gráfico da espessura da camada de alumínio em função da energia dos 76 íons de argônio

Figura 30 - Perfil da posição final dos átomos de Al, em escala monolog (a) e de AL e $\mathrm{C}$ superpostos em escala linear (b) deslocados no processo IBAD. À esquerda da linha vertical preta (em $70 \AA \AA$ em (a) e em $0 \AA$ em (b) ), tem-se o Al e à direita, o PFO. A incidência de íons de argônio, com $(200,600$ e $1000 \mathrm{eV})$, se dá da esquerda para a direita.

Figura 31 (a) Esquema detalhado do processo de formação das três áreas. $\mathrm{O}$ ângulo de incidência do íon foi extrapolado para melhor visualização. (b) Esquema do resultado final.

Figura 32 Imagens de microscopia de fluorescência para as amostras produzidas com íons de 200, 600 e $1000 \mathrm{eV}$.

Figura 33 - Gráfico da intensidade de cada pixel integrada ao longo de uma linha em função da posição no eixo $\mathrm{Y}$ da imagem, para as três imagens da Figura 32. Região I > Polímero/Metal; Região II > Polímero ; Região III > Polímero/Íon

Figura 34 - Imagem de microscopia de fluorescência para a amostra produzida com íons de $1000 \mathrm{eV}$. Gráfico sobreposto em vermelho corresponde à intensidade integrada em função da posição da linha X para as três regiões identificadas.

Figura 35 - Esquema em que a parte de cima ilustra o perfil morfológico das amostras e abaixo o perfil de luminescência esperado. À esquerda a região I( protegida pela máscara), ao centro a região II (onde ocorreu apenas metalização) e à direita a região III (onde metalização e incidência de íons ocorreram simultaneamente).

Figura 36 - Comparação entre os perfis de intensidade ao longo da linha Y (perpendicular às ondulações) para as três regiões da Figura 34.

Figura 37 Espectro de fotoluminescência das amostras de 0, 200, 600 e $1000 \mathrm{eV}$. Inserção: Gráfico do máximo da PL ( 510 nm) em função da energia do íon. (b) Espectro de excitação normalizado das amostras de 0, 200, 600 e $1000 \mathrm{eV}$.

Figura 38 Espectro Raman sob a região metalizada (a) e sob a região não metalizada e a região onde ocorreu unicamente a incidência de íons(b) das amostras obtidas com íons de 0,200,600 e 1000 eV e 0 e 1000 eV, respectivamente. 
Figura 39 Gráficos de corrente em função da voltagem (a) e eletroluminescência

(b) para as amostras com 0, 200, 600 e $1000 \mathrm{eV}$.

Figura 40 Gráficos da absorbância para diferentes números de bicamadas; O detalhe corresponde ao valor da absorbância em 197nm em função do número de bicamadas.

Figura 41 Gráfico da corrente em função da voltagem (a)e do campo elétrico (b) 97 para amostras com diferentes números de bicamadas. $\mathrm{Na}$ inserção, o valor da voltagem Von em função do número de bicamadas.

Figura 42 - Perfil de concentração dos íons de Ar do processo IBAD (com e sem 98 shutter). À esquerda da linha pontilhada, tem-se o Al e à direita, o PFO. A incidência de íons de argônio, com $200 \mathrm{eV}$, se dá da esquerda para a direita.

Figura 43 - (a) Perfil da posição final dos átomos de Al deslocados durante o 99 processo IBAD (com e sem shutter). (b) Perfil da posição dos átomos de $\mathrm{C}$ deslocados no processo IBAD (com e sem shutter). À esquerda da linha pontilhada, tem-se o Al e à direita, o PFO. A incidência de íons de argônio, com $200 \mathrm{eV}$, se dá da esquerda para a direita.

Figura 44 - Perfil dos átomos de alumínio implantados no polímero e dos átomos 100 de carbono deslocados.

Figura 45 - (a) Espectro de luminescência da amostra com espaçador nas regiões Polímero e Polímero/Metal para as diferentes energias de íons. (b) Esquema representativo do experimento, mostrando as duas regiões.

Figura 46 - Gráfico da integral da PLP em função da energia dos íons para as 102 amostras contendo camada ativa de PFO de $40 \mathrm{~nm}$ e de $150 \mathrm{~nm}$ e de 40 $\mathrm{nm}$ com espaçador de PDAC/PSS de $16 \mathrm{~nm}$.

Figura 47 - Razão da intensidade integrada PLM/PLP em função da energia dos 102 íons para (a) amostras fina e espessa. (b) amostras.finas, espessa e com espaçador.

Figura 48 - Simulação do perfil de concentração das nanopartículas em função da profundidade, para doses de. $0,8 \times 1016 \mathrm{~cm}-2$ (a) e $1,5^{\mathrm{x}} 1016 \mathrm{~cm}-2$ (b). Imagem de microscopia de transmissão de ouro implantado em PMMA com doses de 0,8 x $1016 \mathrm{~cm}-2$ (c) e $1,5^{\mathrm{x}} 1016 \mathrm{~cm}-2$ (d). Figuras retiradas das referências. $87 ; 88$

Figura 49 Esquema do efeito da formação de aglomerados sobre a intensidade da 105 PL para interfaces metálicas formadas com íons de diferentes energias. 
Figura 50 - Simulação da alteração na intensidade, para as três amostras, causada 107 por uma semicavidade para diferentes valores de reflectância.

Figura 51 Amostra fina: (a) Gráfico de corrente em função da voltagem para 109 diferentes energias de íons e; (b) Voltagem necessária para atingir uma determinada corrente em função da energia dos íons .

Figura 52 Amostra espessa: (a) Gráfico de corrente em função da voltagem para diferentes energias de íons e; (b) Voltagem necessária para atingir uma determinada corrente em função da energia dos íons .

Figura 53 Gráfico da densidade de corrente em função do campo,para as amostras com 150nm de PFO, onde a distância entre os eletrodos foi alterada para que todas as curvas se sobrepusessem. Entre parêntese o valor da distância utilizado.

Figura 54 - Amostra com espaçador: (a) Gráfico de corrente em função da voltagem para diferentes energias de íons e; (b) Voltagem necessária para atingir uma determinada corrente em função da energia dos íons.

Figura 55 Voltagem necessária para atingir $6 \mathrm{~mA}$ em função da energia dos íons para as amostras fina, espessa e com espaçador.

Figura 56 Ilustração das barreiras de energia (segundo o modelo de tunelamento) para uma amostra com uma interface padrão (a), com a implantação de nanopartículas (b) e com um espaçador entre o catodo e a camada ativa(c). Do lado esquerdo o metal e seu respectivo nível de Fermi e do lado direito o polímero. Dispositivo sob polarização direta.

Figura 57 Amostras com 40 nm de PFO, (a) e (b), com $150 \mathrm{~nm}$ de PFO,(c) e (d) e para amostras com espaçador de $16 \mathrm{~nm}$ e $40 \mathrm{~nm}$ de PFO, (e) e (f). À esquerda, gráficos da luminescência em função da voltagem. À direita, gráficos da luminescência em função da corrente, mostrando a eficiência de eletroluminescência.

Figura 58 Gráfico da luminescência em função da corrente, mostrando a eficiência de eletroluminescência para: (a) Amostras fina, espessa e com espaçador como catodo produzido sem o auxilio de íons; (b) Amostra com maior eficiência de cada tipo(fina, espessa e com espaçador). 



\section{LISTA DE TABELAS}

Tabela 1 - Estrutura molecular dos primeiros cinco poliacenos e o valor do comprimento de onda para o máximo da absorção.

Tabela 2 - Parâmetros de deposição do catodo de alumínio.

Tabela 3 - $\quad$ Principais características das amostras preparadas.

Tabela 4 - Valores de resistência em série obtidos para a segunda série de amostras. 



\section{LISTA DE ABREVIATURAS}

Al Elemento Alumínio

$\mathrm{Ag} \quad$ Elemento Prata

Ar Elemento Argônio

EIE Espectroscopia de impedância eletroquímica

HeNe Hélio - Neônio

HRTEM Microscopia Eletrônica de Transmissão de alta resolução

HOMO Orbital molecular mais alto ocupado

IBAD Deposição assistida por feixes de íons

IBM Mistura por feixe de íons

ITO Óxido de estanho e índio

LACIFID Laboratório de Cristais Iônicos, Filmes Finos e Datação

LbL Camada por camada

LiF $\quad$ Fluoreto de Lítio

LUMO Orbital molecular mais baixo desocupado

OLED Dispositivo orgânico emissor de luz

PEDOT Poli (3,4-etilenodioxitiofeno)

PPV Poli(p-fenileno vinileno)

PMMA Polímero polimetilmetacrillato

PDAC Poli (cloreto de dialildimetil amônia)

PSS Poli (estirenosulfonato)

PFO Polifluoreno

PL Fotoluminescência 
RBS Retroespalhamento Rutherford

SCLC Corrente limitada espacialmente

SRIM "The Stopping and Range of Ions in Matter"

Ta Elemento Tântalo

TRIM "Transport of Ions in Matter"

UPS Espectroscopia de fotoelétrons excitados por luz ultravioleta

UV-VIS Ultra violeta - visível

$\mathrm{V}_{\text {on }} \quad$ Voltagem de funcionamento

XPS Espectroscopia de fotoelétrons excitados por raios- $\mathrm{X}$

W Elemento Tungstênio 


\section{SUMÁRIO}

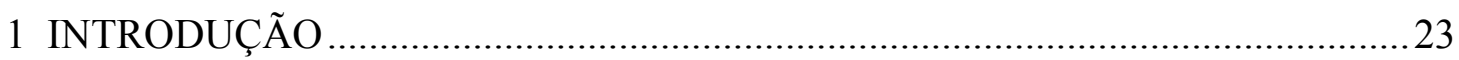

2 NOÇÕES BÁSICAS E CONCEITOS ENVOLVIDOS NO TRABALHO ..............27

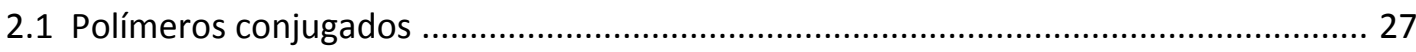

2.1.1 Processos ópticos em polímeros conjugados................................................ 30

2.1.2 Emissão próxima à uma interface metálica.......................................................... 32

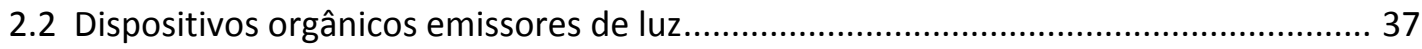

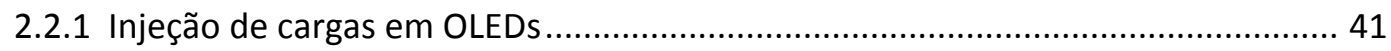

2.2.2 Modificações na interface metal/polímero visando melhora na injeção ............... 44

2.3 Deposição assistida por feixes de íons - IBAD ................................................................. 46

2.3.1 Utilização do IBAD em eletrônica orgânica ......................................................... 50



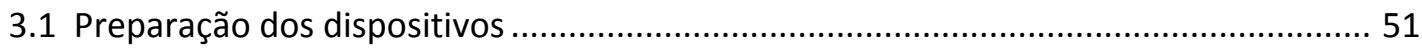

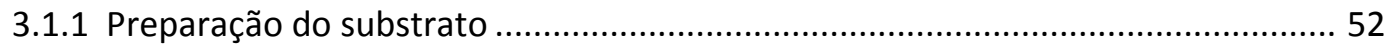

3.1.2 Camada transportadora de buracos ............................................................... 53

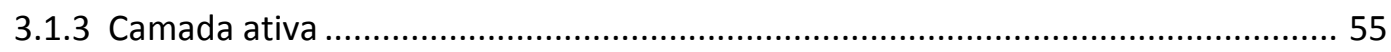

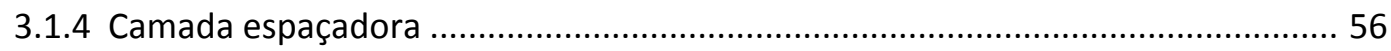

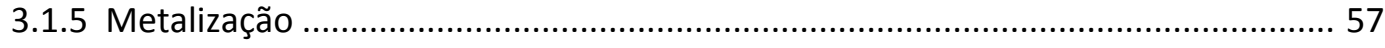

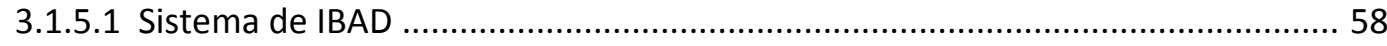



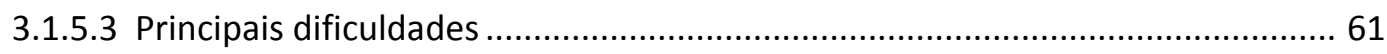

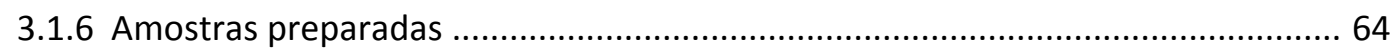

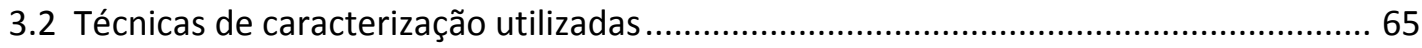

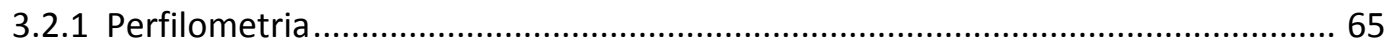

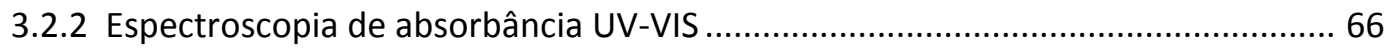

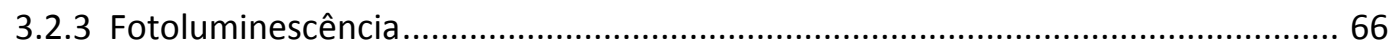

3.2.4 Eletroluminescência e caracterização elétrica ...................................................... 67 


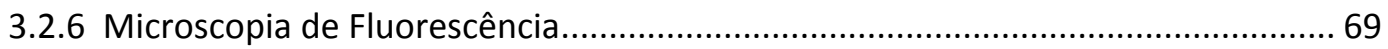

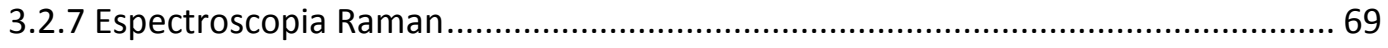

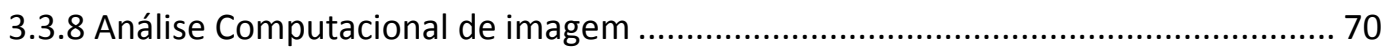

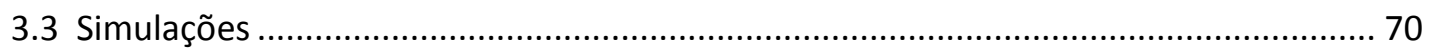

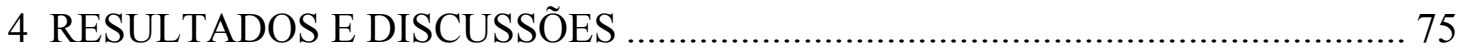

4.1 Caracterização do Catodo metálico .............................................................. 75

4.2 Interfaces Metal/Polímero semicondutor: altas energias .................................... 77

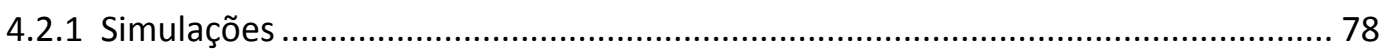

4.2.2 Caracterização por microscopia óptica de fluorescência ................................... 80

4.2.3 Caracterização por Fotoluminescência..................................................... 87

4.2.4 Caracterização por Espectroscopia Raman............................................... 89

4.2.5 Caracterização elétrica e eletroluminescência ............................................. 91

4.3 Interfaces Metal/Polímero: baixas energias ................................................. 93

4.3.1 Caracterização das camadas espaçadoras ................................................. 94



4.3.3 Caracterização por Fotoluminescência.......................................................... 100

4.3.4 Caracterização elétrica ................................................................... 108

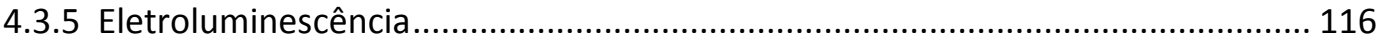

5 CONCLUSÕES E PERSPECTIVAS FUTURAS ........................................ 121






\section{INTRODUÇÃO}

A indústria eletrônica começa a se afastar dos componentes baseados em silício, caros e de difícil manufatura, a favor de alternativas orgânicas ${ }^{1 ; 2}$, mais baratas, de fácil processamento e ainda flexíveis. Assim, os dispositivos orgânicos são um tópico atual e estratégico $^{3 ; 4 ; 5}$. Chamada eletrônica orgânica, esta nova tecnologia ainda tem muitos pontos em aberto para o seu entendimento ${ }^{6 ; 7 ; 8}$. Um esforço coordenado vem sendo feito para que o Brasil possa se desenvolver a tempo de ser tecnologicamente competitivo nesta área.

A eletrônica orgânica tem uma natureza fortemente interdisciplinar ${ }^{6}$ e as contribuições de físicos, químicos e engenheiros têm proporcionado que pesquisa e desenvolvimento tecnológico ocorram de maneira muito próxima. Assim o melhor entendimento das propriedades e dos processos de funcionamento é rapidamente implantado no desenvolvimento de novos dispositivos, mais eficientes. O entendimento da formação de interfaces entre polímeros e metais é um ponto muito importante $6 ; 9 ; 10 ; 11 ; 12 ; 13$, com o uso de filmes cada vez mais finos e áreas maiores ${ }^{14}$, a importância das interfaces é primordial na eletrônica orgânica ${ }^{6}$. No caso de dispositivos orgânicos emissores de luz (OLEDs) a injeção de elétrons através do catodo é o fator limitante na eficiência e no funcionamento com baixas voltagens $^{15 ; 16}$, sendo assim o melhor desempenho desta interface é de vital importância para a melhora destes dispositivos.

A obtenção de OLEDs mais eficientes esbarra cada vez mais na necessidade de metais com baixas funções trabalho, como o cálcio, magnésio e alumínio ${ }^{17}$. Apesar de a função trabalho mais baixa, portanto mais adequada, o cálcio é extremamente reativo e seu uso requer cuidados especiais, tal como o recobrimento dele por uma camada de alumínio, menos reativo ${ }^{17}$. Outro problema enfrentado é a difusão dos átomos de metal para dentro da camada polimérica $^{18 ;}$. 19 metal geralmente se liga ao polímero e cria estados que atuam como supressores de luminescência e armadilhas de cargas, causando assim uma perda de eficiência dos OLEDs. O uso de uma fina camada de isolante, por exemplo, LiF, entre o metal e polímero evita que ocorra a migração do metal para dentro do polímero, evitando assim a criação destes sítios. Além disso, uma melhora na injeção é notada até uma espessura limite, 
porém o motivo desta melhora ainda é controverso. ${ }^{20 ; 21}$ A formação de óxidos na superfície metálica pode atuar de maneira análoga ${ }^{22}$, e ocorre, muitas vezes quando o metal é depositado.

Outra dificuldade encontrada é a formação de um contato não homogêneo entre o metal e o polímero, causado pela formação de clusters de metal sobre a superfície do próprio metal que não permitem um recobrimento homogêneo da superfície polimérica que leva à formação de caminhos preferenciais para a injeção de corrente ${ }^{23}$. Estes caminhos preferências causam uma não uniformidade da distribuição de densidade de corrente ao longo do catodo e levam a diversos problemas que afetam a durabilidade e eficiência dos OLEDs ${ }^{14}$.

O desenvolvimento de dispositivos de grande área traz sérios problemas de não uniformidade e curto-circuito ${ }^{14}$. Ainda assim as tecnologias de fabricação, assim como novos matérias, para a produção de dispositivos de grande área alcançaram grande progresso. Porém a deposição do catodo para estes dispositivos ainda é um desafio a ser vencido ${ }^{24}$. A evaporação dos catodos (por exemplo, $\mathrm{Al}$ ou Ag) ocorre a temperaturas que exigem cadinhos de Ta ou $\mathrm{W}$ e altas correntes para atingir a temperatura necessária, o que causa uma deterioração gradual do cadinho. No caso específico do alumínio ele pode facilmente vazar do cadinho, gerando danos no sistema. ${ }^{24}$ Dificuldade para manter uma taxa constante por longos períodos também é apresentada. Em uma produção em larga escala, estes problemas aparentemente simples causam sérios transtornos, comprometendo a eficiência de produção e conseqüentemente o custo final do produto. Por este motivo um método alternativo de deposição do catodo tem sido buscado. O método de sputtering é uma das técnicas mais $\operatorname{cotadas}^{24}$ um esforço concentrado tem sido feito para aplicar a técnica de sputtering em dispositivos de grande área, mas a técnica ainda apresenta problemas de deterioração da camada orgânica devido ao bombardeamento por íons com altas energias. Assim o entendimento dos danos causados por íons em camadas orgânicas é um tópico de interesse tecnológico e comercial. Ainda assim, na quase totalidade dos trabalhos realizados o catodo é depositado por evaporação. Uma técnica alternativa à evaporação para a formação de filmes finos de metal é a deposição assistida por feixes de íons (IBAD) ${ }^{25}$. Esta técnica combina simultaneamente deposição de filme a vapor e bombardeamento com um feixe de íons de baixa energia controlados independentemente. 
Não só a formação das interfaces, como sua influência nos processos e os próprios mecanismos dos processos que ocorrem através da interface (ou que estão relacionados a ela) ainda têm muitas lacunas em aberto permanecendo controversos e pouco entendidos ${ }^{6}$.

O objetivo dessa dissertação é produzir OLEDs com interfaces híbridas (entre o contato elétrico e polímeros conjugados) formadas pela técnica IBAD. A formação de um contato elétrico mais homogêneo, entre o catodo e o polímero, será também analisada. Os efeitos da estrutura eletrônica e molecular na interface serão estudados por meio da análise dos mecanismos de operação dos dispositivos de polímeros conjugados. Um particular enfoque foi feito na injeção/coleta de portadores de carga através da interface, eletroluminescência e na influência nas propriedades ópticas pelas mesmas interfaces. A utilização da técnica de deposição IBAD, praticamente inexplorada em eletrônica orgânica, tem o objetivo de trazer mais elementos para que a formação de interfaces e a relação das mesmas com o funcionamento dos OLEDs possam ser entendidos. 


\section{NOÇÕES BÁSICAS E CONCEITOS ENVOLVIDOS NO TRABALHO}

\subsection{Polímeros conjugados}

Existem duas classes de semicondutores orgânicos, as moléculas pequenas e os polímeros $^{26}$. Ambas possuem ligações $\pi$ (descritas abaixo) conjugadas que permitem a mobilidade eletrônica, sendo assim responsáveis pelo caráter semicondutor. Neste trabalho apenas os polímeros conjugados são de interesse.

Polímeros são moléculas orgânicas (baseadas em carbono) extensas formadas pela repetição de moléculas menores, denominadas monômeros. O carbono possui quatro elétrons na sua camada de valência, assim pode formar até quatro ligações. Nos polímeros conjugados os átomos de carbono apresentam ligações que se alteram entre duplas e simples e dão origem às ligações $\pi$ conjugadas. A hibridização $\mathrm{sp}^{2}$ do átomo de carbono torna possível 3 ligações $\sigma$ (compostas pelos orbitais $2 \mathrm{~s}, 2 \mathrm{p}_{\mathrm{x}}$ e $2 \mathrm{p}_{\mathrm{y}}$, que são localizadas e responsáveis pela rigidez da molécula) e uma ligação $\pi$, que provém da superposição de dois orbitais $2 p_{z}$. Os elétrons destes orbitais não são localizados e suas ligações são fracas. A Figura 1 ilustra a origem das ligações $\pi$. 


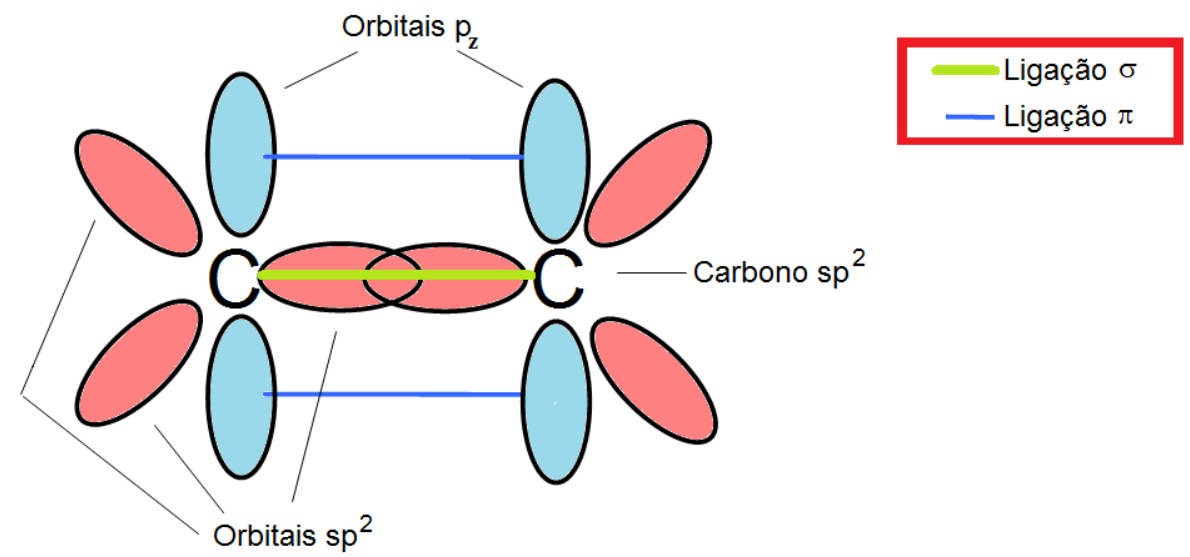

Figura 1-Representação dos orbitais $\pi$ e $\sigma$ de uma molécula conjugada.

Como as ligações $\pi$ são mais fracas, a transição de mais baixa energia para uma molécula conjugada se dá através da transição entre os orbitais $\pi$ e $\pi^{*}$ (bandas ocupadas e desocupadas, respectivamente). Estas transições tem um gap de energia que fica normalmente entre 1,5 e 3 eV e assim, é possível que ocorra a excitação de um elétron de uma banda a outra sem que ocorra destruição da molécula, conferindo a ela, suas propriedades semicondutoras. Na tabela 1, pode-se ver como o comprimento de conjugação influencia diretamente o gap de energia da molécula pois o máximo de absorção (diretamente ligado ao gap de energia) aumenta junto com o aumento do comprimento de conjugação da molécula. 
Tabela 1- Estrutura molecular dos primeiros cinco poliacenos e o valor do comprimento de onda para o máximo da absorção.

\begin{tabular}{|c|c|c|}
\hline Molécula & Estrutura molecular & Máximo de absorção \\
\hline Benzeno & & $255 \mathrm{~nm}$ \\
\hline Naftaleno & & $315 \mathrm{~nm}$ \\
\hline Antraceno & & $380 \mathrm{~nm}$ \\
\hline Tetraceno & & $480 \mathrm{~nm}$ \\
\hline Pentaceno & & $580 \mathrm{~nm}$ \\
\hline
\end{tabular}

Na Figura 2 o diagrama esquemático dos níveis de energia é apresentado para o orbital $\mathrm{p}_{z}$ do carbono e para a ligação conjugada de dois carbonos e para infinitos carbonos. Conforme pode ser visto, o aumento da conjugação leva a uma redução do gap de energia, conforme ilustrado na Tabela 1. Os dois estados das bandas de energia recebem os nomes de HOMO (Highest Occupied Molecular Orbital) e LUMO (Lowest Unoccupied Molecular Orbital), que representam, respectivamente, o estado de mais alta energia da banda de valência e o estado de menor energia da banda de condução. 


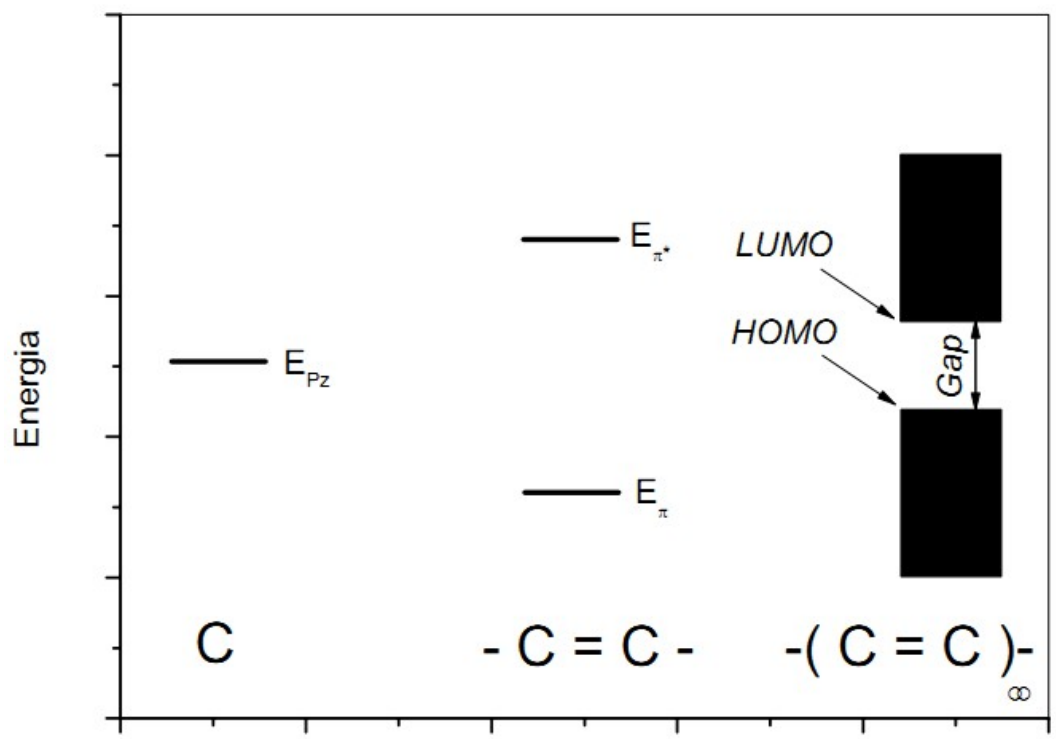

Figura 2 - Diagrama esquemático dos níveis energéticos para um carbono, para dois carbonos ligados por uma dupla ligação e para infinitos segmentos deste, ligados consecutivamente.

\subsubsection{Processos ópticos em polímeros conjugados}

A absorção de luz por uma molécula de polímero conjugado resulta na promoção de um elétron de um orbital de mais baixa energia $(\pi)$ para outro de mais alta energia $\left(\pi^{*}\right)$, processo este também chamado de transição interbanda $\pi-\pi^{*}$ ou simplesmente excitação. $\mathrm{O}$ estado fundamental de quase todas as moléculas orgânicas é um estado singleto ${ }^{27}$, denominado $\mathrm{S}_{0}$, no processo de excitação não ocorre mudança no estado de spin e o estado excitado também é um estado singleto. Um elétron excitado tende a procurar estados de menor energia, eliminando o excesso de energia através de processos de relaxação energética. Este processo pode ser intramolecular (dentro de um mesmo segmento conjugado), ou intermolecular (entre diferentes estados conjugados).

Dentre os processos intramoleculares tem-se o processo de relaxação vibracional, chamado de conversão interna (C.I.) que é um processo não radiativo extremamente rápido ( 0,1 ps) e ocorre através da ativação de fônons fazendo com que o elétron vá para o estado vibracional de menor energia do estado excitado. Um segundo processo que ocorre é o 
cruzamento intersistemas (CIS) que transfere o elétron excitado para estados tripletos de mais baixa energia. Em polímeros conjugados existe uma probabilidade de $75 \%$ dos elétrons excitados relaxarem via estados tripletos ${ }^{28}$. O processo radiativo que ocorre a partir do decaimento do estado singleto $\left(\mathrm{S}_{1}\right)$ para o estado fundamental $\left(\mathrm{S}_{0}\right)$ é denominado fluorescência (F) e possui tempos de vidas típicos da ordem de $10^{-11} \mathrm{~s}$. Processos não radiativos, tais como relaxações vibracionais, concorrem com o processo radiativo, diminuindo sua eficiência de produzir fluorescência. Assim a eficiência máxima de fluorescência é de $25 \%$. O processo radiativo de relaxação dos estados tripletos é chamado de fosforescência, processo este que também compete com processos não radiativos mediados por fônons. Como os estados tripletos têm menor energia que os estados singletos, tem-se um desvio para o vermelho do espectro de emissão da fosforescência em relação à fluorescência e este também sofre um deslocamento para o vermelho em relação ao espectro de absorção. Os processos estão ilustrados no diagrama de Jablonski, na Figura 3.

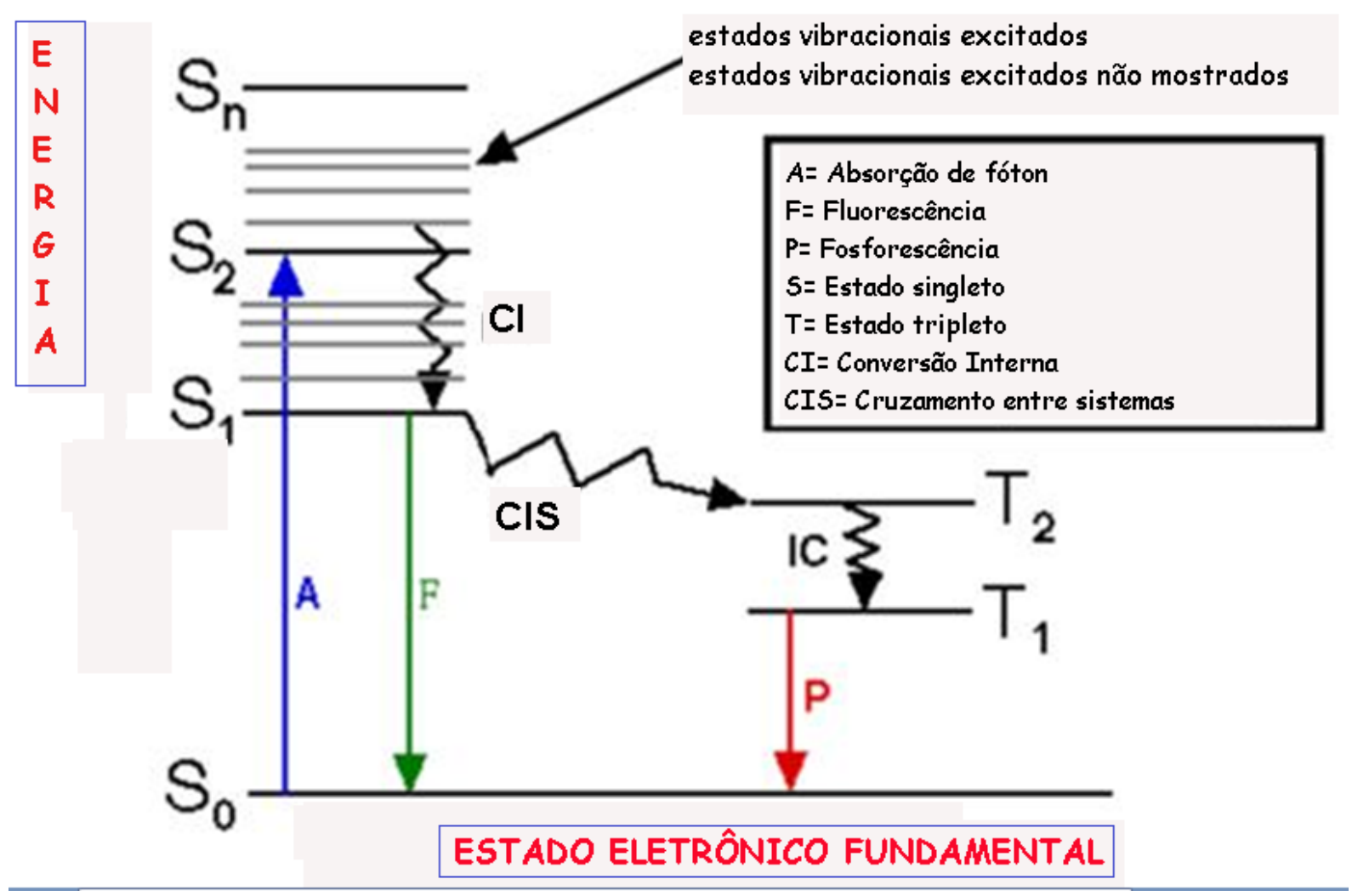

Figura 3 - Diagrama de Jablonski ilustrando a excitação óptica e relaxação energética de um estado excitado através de diferentes processos intramoleculares. 
A interação dipolo-dipolo entre diferentes segmentos conjugados é uma forma intermolecular de relaxação energética. Este processo, denominado mecanismo de transferência ressonante Förster, é baseado na interação Coulombiana entre o segmento excitado e o segmento para o qual o estado excitado será transferido e depende da distância entre os dois segmentos $^{29}$, podendo ocorrer de forma seqüencial competindo com os processos de relaxação intramoleculares. O estado final alcançado neste processo de transferência seqüencial de energia e de mais baixa energia é muitas vezes chamado de difusão espectral. $\mathrm{O}$ processo está ilustrado na Figura 4.

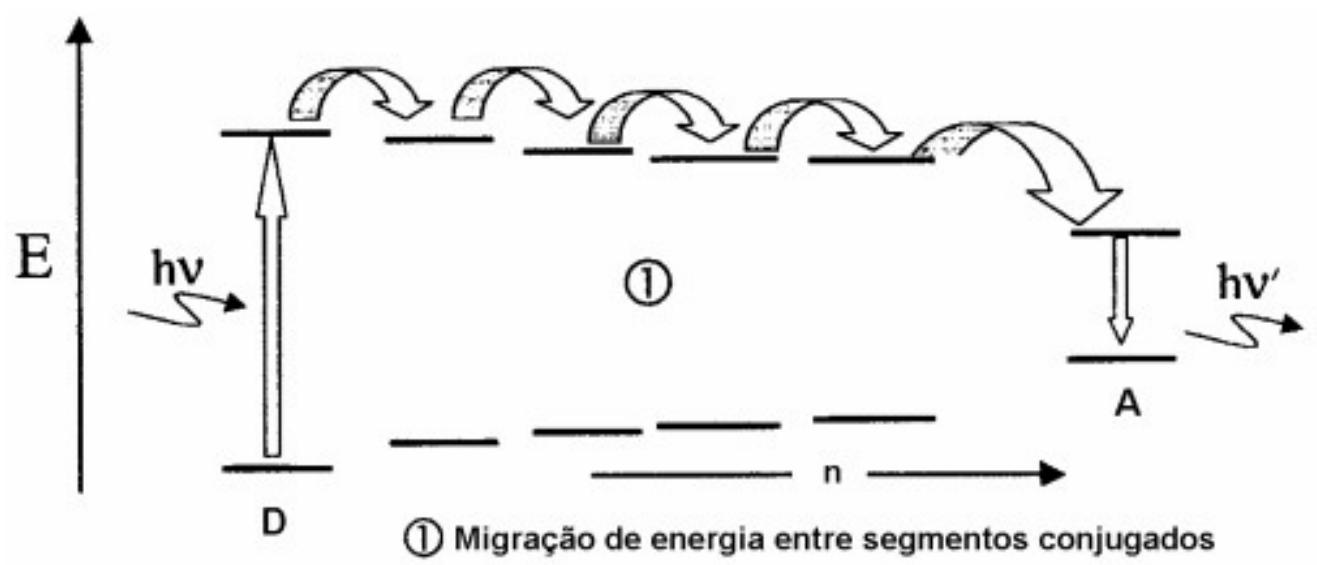

Figura 4 - Dinâmica da migração de energia entre segmentos conjugados.

\subsubsection{Emissão próxima à uma interface metálica}

Uma molécula excitada pode ser visualizada como um dipolo oscilante. A Figura 5 representa a emissão de uma molécula com momento de dipolo $\mu$ a uma distância $d$ da superfície metálica. A radiação gerada $\left(E_{1}\right)$ por este dipolo oscilante sofre uma reflexão $\left(E_{2}\right)$ e uma mudança de fase na superfície metálica. Um atraso ocorre entre a emissão de $E_{l}$ e o reencontro de $E_{2}$ com o dipolo. Este atraso é dado por $t=2 n d / c$, onde $n$ é o índice de refração do material entre o dipolo e a superfície metálica, $d$ a distância que separa o dipolo e a superfície metálica e $c$ a velocidade da luz no vácuo. Se este tempo for menor que o tempo de decaimento radiativo, a interação da radiação $E_{2}$ com o dipolo poderá influir neste tempo de 
vida. Assim, a distância e o material que existem entre o dipolo e a superfície metálica podem influenciar o tempo de vida do estado excitado, através da interação da radiação $E_{2}$ com o dipolo, que poderá aumentar ou diminuir ${ }^{30 ; 31}$. Outra situação possível é que a radiação refletida sofra interferência com radiação emitida contrapropagante $E_{1}$, produzindo interferências destrutivas ou construtivas dependendo da fase entre os dois feixes de luz.

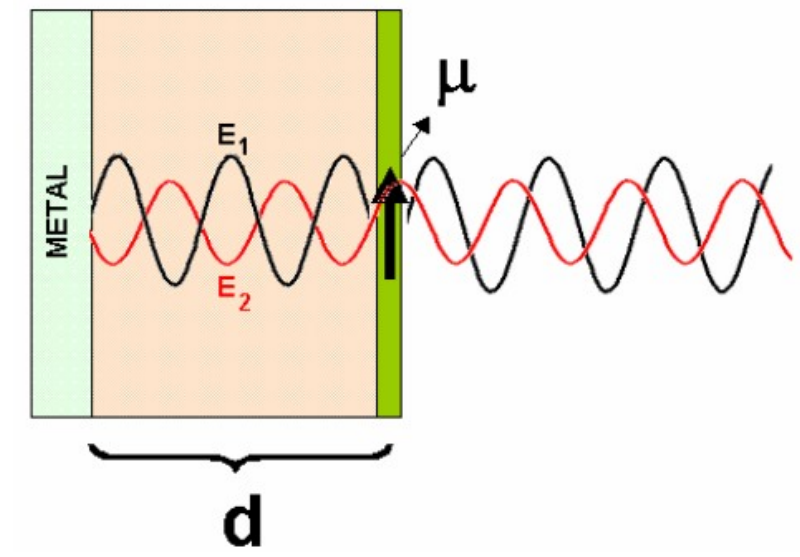

Figura 5 - Emissão $\left(E_{1}\right)$ e reflexão $\left(E_{2}\right)$ de um dipolo oscilante $(\mu)$ situado a uma distância d da superficie metálica.

Se a distância entre a molécula excitada e a superfície for pequena $\left(\mathrm{d}<\mathrm{r}_{0}\right.$, sendo $\mathrm{r}_{0}$ uma distância típica), pode ocorrer transferência ressonante do tipo Förster entre o segmento conjugado do polímero conjugado e estados de plásmons da superfície metálica ${ }^{32}$. Nesse caso, ocorre a competição entre o processo emissivo molecular e a transferência de energia não radiativa para estados de plásmons no metal, provocando assim uma diminuição no tempo de decaimento radiativo da molécula. Diversos modelos explicam a transferência de energia em termos de interações entre dipolos, tanto com abordagens clássicas ${ }^{33}$ quanto quânticas ${ }^{34}$, e que levam ao mesmo resultado. A distância típica de interação é dada pelo raio de Förster $r_{0}$, que equivale à distância para a qual a taxa de transferência se iguala a todas as outras taxas concorrentes, ou seja, é a distância para a qual metade das excitações relaxam por transferência ressonante Förster. A eficiência desta transferência de energia $E_{F}$ pode ser escrita em termos da distância da molécula e da superfície metálica $r$ e do raio de Förster $r_{0}$ como:

$$
E_{F}=\frac{r_{0}^{6}}{r_{0}^{6}+r^{6}}
$$


A Figura 6 ilustra a variação da eficiência de emissão $\left(1-\mathrm{E}_{\mathrm{F}}\right)$ considerando apenas a transferência ressonante Förster como processo concorrente não radiativo em função da distância da molécula emissora e da superfície metálica. Três efeitos são esperados quando uma molécula excitada está próxima de uma superfície metálica: a interação do campo refletido do dipolo $E_{2}$ no próprio dipolo durante a emissão descrita como um dipolo oscilante forçado; a interferência da radiação refletida com a radiação emitida; e a transferência de energia não radiativa do estado excitado para estados de plásmons na superfície metálica.



Figura 6 - Eficiência da emissão (1-E $E_{F}$ em função da distancia entre a molécula emissora e a superfície metálica, considerando transferência ressonante Förster, onde $r_{0}$ é o raio de Förster.

Em sua tese de doutorado, Célio A. M. Borges ${ }^{32}$ estudou a emissão de um filme de prova extremamente fino $(5 \mathrm{~nm})$ de poli(p-fenileno vinileno) (PPV) nas proximidades de uma superfície metálica. A distância do filme de prova emissor foi variada por um filme espaçador inerte. O estudo demonstrou a presença de uma região de extinção nas proximidades da interface $(<5 \mathrm{~nm})$ e uma região de amplificação da luminescência entre 5 e $90 \mathrm{~nm}$, que foram relacionadas à transferência do tipo Förster e aos efeitos de interferência de uma semicavidade 
óptica, respectivamente. Neste trabalho também foi variada a espessura e o material (ouro e alumínio) da camada metálica. A principal diferença observada entre os dois materiais metálicos foi que com o aumento da espessura do filme de alumínio ocorre também um aumento do raio médio de estruturas na forma esferoidal, que são visíveis na superfície, enquanto para o ouro o raio, destas estruturas, praticamente não varia. Os resultados do ouro mostram que um processo único de supressão ocorre independente da espessura. Já para o filme de alumínio existe uma variação com a espessura do filme, ou seja, da morfologia da superfície.

De acordo com Kuhn e coautores ${ }^{30}$, a intensidade da luz emitida por uma molécula localizada a uma distância L de uma parede aceitadora de moléculas aceitadoras, considerando a interação dipolar entre elas, é dada por:

$$
\frac{I(L)}{I_{\infty}}=\left[1+\left(\frac{R_{0}}{L}\right)^{4}\right]^{-1}
$$

Onde $\mathrm{I}_{\infty}$ é a intensidade pra a molécula livre de interação com a parede aceitadora e $\mathrm{R}_{0}$ é o raio de Förster. Assumindo os efeitos de interferência produzidos por uma cavidade óptica, um espectro teórico aproximado pode ser calculado segundo a aproximação de Deppe e colaboradores ${ }^{35}$. Eles mostram que a intensidade $\mathrm{I}_{\mathrm{C}}$ da luz emitida em um comprimento de onda $\lambda$ de uma camada fina de polímero, separada por uma camada espaçadora com índice de difração $n$ e espessura $L$ de uma superfície metálica com refletividade $R_{l}$ pode ser calculada pela seguinte relação:

$$
I_{C}(\lambda, L)=\left[1+\left(\frac{R_{0}}{L}\right)^{4}\right]^{-1}\left\{\frac{\left(1-R_{2}\right)\left[1+R_{1}-2 \sqrt{R_{1}} \cos \left(\frac{4 \pi L}{\lambda}\right)\right]}{1+R_{1} R_{2}-2 \sqrt{R_{1} R_{2}} \cos \left(\frac{4 \pi L_{1}}{\lambda}\right)}\right\} I_{0}(\lambda)
$$

Onde $I_{o}$ é a intensidade de emissão do filme no espaço livre e $R_{2}$ a refletividade do filme polimérico emissor. $L_{l}$ é a espessura óptica da cavidade e é dada por:

$$
L_{1}(\lambda)=n L+\left|\frac{\emptyset_{m}}{4 \pi} \lambda\right|
$$

$\Phi_{\mathrm{m}}$ é a defasagem da luz ao ser refletida pelo metal e calculada por:

$$
\emptyset_{m}=\operatorname{arctg}\left(\frac{2 n k_{m}}{n^{2}-n_{m}^{2}-k_{m}^{2}}\right)
$$

Sendo $n_{m}$ e $k_{m}$ as partes real e imaginária, respectivamente, da constante dielétrica do metal. Assim o primeiro termo da equação 2.3 está relacionado à transferência de energia, o 
segundo termo é para o efeito de interferência da interface, e $\mathrm{I}_{0}$ é a intensidade padrão, sem nenhuma interferência.

A Figura 7 apresenta o gráfico da razão entre $\mathrm{I}_{\mathrm{C}} / \mathrm{I}_{0}$, que equivale à amplificação proporcionada pela interferência em função da posição $L$ da camada ativa em relação à uma superfície metálica de alumínio. Foram usados 6 valores diferentes para a refletividade $\mathrm{R}_{1}$ do metal. Os valores dos outros parâmetros estão mostrados no detalhe da figura. Vê-se que quanto menor a refletividade do filme menor a interferência, o que leva a uma menor amplificação. $\mathrm{I}_{\mathrm{C}} / \mathrm{I}_{0}$ é igual à unidade para refletividade $\mathrm{R}_{1}=0$ e varia para outros valores de reflectividade. Na parte superior da figura tem-se a representação das amostras utilizadas neste trabalho. Deve-se fazer a integral de $\mathrm{I}_{\mathrm{C}} / \mathrm{I}_{0}$ ao longo de toda a espessura para se ter a emissão d eum filme espesso.

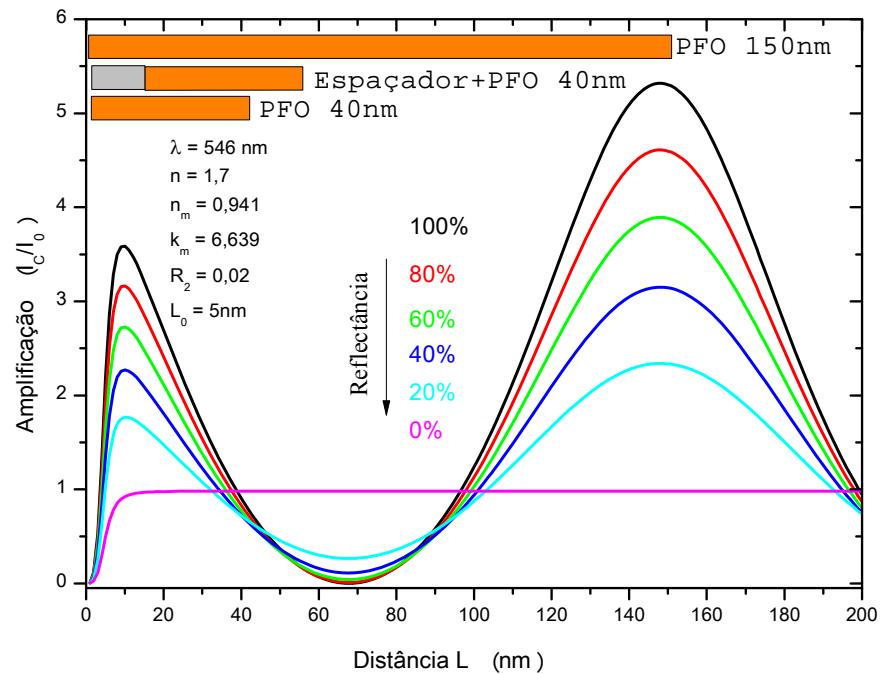

Figura 7 - Gráfico da razão entre $I_{C}$ e $I_{0}$, em função da distância entre a molécula emissora e a superficie metálica, para superficies com reflectâncias de 100, 80, 60, 40, $2020 \%$. Na parte superior estão representadas as dimensões das amostras utilizadas neste trabalho, para visualização. 


\subsection{Dispositivos orgânicos emissores de luz}

Conforme visto acima, existem dois tipos de semicondutores orgânicos. Nesta seção serão tratados exclusivamente os dispositivos formados por polímeros conjugados, neste caso os OLEDs. A Figura 8(a), apresenta o esquema mais básico de um OLED, uma camada ativa polimérica entre dois eletrodos. Este arranjo de camadas é chamado usualmente de estrutura vertical, pois uma camada é colocada sobre a outra. A polarização para passagem de corrente pelo dispositivo é apresentada na figura e se faz pela injeção de buracos pelo anodo (eletrodo positivo transparente) e de elétrons pelo catodo (eletrodo negativo metálico). A Figura 8 (b) apresenta o digrama esquemático das bandas de energia de um OLED sem polarização. A linha pontilhada, acima, representa a energia de vácuo $\mathbf{E}_{\text {vácuo }}$ do sistema. A função trabalho, que é a diferença entre a energia de vácuo e o nível de Fermi de um sistema, do ITO ITO e do catodo catodo são apresentados nos extremos da figura. Ao centro temos os níveis de energia referentes ao polímero, onde $\chi_{\mathrm{e}}$ é a afinidade eletrônica, que é a mínima energia necessária para remover um elétron da LUMO, e $\mathrm{I}_{\mathrm{pol}}$ é a energia de ionização do polímero, que é a energia necessária para remover um elétron da HOMO. Por fim Egap é a diferença entre $I_{e}$ e $\chi_{\mathrm{e}}$ que é chamado gap de energia.

b)

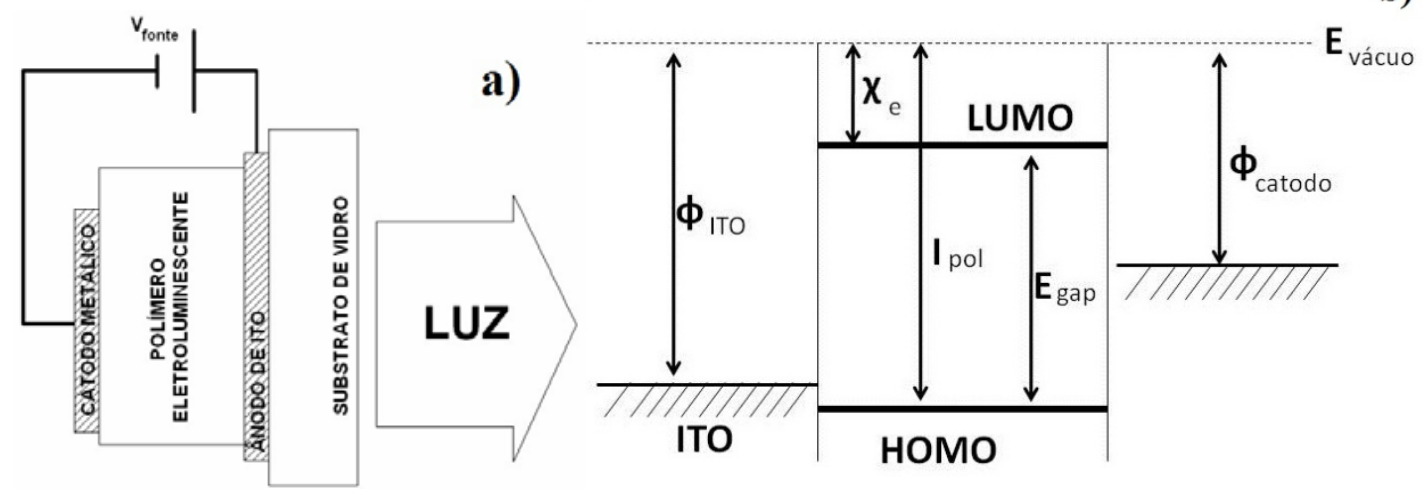

Figura 8 - (a) Esquema da estrutura básica de um OLED. (b) Diagrama esquemático das bandas de energia de um OLED. 
O mecanismo básico de funcionamento de um OLED está ilustrado na Figura 9. À esquerda tem-se o anodo e A é a função trabalho do anodo, o $\Delta_{\mathrm{H}}$ é a barreira energética para a injeção de buracos (identificada na figura pelo número 1 e é dada pela diferença entre o nível energético da HOMO ( номо) e a A. De maneira análoga, temse do lado direito a barreira energética para a injeção de elétrons $\left(\Delta_{\mathrm{E}}\right)$. Após a injeção de elétrons na LUMO, pelo eletrodo negativo (catodo) e buracos na HOMO, pelo eletrodo positivo (anodo), tem início o processo de transporte (identificado na figura pelo número 2. A aplicação de um campo elétrico (representado pela inclinação dos níveis energéticos na região do polímero) faz com que os elétrons se movam no sentido contrário aos buracos. Esta corrente de portadores com cargas opostas pode interagir ou não. Quando não ocorre interação, os elétrons atingem a interface anodo/polímero e podem atingir o anodo, abandonando assim o LUMO. De maneira análoga, os buracos podem atingir o catodo e se recombinar com elétrons. Quando os elétrons e buracos se ligam através de uma interação coulombiana (identificado na figura pelo número 3 na região do polímero, eles formam um éxciton. Conforme visto, este éxciton pode se recombinar radiativamente, emitindo assim um fóton (identificado na figura pelo número 4.

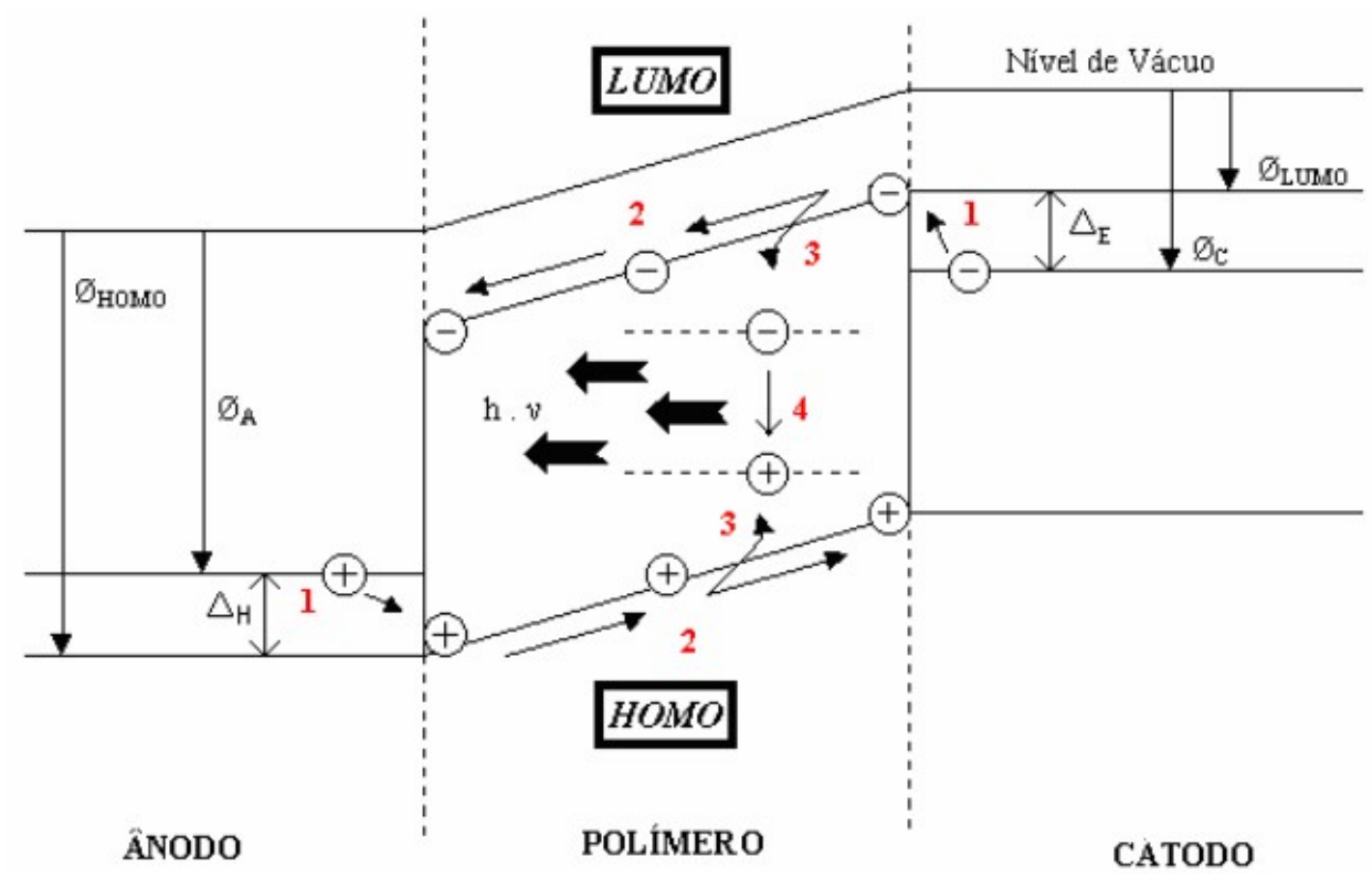

Figura 9 - Diagrama de bandas de energia para um dispositivo polarizado, destacando o processo de funcionamento. 
Apesar dos polímeros conjugados apresentarem uma alta resistência, da ordem de $10^{15} \Omega \mathrm{cm}$, o uso de filmes poliméricos com a espessura da ordem de $10^{-9}-10^{-8} \mathrm{~m}$ permite que com baixas voltagens $\left(\sim 10^{1} \mathrm{~V}\right)$, altos campos elétricos sejam produzidos no interior do dispositivo ${ }^{17 ;} 26\left(\sim 10^{6} \mathrm{~V} / \mathrm{cm}\right)$. A condução geralmente ocorre por mecanismo hopping $^{36}$, onde os elétrons saltam de um estado localizado para outro. Quando os contatos elétricos possuem suas funções trabalho próximas aos níveis energéticos da camada ativa, o contato elétrico é chamado de ôhmico ${ }^{13}$ e neste caso não existe dificuldade para o eletrodo injetar e receber elétrons. Porém geralmente existe uma diferença entre estes níveis e assim camadas intermediárias são depositadas entre o eletrodo e a camada ativa, de forma a diminuir a barreira de energia. OLEDs de alta eficiência utilizam geralmente várias camadas, com diversas funções, tais como: bloquear a injeção de buracos para proporcionar um melhor balanço (como será visto adiante); transportar os elétron e buracos para a camada ativa, proporcionando assim que os buracos e elétrons se recombinem longe das interfaces metal/polímero onde a densidade de defeitos é maior; aumentar a regularidade superficial do eletrodo.

Usualmente vidro recoberto com óxido de estanho e índio (ITO) é utilizado como anodo e função trabalho do $\mathrm{ITO}^{37}$ é de aproximadamente 4,5 eV. Este valor não é muito diferente do nível HOMO dos principais polímeros utilizados. Ainda assim, diversos tratamentos são utilizados para que a diferença entre os níveis de energia seja menor. Dentre estes tratamentos, o tratamento com ozônio no qual a incidência de uma luz ultravioleta dissocia o oxigênio formando ozônio e radicais livres de oxigênio, que interagem com o ITO promovendo a limpeza do mesmo e a descontaminação de carbono da superfície, o que proporciona não só um aumento da função trabalho, como também uma redução no caráter hidrofóbico do ITO, o que facilita a deposição da camada polimérica $^{38}$. Apesar de não apresentar grandes problemas em relação à função trabalho, a migração de átomos de índio do ITO para o interior da camada ativa é um problema grave enfrentado $^{18 ; 19}$. Outro problema é a excessiva rugosidade do ITO em relação à espessura dos filmes poliméricos. O uso de uma camada transportadora de buracos resolve estes dois problemas, tornando a superfície mais homogênea e também evitando que os átomos de índio atinjam a camada ativa ${ }^{39}$. Usualmente o poli $(3,4-$ etilenodioxitiofeno): poli (estirenosulfonato) (PEDOT:PSS) é ultilizado.

A interface do catodo é geralmente formada por um metal, que atua como um bom injetor de elétrons. Porém, a grande diferença entre a função trabalho da maioria 
dos metais nobres e o nível energético do material polimérico favorece a formação de um contato Schottky $^{47}$, que impõe dificuldades à injeção/coleta. $\mathrm{O}$ melhor casamento metal/polímero é feito através do uso do cálcio como catodo metálico, pois ele possui uma função trabalho mais próxima à LUMO da camada ativa. Porém, o cálcio é muito reativo e apresenta baixa estabilidade às condições ambientais. A Figura 10 apresenta 0 diagrama esquemático das bandas de energia para um dispositivo similar ao que utilizamos neste trabalho, com ITO, PEDOT:PSS e PFO e com diferentes metais como catodo. Os valores da HOMO (5,61 - 5,8 eV) e da LUMO (2,12 - 2,25 eV) utilizados são para os polifluorenos em geral ${ }^{40 ; 41}$. Conforme pode ser visto, para o uso do ITO, PEDOT:PSS e alumínio, como contatos elétricos, o contato do anodo tem uma barreira bem menor de energia para injetar lacunas do que o catodo para injetar elétrons. Em um OLED ideal, a altura da barreira $\Delta_{\mathrm{E}}$ para a injeção de elétrons através do catodo e $\Delta_{\mathrm{H}}$ para a injeção de buracos no anodo deve ser zero.

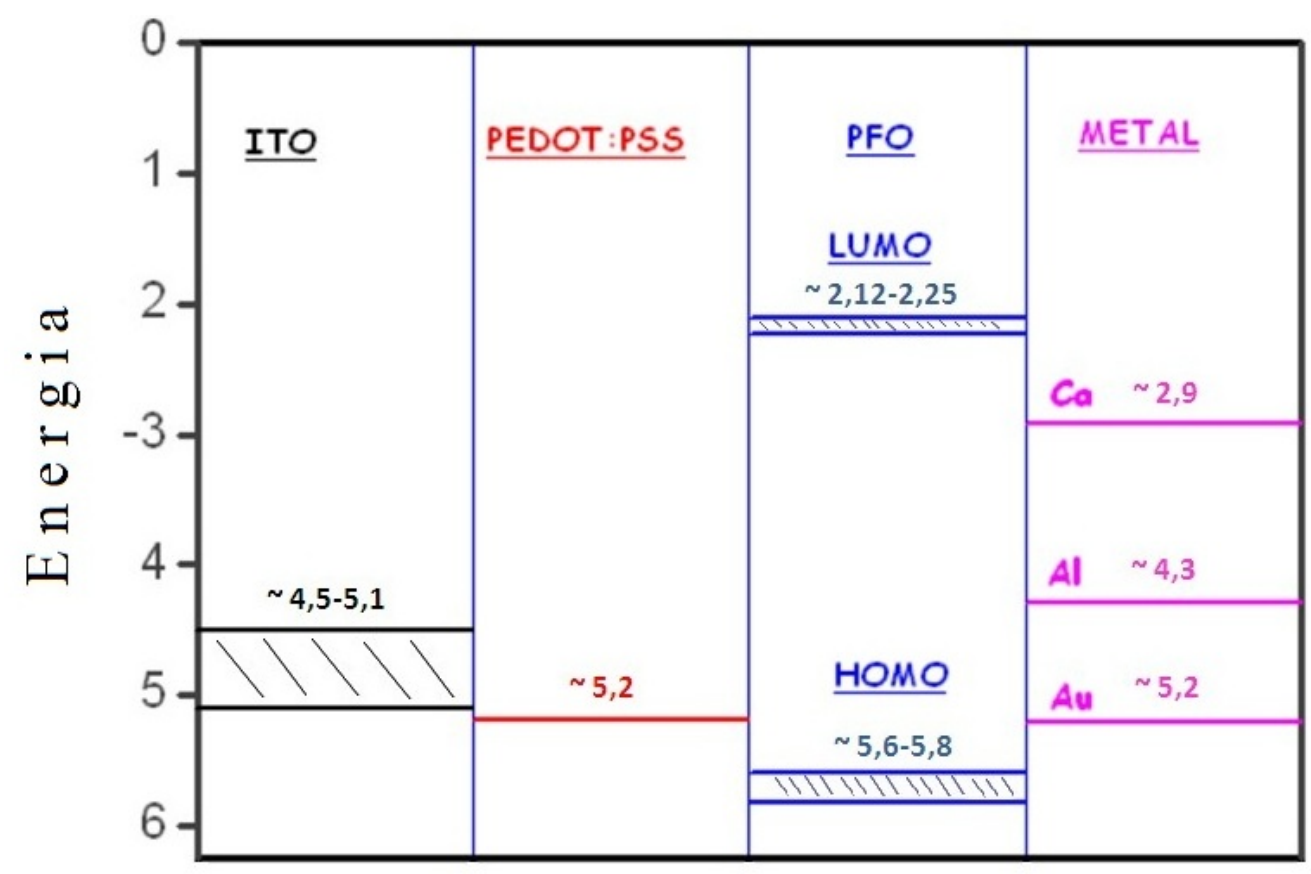

Figura 10 - Diagrama esquemático das bandas de um OLED, com o uso de PEDOT:PSS, PFO e diferentes metais.

Nota-se que o contato não tem o caráter ôhmico, pois a injeção dos portadores (principalmente dos elétrons) enfrenta uma barreira de energia para chegar à camada ativa. Assim as características elétricas do dispositivo são determinadas pelos processos de injeção através das interfaces. Para o caso de contatos ôhmicos a corrente segue a 
dependência característica de correntes limitadas por cargas espaciais (space charge limited currents - SCLC) ${ }^{42}$, onde as características de condução do polímero determinam as características elétricas

Conforme visto, nem todos os elétrons e buracos que são injetados no OLED se recombinam. Devido à grande diferença que geralmente existe entre $\Delta_{\mathrm{H}}$ e $\Delta_{\mathrm{E}}$ (ver Figura 9), a corrente total, que é a soma da corrente de buracos mais a corrente de elétrons, não é balanceada e a corrente de buracos é maior que a de elétrons. Outra desigualdade apresentada, é que a mobilidade dos elétrons, em geral, é maior que a mobilidade dos elétrons. Isto faz com que exista uma região preferencial de recombinação, que fica mais próxima do catodo.

A baixa durabilidade dos OLEDs é um dos principais problemas enfrentados ${ }^{43}$. A baixa eficiência (relação entre corrente e luminância) de recombinação leva à necessidade de altas correntes, que através do efeito Joule aquecem o OLED. O aquecimento, se atingir a temperatura de transição vítrea do polímero, pode dar origem ao processo de recristalização do polímero o que leva a uma perda de eficiência, sendo que os mecanismos envolvidos ainda não são definidos ${ }^{44}$. Caminhos preferenciais para o fluxo dos elétrons (seção 2.2.2) são um dos principais motivos de falha dos OLEDs e a corrente concentrada em uma área reduzida leva ao aquecimento desigual ${ }^{44}$, que pode gerar um curto circuito. A migração dos átomos de alumínio sujeitos a altos campos também ocorre e a formação de dark $\operatorname{spots}^{45}$ (áreas onde não ocorre a eletroluminescência) é observada. A degradação também ocorre devido à exposição ao oxigênio quando o OLED está em funcionamento ${ }^{17}$, sendo assim necessário o encapsulamento do mesmo para evitar esta fonte de degradação. Por fim, a migração de átomos do catodo e/ou anodo quando expostos aos altos campos ocorre e também leva à degradação.

\subsubsection{Injeção de cargas em OLEDs}


Processos de injeção de portadores governam o funcionamento dos OLEDs. Conforme visto na seção anterior, a interface catodo/polímero possui a maior diferença energética entre sua função trabalho e a LUMO do polímero, assim apenas os processos de injeção nesta interface ${ }^{10}$ serão aqui tratados.

O modelo teórico de emissão termiônica de Richardson-Schottky ${ }^{46}$ (RS) é normalmente utilizado em junções metal semicondutor. A densidade de corrente neste modelo depende da temperatura ( $\mathrm{T}$ ) e do campo elétrico aplicado (E) e é dada pela equação 2.6, onde A é uma constante empírica e $\Delta$ a magnitude da barreira de potencial:

$$
J_{R S}(E, T)=A T^{2} \exp \left[-\frac{\left(\Delta-\left(e^{3} E / 4 \pi \varepsilon \varepsilon_{0}\right)^{1 / 2}\right)}{k T}\right]
$$

Este modelo se fundamenta na premissa de que um elétron é injetado quando ele possui energia térmica suficiente para sobrepor a barreira de potencial. Assim, a aplicação de um campo elétrico promove a injeção de elétrons através da barreira de potencial. Este modelo despreza efeitos de tunelamento ou espalhamento pela barreira.

Outro modelo, muito utilizado, é o de Fowler-Nordheim, que se baseia no tunelamento através de uma barreira triangular para um contínuo de estados e a relação entre a densidade de corrente e o campo elétrico aplicado é dada pela equação 2.7 , onde B é uma constante empírica e $m_{\text {eff }}$ é a massa efetiva do elétron.

$$
J_{F N}(E)=B E^{2} \exp \left[\frac{-4 \sqrt{2 m_{e f f}} \Delta^{3 / 2}}{3 \hbar e E}\right]
$$

A Figura 11, apresenta os níveis energéticos para um dispositivo sujeito a um campo elétrico externo, e representa a barreira de potencial triangular através da qual ocorre o tunelamento (setas vermelhas). Este modelo apresenta bons resultados para alguns sistemas ${ }^{47}$; ${ }^{48}$, porém apresenta algumas falhas, tais como considerar a barreira triangular (desprezando o efeito de cargas imagens), considerar um contínuo de estados não ligados e desprezar a contribuição térmica. 


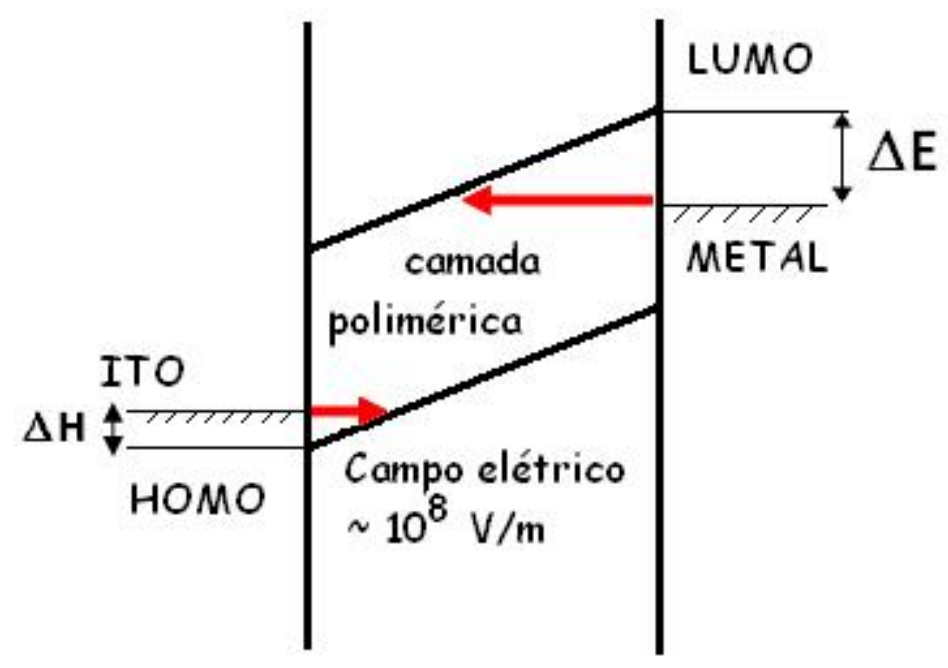

Figura 11 - Diagrama de energias para um dispositivo sob um campo elétrico. As setas em vermelho indicam a distância para o tunelamento que deve ser superada para a injeção através de cada barreira.

Polímeros conjugados apresentam um elevado grau de desordem, assim os modelos com estados energéticos bem definidos são uma aproximação fora da realidade. Na Figura 12 o diagrama esquemático com estado energético bem definido (sem armadilhas profundas) é apresentado à esquerda, e um esquema mais realístico (com armadilhas) é mostrado à direita.
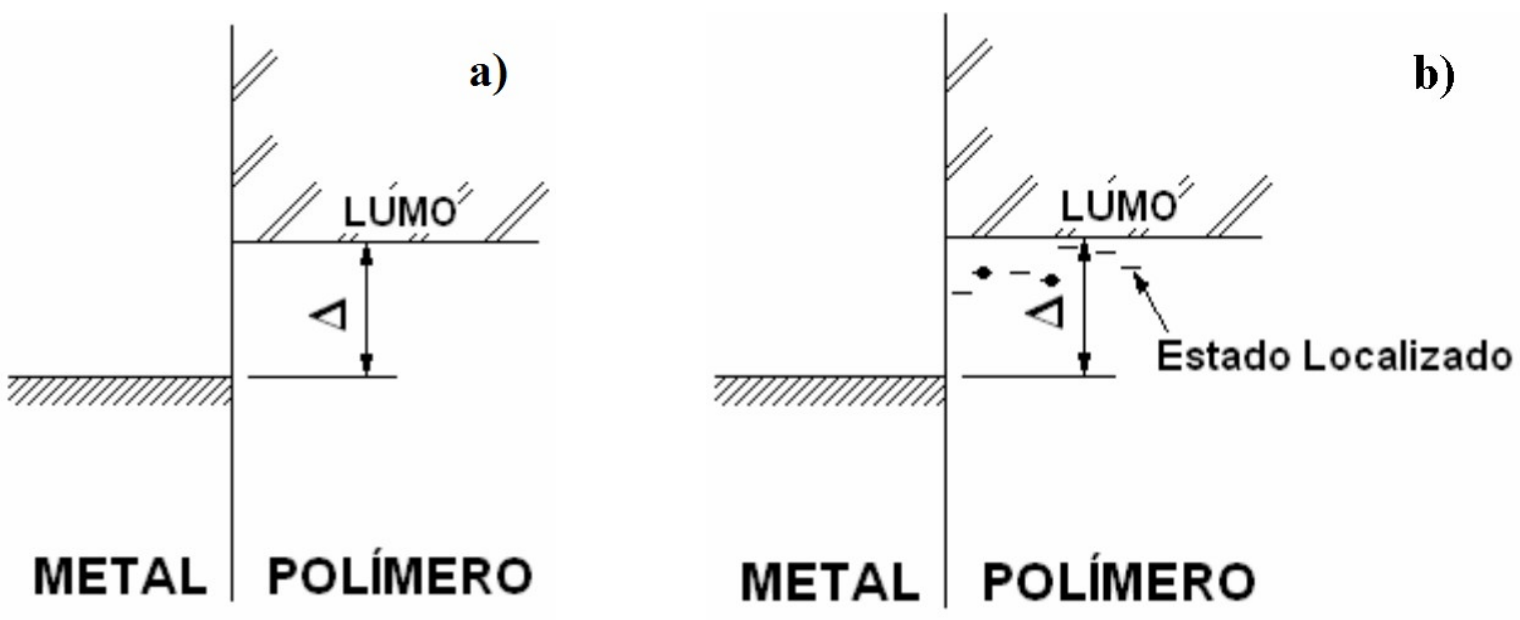

Figura 12- Digrama esquemático das bandas de energia para um contato elétrico sem armadilhas profundas (a) e com armadilhas profundas(b).

O processo de formação das bandas de energia após o contato entre o metal e o polímero é bem mais complexo que os modelos acima, onde simplesmente são consideradas 
os níveis energéticos dos materiais isolados. Uma vez que o contato entre os dois materiais ocorra, existe um fluxo de cargas através da interface até que o equilíbrio seja atingido e os níveis de Fermi se alinhem ${ }^{10}$. Arkhipov e colaboradores ${ }^{49}$ elaboraram um modelo no qual os estados localizados são levados em consideração, assim como o efeito de carga imagem. Porém ainda não existe um consenso, pois a injeção de portadores e a formação das bandas de energia nas proximidades da interface metal polímero são temas que ainda têm muito a ser estudado ${ }^{6}$.

\subsubsection{Modificações na interface metal/polímero visando melhora na injeção}

A barreira de energia entre o polímero e o metal é, em geral, o fator limitante na eficiência de um dispositivo. Selecionar metais com o nível de Fermi próximo ao nível energético do polímero é uma forma de melhorar a eficiência da injeção de elétrons. Todavia, experimentos de espectroscopia de fotoelétrons excitados por luz ultravioleta e raios-x (UPS e XPS, respectivamente) mostram que a diferença de energia na interface metal/polímero não pode ser prevista utilizando a "regra de afinidade", baseada unicamente na diferença das funções trabalho ${ }^{50}$. Isto acontece devido às interações químicas que ocorrem entre o metal e o polímero. A difusão dos átomos de metal ocorre por alguns poucos nanômetros na região da interface. No caso do alumínio, ocorre a ligação covalente com o polímero, o que causa uma diminuição da fotoluminescência, e uma degradação da conjugação do polímero ${ }^{21}$. A deposição do alumínio em uma superfície polimérica contaminada com oxigênio leva a uma melhora da fotoluminescência. A camada de óxido atua de duas maneiras principais em relação à injeção de elétrons. Em primeiro lugar, uma camada de óxido atua como uma camada isolante, pois a maioria dos óxidos são semicondutores de bandgap largo, com estados eletrônicos que não são acessíveis ${ }^{10}$. Assim o elétron precisa tunelar através desta barreira para atingir os estados do polímero. Outro efeito seria a formação de um dipolo na interface, que dependendo da orientação tanto pode aumentar como diminuir a barreira de energia na interface. Os efeitos de uma camada de óxido de alumínio $\left(\mathrm{Al}_{2} \mathrm{O}_{3}\right)$ entre o alumínio e a camada ativa foram estudados por $\mathrm{Li}$ e colaboradores ${ }^{22}$ que analisaram as características 
elétricas e de eletroluminescência variando a espessura da camada de óxido e concluíram que até um valor limite de espessura, a camada de óxido ajuda a injeção de elétrons permitindo altos campos locais e um alinhamento do nível de Fermi com a LUMO do material ativo, porém, para espessuras maiores o efeito de tunelamento leva a uma piora da injeção. A camada de óxido também evitou a formação de estados responsáveis pela extinção de éxcitons e também por armadilhas para portadores, comuns na interface alumínio/camada ativa.

O uso de finas camadas isolantes (por exemplo, de LiF) entre o metal e a camada ativa é análogo ao caso do óxido, ${ }^{20 ;} 21$ evitando o contato do metal com a camada ativa e melhorando a injeção.

O uso de íons de argônio para irradiar o filme polimérico antes da deposição do filme de metal produz interfaces mais definidas ${ }^{51}$. Isto se deve aos íons modificarem a estrutura molecular através de danos causados na camada superficial do polímero, ou seja, os íons quebram algumas ligações $\mathrm{C}-\mathrm{C}$ ou $\mathrm{C}-\mathrm{H}$, tornando o polímero mais reativo, e o metal se liga a estas ligações livres. Assim o metal difunde menos para o interior do polímero formando uma interface mais abrupta. Isto evita que estados danosos ao funcionamento do OLED sejam formados. A maior reatividade do polímero também favorece a formação de contatos mais homogêneos $^{23}$, conforme pode ser visto na Figura 13. A maior reatividade da superfície polimérica cria uma maior densidade superficial de centros de nucleação e isto leva a uma diminuição da mobilidade do adátomo (átomo adsorvido em uma superfície). As conseqüências podem ser vistas dos dois lados da interface. Do lado da camada polimérica ocorre a formação de uma interface mais definida, pois a maior reatividade reduz a difusão do adátomo para o interior da camada polimérica. Já do lado da camada metálica, a maior densidade de centros de nucleação evita que regiões da superfície do polímero fiquem descobertas e também leva à formação de clusters menores e em maior número, propiciando assim um recobrimento mais homogêneo do polímero pelo metal. 
(a)

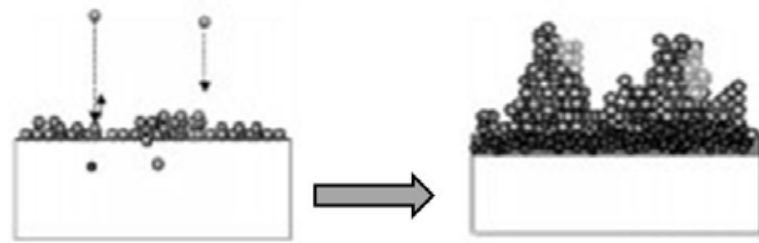

(b)
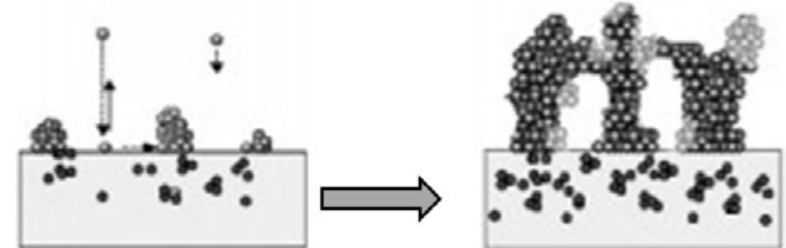

Figura 13 - Desenho esquemático da formação da interface metal/polímero para polímeros reativos (a) e polimeros consideravelmente inertes (b). Figura retirada da referência ${ }^{23}$.

A formação de clusters maiores, conforme pode ser vista na Figura 13 (b), leva a uma densidade superficial de corrente não homogênea, devido a caminhos preferenciais para a injeção de elétrons. Isto leva à formação de dark spots ${ }^{45}$, hot spots $^{44}$ e também de curtos $\operatorname{circuitos}^{14}$, que estão entre os principais mecanismos de degradação de OLEDs.

\subsection{Deposição assistida por feixes de íons - IBAD}

A deposição assistida por feixes de íons (IBAD), do inglês ion beam assisted deposition, foi desenvolvida nos anos 80 na Universidade de Tókio, Japão ${ }^{52}$ e, simultaneamente, em alguns centros nos EUA. Esta técnica combina, de forma simultânea, deposição de filme a vapor e bombardeamento com um feixe de íons de baixa energia, que são controlados independentemente. Neste sistema, os principais parâmetros para a formação dos filmes finos são: (i) a energia e o fluxo de íons, (ii) a direção de incidência do feixe de íons em relação à superfície do substrato, (iii) o fluxo dos átomos evaporados pelo canhão de elétrons, (iv) a razão da taxa de chegada íons/átomos evaporados, (v) a 
temperatura do substrato e (vi) a pressão da câmara do sistema ${ }^{52 ;}$ 53. Além desses parâmetros, deve-se ser considerar, tanto o material evaporado, como o íon utilizado.

A Figura 14 (a) esquematiza o processo e a formação do filme no sistema usado, onde se utiliza um polímero como substrato, sobre o qual evapora-se alumínio assistido por íons de argônio. Observa-se que, no esquema, a direção de incidência dos íons não é a mesma que a do metal evaporado, que por motivos técnicos não pode ser igual. Devido à grande diferença entre a energia cinética do material evaporado e dos íons acelerados ${ }^{54}$, onde a energia do material evaporado é bem menor que a dos íons, o ângulo de incidência do íon que é considerado.
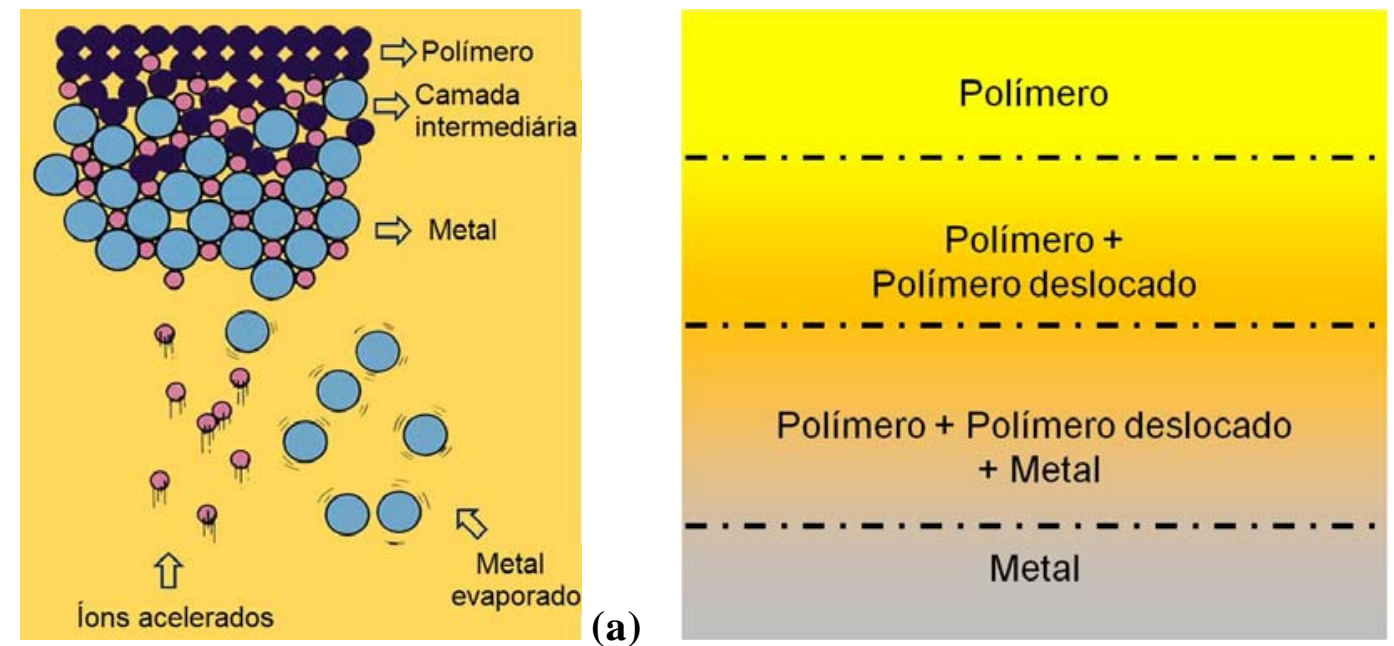

(b)

Figura 14 - Esquema do processo de IBAD realizado (a). Esquema da interface formada por IBAD (b).

A interface entre o filme metálico produzido e o polímero não é abrupta, como seria em uma evaporação sem a assistência de íons, mas sim gradual, com a presença de uma camada intermediária. A formação desta interface é um evento que ocorre tipicamente em poucos segundos. Conforme pode ser visto na Figura 14 (a), na chamada camada intermediária, a interface híbrida é formada pela penetração dos íons e também do material evaporado, pois ocorre transferência de momento entre os íons e os átomos evaporados, quando se chocam. À medida que o filme vai crescendo sobre o substrato, a penetração vai diminuindo até que efetivamente cessa em um determinado momento. A espessura da camada intermediária depende dos parâmetros do IBAD (principalmente, energia do íon e material do substrato), e pode variar entre poucos até várias centenas de Angstroms. A Figura 14 (b) representa a interface formada pelo processo IBAD em um polímero. Três regiões diferentes 
são criadas pelo IBAD. Na primeira região, que faz fronteira com o polímero em seu estado natural, o polímero sofre apenas a penetração dos íons, quando o íon se choca com o polímero ele pode descolar átomos da cadeia polimérica, criando assim o que se denomina polímero deslocado. Nesta região o polímero deslocado coexiste com o polímero em seu estado natural. Mais próximo à superfície do polímero (segunda região) o metal também penetra no polímero (assim como o íon), sendo que nesta região o polímero sofre a penetração de íons e do material evaporado e coexistem metal, polímero e polímero deslocado. Existe um gradiente de concentração do polímero (que diminui com a deposição do metal) em oposição ao gradiente de concentração do metal (que aumenta com a sua deposição). Desta forma ocorre uma transição, da região danificada para a região onde apenas metal e íons coexistem (região três), denominada região bulk. A seguir serão feitas considerações sobre cada uma das regiões.

Região com polímero e polímero deslocado: O efeito mais evidente do IBAD sobre esta região é produzido pela penetração do íon, que pode ser interpretado como uma implantação iônica ${ }^{55}$ (porém com energia bem menor que implantações usuais). Durante o processo de implantação o íon perde energia através de interações com o núcleo e com os elétrons do substrato. O primeiro efeito sobre o polímero é o eventual deslocamento de átomos da cadeia polimérica (que pode causar uma quebra da cadeia), uma vez que a energia de ligação do polímero é menor que a do ín $^{56 ; 57}$. Como o IBAD é um processo dinâmico, à medida que a camada depositada cresce, diminui a energia com que o íon atinge o bulk até que por fim o íon não chega mais no substrato. Outro efeito, que em um primeiro momento é desprezado, é o aumento da temperatura. O processo de IBAD tem como uma das características (geralmente, tida como vantagem), o fato de utilizar substratos com temperaturas mais baixas que processos similares não assistidos por feixe iônico ${ }^{55}$. Isso ocorre devido às colisões atômicas dos íons fornecerem localmente a energia térmica necessária para a mobilidade atômica e a reatividade química. A temperatura em torno da posição final do íon pode chegar a alguns milhares de graus ${ }^{58}$, se são considerados os primeiros vizinhos e um período de tempo muito pequeno $\left(10^{-13} \mathrm{~s}\right)$, sendo que rapidamente a energia se dissipa na rede. Se por um lado, para estes casos é possível evitar que o substrato seja aquecido excessivamente para fornecer as condições de nucleação, é preciso lembrar que, este aumento local da temperatura, provoca um gradiente de temperatura ao longo do substrato, o qual dependerá da condutividade térmica do substrato, além da quantidade, energia e massa do íon energético. Uma vez que o íon de argônio atinja sua posição final, após transferir sua energia cinética para o polímero, ele deve se neutralizar, capturando um elétron (o porta amostras é 
aterrado). Sendo o argônio um gás inerte e o polímero permeável, o argônio deve difundir para fora da camada polimérica.

Região com polímero, polímero deslocado e metal: Essa região é formada pela penetração dos átomos de metal (que ganharam energia cinética dos íons de argônio através de colisões) no polímero e também dos íons de argônio, em um processo semelhante ao descrito na seção anterior. À medida que a quantidade de alumínio depositado aumenta, tem início um novo processo, também chamado de ion beam mixing (IBM) ${ }^{55}$ que consiste, como o nome sugere, em misturar duas camadas, no presente caso uma de polímero e outra de alumínio. Assim, o IBM consiste em depositar uma camada de um material sobre um substrato e incidir um feixe de íons acelerados sobre esta camada, sendo que é importante que a espessura desta camada permita que o íon atinja a interface entre ela e o substrato. $\mathrm{O}$ íon promove um deslocamento dos átomos através da interface formando assim uma interface híbrida. No caso do IBAD, tem-se um processo semelhante, porém dinâmico, uma vez que a espessura da camada de alumínio aumenta gradativamente. Este processo de IBM dinâmico ocorre até que a camada de alumínio seja espessa o suficiente para que o íon não chegue mais no polímero, quando então tem início a formação da camada bulk. Mais uma vez, os íons de argônio difundirão para fora do polímero; mas, à medida que, a quantidade de alumínio aumentar, aumenta também a chance do argônio ficar retido, o que será tratado na próxima seção.

Região bulk: A partir do momento em que não se tem mais a presença de polímero na camada formada, tem início a formação da região denominada bulk. Aqui será considerada uma abordagem específica para o caso, isto é, íons de argônio com energias da ordem de 0,1-1 $\mathrm{KeV}$ e com a deposição de alumínio. Uma abordagem mais ampla do tópico pode ser encontrada na literatura ${ }^{59}$.

Durante o crescimento da camada de alumínio, o bombardeio de íons de argônio aumenta a taxa de nucleação e a mobilidade dos átomos, o que resulta em uma ocupação das vacâncias e uma interrupção do crescimento colunar, eventos estes que propiciam um aumento da densidade da camada. ${ }^{59 ;} 60$ Terrasi e colaboradores ${ }^{61}$ mostraram que o filme formado é policristalino e que o tamanho dos grãos diminui com o aumento da energia do feixe de íons. O aumento da mobilidade atômica causado pelo feixe de íons induz à formação de novos sítios de nucleação, diminuindo, desta forma, o tamanho dos grãos. A diminuição da espessura causada por sputtering (remoção de átomos da superfície pelo choque dos 
íons $)^{25 ;}$, também é observada. A taxa de sputerring tem relação direta com a energia do feixe de íons e com o fluxo. A retenção dos íons de argônio na camada formada foi demonstrada, utilizando Rutherford Backscattering (RBS) ${ }^{59 ; 61}$.

\subsubsection{Utilização do IBAD em eletrônica orgânica}

Poucos estudos foram realizados utilizando IBAD em eletrônica orgânica. Antony e colaboradores $^{62 ; 63 ; 64 ; 65 ; 66}$ usaram a técnica IBAD para depositar a camada orgânica, formada por moléculas pequenas (Alq3), utilizando diversos íons e obtiveram uma melhora da eficiência para determinados tipos de íons. Neste caso, o IBAD foi utilizado visando as propriedades do bulk e não da interface. Em outros trabalhos ${ }^{67 ; 68}$, IBAD foi usado para formar o catodo, porém evaporando primeiro alumínio para a formação de uma camada buffer do metal (processo não auxiliado pelo bombardeio dos íons) e, apenas depois, evaporaram alumínio bombardeado simultaneamente por íons de argônio para a formação do filme. Desta forma, a interface polímero/metal também não foi afetada, sendo que apenas as propriedades de bulk do catodo foram afetadas. Conseguiram assim, uma melhora da durabilidade do dispositivo, creditada ao aumento da densidade do catodo e que se torna menos permeável ao vapor de água e ao oxigênio. 


\section{MATERIAIS E MÉTODOS}

Neste capítulo, na primeira parte, as etapas de confecção do dispositivo (também denominado amostra) são apresentadas e uma maior ênfase é dada à descrição do processo de IBAD, que não é usual em eletrônica orgânica. Em uma segunda parte, as técnicas de caracterização utilizadas são descritas brevemente. Em seguida, foi feita uma apresentação detalhada das simulações realizadas neste trabalho.

Cabe mencionar que foram preparadas várias séries de amostras e duas delas, mais relevantes, serão aqui apresentadas. $\mathrm{Na}$ preparação da primeira foram sendo definidos parâmetros para otimização da amostra, aproveitados, posteriormente, na segunda série.

\subsection{Preparação dos dispositivos}

Os dispositivos estudados utilizaram uma estrutura vertical, em camadas. O método de preparação do substrato é descrito; assim como, o procedimento utilizado para a deposição de cada camada polimérica. As etapas para preparação estão descritas abaixo. Na última parte, a metalização é explicada em detalhes, primeiro, descrevendo o equipamento utilizado; depois, os detalhes experimentais e, por fim, apontando as dificuldades encontradas. 


\subsubsection{Preparação do substrato}

Lâminas de vidro medindo aproximadamente $20 \times 10 \times 1 \mathrm{~mm}$ (comprimento $\times$ largura $\mathrm{x}$ espessura, respectivamente), recobertas com uma fina camada de óxido de índio dopado com estanho (ITO), foram utilizadas como substrato. Para a correta operação do dispositivo, é necessário que parte do ITO seja removida, para evitar curto circuito, o que não foi feito para todas as amostras da primeira série. Na Figura 15, são apresentadas as etapas de (a) a (e) referentes ao processo de preparação do substrato vidro/ITO, sendo que:

Na etapa (a) é feita a limpeza do substrato vidro/ITO com acetona e banho ultrasônico, para eliminar possíveis contaminantes e, posteriormente, o enxágue com água destilada e secagem com nitrogênio.

$\mathrm{Na}$ etapa (b) é realizada a aplicação da fita adesiva sobre o substrato vidro/ITO para demarcar uma faixa com aproximadamente $3 \mathrm{~mm}$ de largura. Na primeira série de amostras, no processo de decapagem, quando realizado, aplicou-se a fita adesiva por toda a amostra, deixando apenas uma lateral de $4 \mathrm{~mm}$ sem recobrimento.

$\mathrm{Na}$ etapa (c) é depositada uma pasta de zinco em pó com água ultrapura (suspensão aquosa de zinco) de forma a recobrir toda a superfície.

$\mathrm{Na}$ etapa (d) o substrato é mergulhado em uma solução de $\mathrm{HCl}$ 1,0 mol/l. Isto permite que o ITO sofra uma corrosão seletiva na área descoberta (sem fita adesiva). O zinco entra em contato com o ácido clorídrico, reage e forma cloreto de zinco que, por sua vez, reage com o ITO desprotegido, formando sais de estanho e índio, solúveis em água. Após 30 segundos de imersão, a lâmina é removida da solução ácida e um "cotonete" é utilizado para remover o que restou da suspensão de zinco e co-produtos.

$\mathrm{Na}$ etapa (e), uma faixa de ITO sob a fita adesiva permanece intacta, após a retirada desta fita. A lâmina é novamente limpada, primeiro com detergente, depois com acetona e álcool isopropílico e, no final, secadas com jatos de nitrogênio. 
(a)

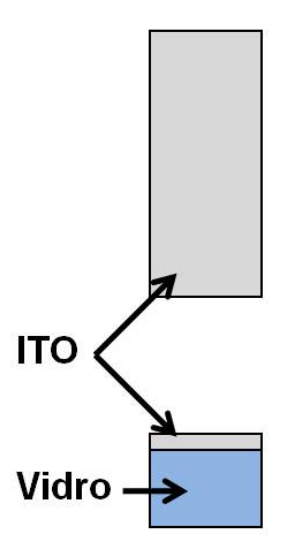

(b)

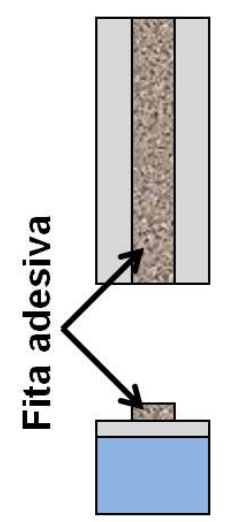

(c)

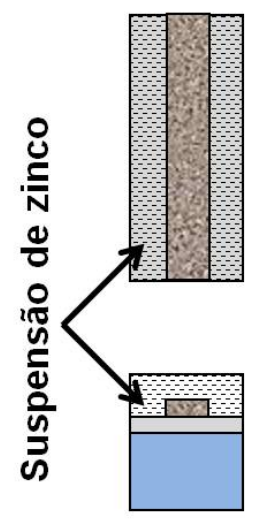

(d)

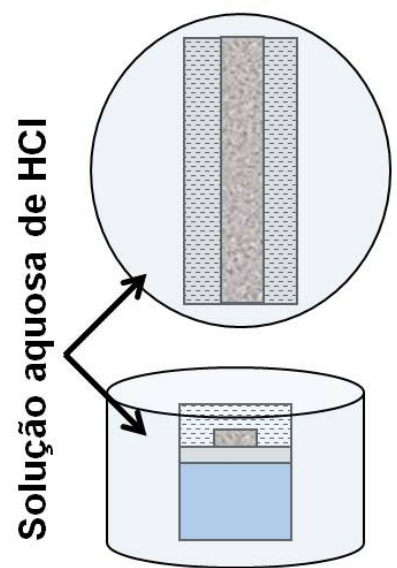

(e)

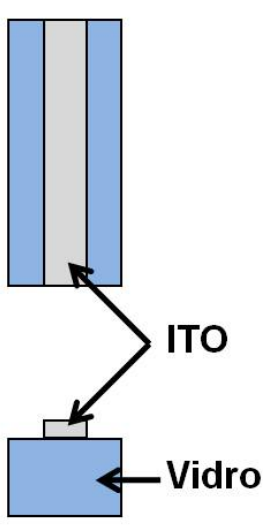

Figura 15 - Etapas do processo de decapagem do substrato vidro/ITO. Visão de cima (parte superior) e visão lateral (parte inferior).

Para o posterior tratamento do ITO (seção 3.2), usa-se um reator de UV-Ozônio, que consiste em uma lâmpada de mercúrio dentro de uma caixa de alumínio, produzido pelo Grupo de Polímeros Bernhard Gross do IFSC. Este tratamento torna o ITO mais hidrofílico. Para a realização do tratamento, as lâminas são colocadas dentro da caixa e a lâmpada é mantida ligada por 4 minutos. Este procedimento foi realizado na capela, devido à toxicidade do ozônio liberado pelo processo.

\subsubsection{Camada transportadora de buracos}

Para formar a camada transportadora de buracos (seção 3.2) utilizou-se uma blenda polimérica contendo (poli (3,4-etilenodioxitiofeno) (PEDOT) e (poli (estirenosulfonato) (PSS), na proporção de 1:2,5 (em massa), respectivamente. Esta blenda, também chamada de PEDOT:PSS, é fornecida pela CLEVIOS, já dissolvida em água. Na Figura 16 é apresentada a estrutura química desses dois polímeros. 


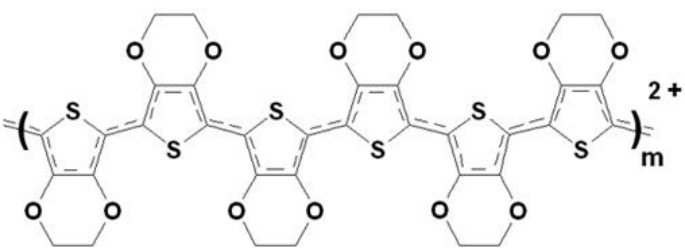

(a)

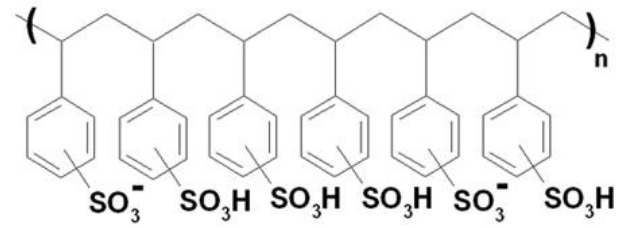

(b)

Figura 16 - Estrutura química dos polímeros (poli (3,4-etilenodioxitiofeno) (PEDOT) (a) e (poli (estirenosulfonato) (PSS) (b). Fonte: CLEVIOS

Na Figura 17, é apresentado um esquema do método spin coating ${ }^{69}$ (centrifugação). Primeiramente, no item (a) a solução de blenda é depositada sobre o substrato com o auxílio de uma pipeta. Assim que o processo de centrifugação é iniciado, o excesso de solução é expelido da lâmina, representado em (b) e, após a eliminação do excesso de solução, tem início o processo de evaporação do solvente, conforme representação esquemática em (c). Dependendo da volatilidade do solvente, outros processos podem ser usados para eliminá-lo da solução.

Esse método foi utilizado para formação do filme polimérico sobre a lâmina de vidro + ITO. Uma rotação de $3000 \mathrm{rpm}$ e um tempo de centrifugação de $60 \mathrm{~s}$ foram utilizados. Ao final, o substrato vidro/ITO/filme polimérico foi colocado por $30 \mathrm{~min}$ em um forno a vácuo a $120^{\circ} \mathrm{C}$ para que toda a água evaporasse. O filme obtido apresentou espessura de aproximadamente $60 \mathrm{~nm}$.

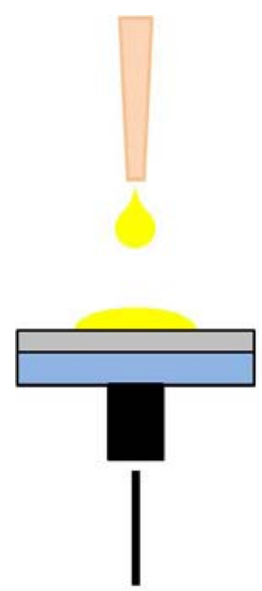

(a)

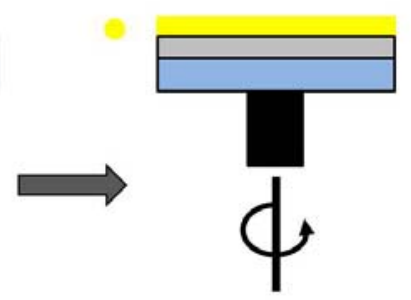

(b)

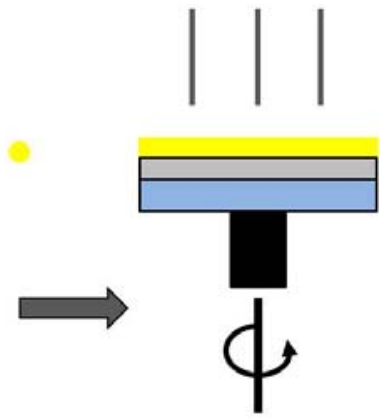

(c)

Figura 17 - Método spin coating para obtenção de filme polimérico.. (a) Deposição da solução de blenda por meio de uma pipeta sobre o substrato vidro/ITO. b) Centrifugação para eliminar o excesso de solução (c) Evaporação do solvente com formação do filme polimérico. 


\subsubsection{Camada ativa}

Como camada ativa, foi utilizado o polifluoreno (PFO) ADS GE108, produzido pela empresa Canadense ADS, cujo nome é: Poly[(9,9-dioctyl-2,7-divinylenefluorenylene)-alt-co\{2-methoxy-5-(2-ethylhexyloxy)-1,4-phenylene\}] e cuja estrutura química pode ser vista na Figura 18. Este polímero foi escolhido devido às boas propriedades de emissão e estabilidade.

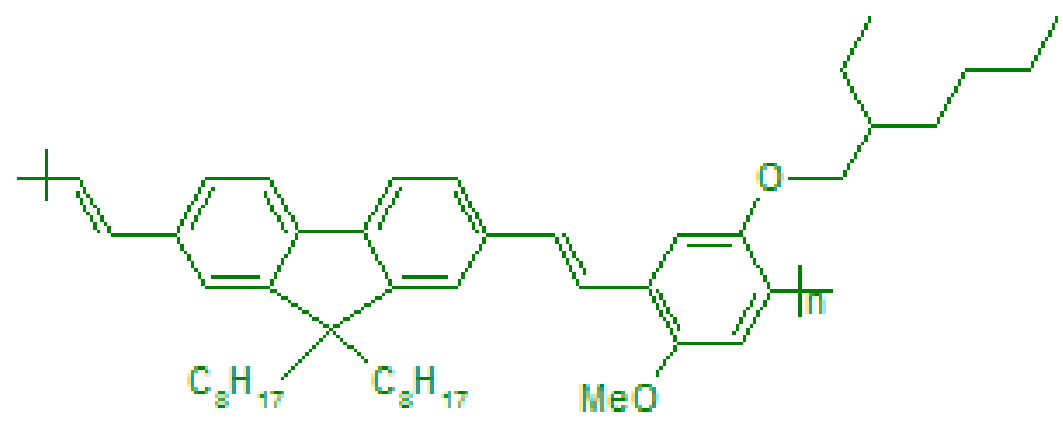

Figura 18 - Estrutura química do ADS GE108. Fonte: ADS

Os espectros de emissão e excitação para quartzo/ADS GE108 e de absorção para vidro/ADS GE108 obtidos estão apresentados nas Figura 19 (a) e (b), respectivamente. Podese observar o máximo de absorção a $480 \mathrm{~nm}(\sim 2,58 \mathrm{eV})$ e o máximo de emissão a $510 \mathrm{~nm}$ $(\sim 2,43 \mathrm{eV})$, que corresponde à região de emissão da cor verde. 
(a)

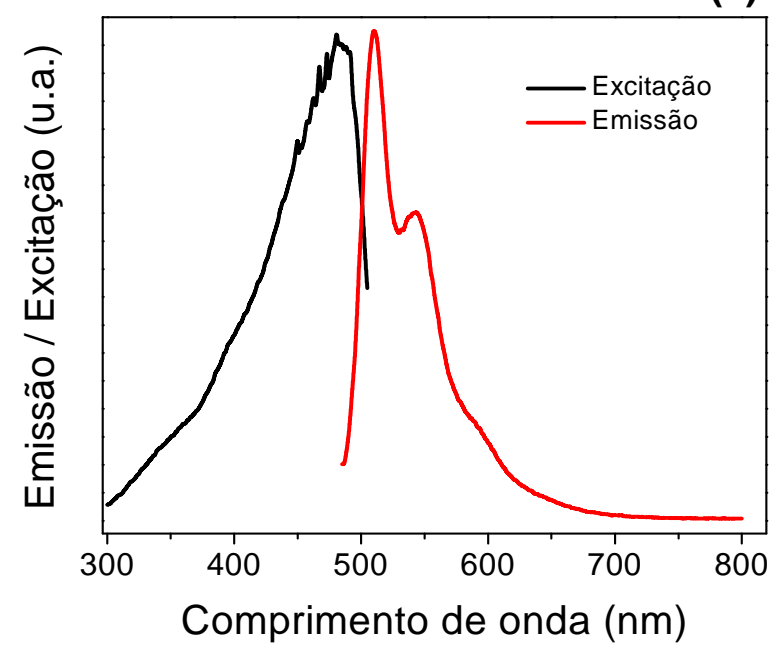

(b)

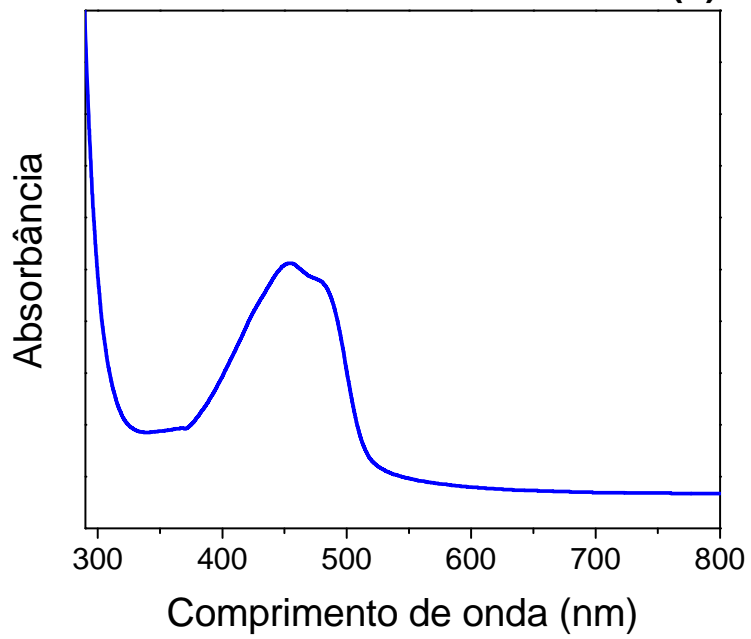

Figura 19 - (a) Espectro de emissão para o substrato quartzo/ADS GE108 e (b) espectro de excitação para o substrato vidro/ADS GE108.

Diferentes concentrações do solvente clorofórmio foram empregadas, de acordo com a espessura desejada para o filme ${ }^{69}$, sendo que o clorofórmio utilizado é de procedência da J. T. Baker e apresenta 99\% de pureza. . Para cada concentração diferente utilizada, a espessura do filme formado sobre o vidro foi medida por meio de um perfilômetro. O filme foi feito também pela técnica de spin coating, aplicando $2000 \mathrm{rpm}$ durante $30 \mathrm{~s}$ de tempo de centrifugação. Não foi necessário nenhum processo extra de secagem, pois o clorofórmio é extremamente volátil.

\subsubsection{Camada espaçadora}

Para separar a camada ativa (já depositada sobre o substrato vidro/ITO) do metal, utilizou-se uma estrutura formada por bicamadas automontadas (também chamadas de Layer by Layer- LbL), que consistem em camadas poliméricas, carregadas positivamente e negativamente sobrepostas, de forma alternada. A camada polimérica positiva corresponde ao poli(cloreto de dialildimetil amônia) (PDAC) e a negativa é constituída pelo polímero poli(estireno sulfonado) (PSS). Ambos os polímeros foram diluídos em água ultrapura numa 
concentração de $0,5 \mathrm{~g} / 1$. A Figura 20 apresenta a estrutura química desses dois polímeros. Utilizou-se também o método chamado spin self-assembly method $^{70}$, que consiste em utilizar o método de spin coating para depositar cada camada polimérica.



a) PDAC

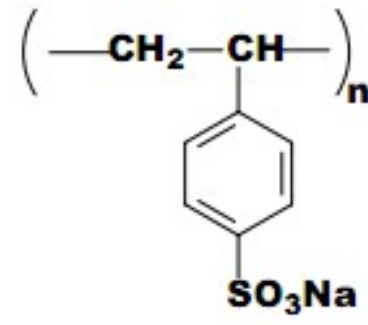

b) PSS

Figura 20 - Estruturas químicas do poli(cloreto de dialildimetil amônia) (PDAC)(a) e do poli(estireno sulfonado) (PSS) (b).

Para saber se o crescimento das bicamadas de PDAC e PSS ocorre de maneira homogênea sobre o filme de PFO, as bicamadas foram crescidas sobre uma lâmina de quartzo recoberta com esse filme e o crescimento do mesmo foi acompanhado com a técnica de absorção.

\subsubsection{Metalização}

Finalizando a estrutura vertical, uma camada de alumínio foi depositada sobre a camada ativa (ou sobre o espaçador PDAC:PSS) atuando como catodo, utilizando o processo IBAD conforme mencionado anteriormente. A seguir, o equipamento IBAD utilizado é apresentado, depois os detalhes experimentais e por fim as principais dificuldades encontradas são apontadas. 


\subsubsection{Sistema de IBAD}

O sistema de IBAD consiste basicamente de uma câmara de aço inoxidável (onde fica o suporte da amostras), acoplada a três sistemas principais: (1) sistema de vácuo, responsável por manter a pressão necessária na câmara para que a fonte de íons e o evaporador por feixe de elétrons possam funcionar (além de proporcionar a formação de filmes com poucos contaminantes), (2) fonte de íons e (3) evaporador. Sistemas secundários para monitorar pressão, espessura da camada formada e temperatura da amostra também fazem parte do sistema.

Na Figura 21, mostra-se um esquema do sistema de IBAD utilizado, que pertence ao Laboratório de Cristais Iônicos, Filmes Finos e Datação (LACIFID) ${ }^{71}$, localizado no Instituto de Física da Universidade de São Paulo, e consiste em:

a) Câmara cilíndrica de aço inox com $60 \mathrm{~cm}$ de diâmetro e $70 \mathrm{~cm}$ de altura;

b) Sistema de vácuo, composto por uma bomba mecânica (taxa de bombeamento de $40 \mathrm{~m}^{3} / \mathrm{h}$ ) e uma criogênica $(1.500 \mathrm{l} / \mathrm{s}$ ), monitorado por dois sensores de pressão (um pirani e um penning). Este sistema tem uma pressão de fundo de $\sim 1,2 \times 10^{-7}$ Torr e uma pressão de

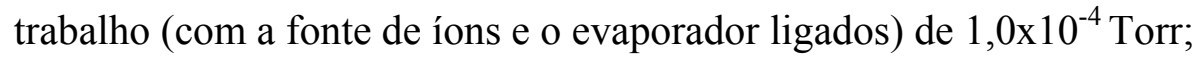

c) Fonte de íons do tipo Kaufman (modelo MPS-3000, da marca Ion Tech) com diâmetro de feixe de $5 \mathrm{~cm}$ na saída e energia de íons de no intervalo de $50 \mathrm{eV}$ a $1200 \mathrm{eV}$, corrente de feixe máxima de $200 \mathrm{~mA}$ (densidade de corrente máxima de $10 \mathrm{~mA} / \mathrm{cm}^{2}$ na saída da fonte de íons) e direção do fluxo aproximadamente normal ao substrato. O fluxo de gás Ar, utilizado na fonte iônica, é controlado por um controlador de fluxo de massa (modelo MFC 1179, da marca MKS);

d) Evaporador por feixe de elétrons (modelo EB3, da marca Edwards) com potência de $3 \mathrm{~kW}(5 \mathrm{kV}$ e $600 \mathrm{~mA})$, que utiliza cadinhos intermetálicos de $4 \mathrm{cc}\left(\mathrm{cm}^{3}\right)$ para o material a ser evaporado. O ângulo de incidência dos átomos evaporados em relação ao substrato é de $45^{\circ}$;

e) Monitor de deposição (modelo XTC/2, da marca Leybold);

f) Porta amostras medindo $2,5 \mathrm{~cm}$ x 2,5 cm, centralizado em relação ao feixe de íons e o fluxo de material evaporado, permitindo uniformidade da amostra nestes limites. Acoplado ao porta amostra existe um termopar, que permite um monitoramento da temperatura da amostra; 
g) Copo de Faraday com $5 \mathrm{~cm}$ de diâmetro, que permite a medida da taxa de íons que chegam ao substrato.

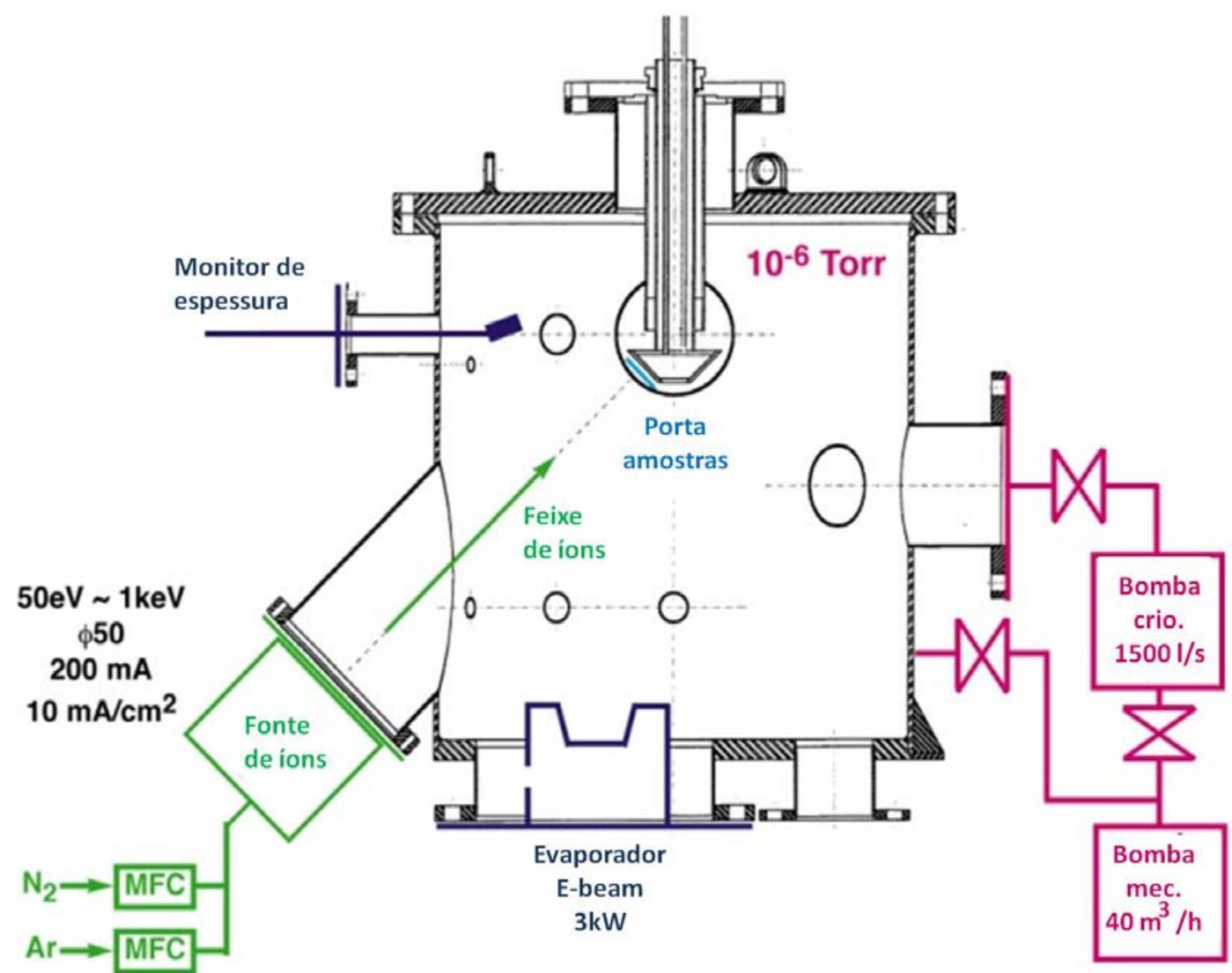

Figura 21 - Esquema do sistema de IBAD.

\subsubsection{Detalhes experimentais}

Foram utilizados, nas deposições, alumínio com pureza de 99,99 \% e gás de argônio com pureza de 99,995 \% para obtenção dos íons de Ar. Na Figura 22, um esquema da amostra após a deposição do alumínio é apresentado. Uma máscara foi utilizada sobre o porta amostras para delimitar o formato do catodo formado durante a deposição. A área destacada em verde corresponde à área de sobreposição do ITO e do metal, esta é a área efetiva do OLED, com aproximadamente $9 \mathrm{~mm}^{2}$. Essa é a configuração das amostras da segunda série. Conforme já foi dito, a decapagem das amostras da primeira série é diferente (tendo sido 
parcial ou ausente), de modo que a área efetiva do OLED é maior. No caso de ausência completa da decapagem, a sobreposição do alumínio sobre o ITO é completa, correspondendo a área efetiva do OLED a um retângulo completo da figura. As Figura 22 (b) e (c) apresentam os cortes indicados em (a) e evidenciam a estrutura vertical do OLED. No corte B (Figura 22 (c)), pode-se ver que o ITO não fica embaixo de toda a parte metalizada, o que impede um possível curto circuito quando o contato elétrico é realizado, uma vez que o filme é muito fino. Na parte direita da Figura 22 (b), os polímeros foram removidos, para que o ITO ficasse exposto e o contato elétrico pudesse ser feito.

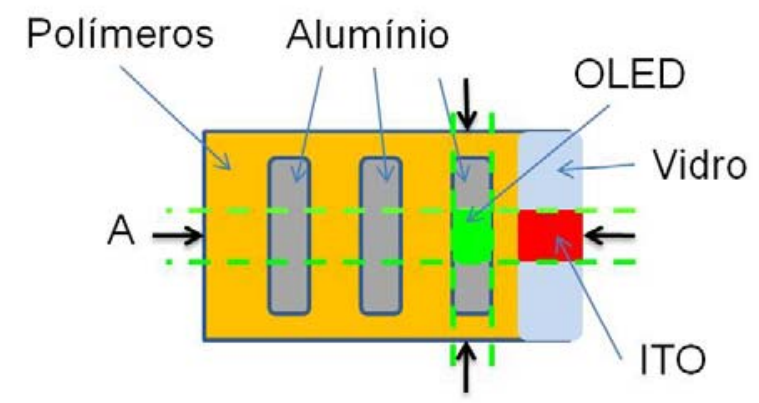

(a)
$\mathrm{B}$

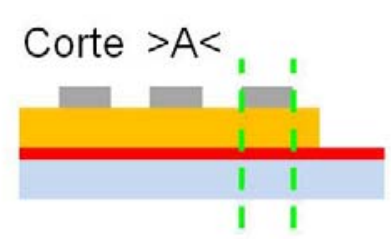

(b)

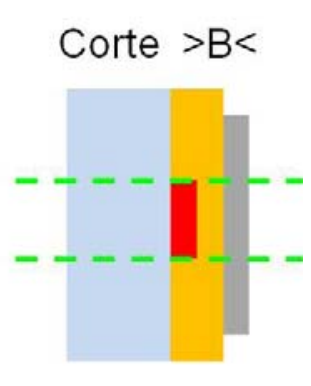

(c)

Figura 22 - Esquema da amostra: (a) vista de cima (à direita da amostra os polímeros foram removidos); (b) e (c) Cortes $A$ e $B$, respectivamente, conforme indicado.

Conforme visto na seção 3.4, o processo de IBAD altera as características do filme, tais como, por exemplo, a densidade. O medidor de espessura afere a espessura de forma indireta, através da massa do material evaporado e depositado sobre o cristal de quartzo. Para que se possa ter um referencial da quantidade de material evaporado, independente da energia do feixe iônico, o medidor de espessura fica fora do alcance do feixe de íons. Assim adotou-se como padrão evaporar a quantidade de alumínio necessária para formar um filme não assistido (energia do íon igual a zero) de $100 \mathrm{~nm}$ em todas as amostras.

$\mathrm{Na}$ Figura 21, pode-se ver que existe uma diferença de $45^{\circ}$ entre o ângulo de incidência do feixe de íons (que é normal ao substrato) e o de deposição do material evaporado. Esta diferença pode ser desconsiderada, uma vez que a energia com que os átomos do material evaporado chegam ao substrato é da ordem de décimos de $\mathrm{eV}$, enquanto os íons tem energia da ordem de centenas de $\mathrm{eV}$, assim prevalece o ângulo de incidência do íon, que é aproximadamente normal ao substrato. 
Um parâmetro fundamental na técnica de IBAD é a razão de transporte, que é a relação entre o número de átomos evaporados e o número de íons que atinge uma área em um determinado intervalo de tempo. Utilizou-se nas amostras preparadas, a razão de transporte igual a 1, isto é, para cada átomo de alumínio evaporado, tinha-se um íon de argônio. Para manter esta taxa, deve-se sujeitar às implicações que a energia dos íons (a qual está diretamente ligada à velocidade dos íons) tem na corrente dos mesmos. Ora regulava-se a corrente de íons, ora a taxa de evaporação, pois ambas estão sujeitas a limitações técnicas do equipamento usado.

A tabela 2 mostra os principais parâmetros de deposição (energia do íon, taxa de deposição do material evaporado e densidade de corrente do feixe de íons) e também o aumento de temperatura do porta amostra ocorrido entre o início e o final da deposição. Não foram adicionados os parâmetros de todas as energias utilizadas, pois a análise deste subconjunto é suficiente para os estudos que serão apresentados.

Tabela 2 - Parâmetros de deposição do catodo de alumínio.

\begin{tabular}{cccc}
\hline Energia do íon (eV) & $\begin{array}{c}\text { Taxa de deposição } \\
(\mathbf{n m} / \mathbf{s})\end{array}$ & $\begin{array}{c}\text { Densidade de } \\
\text { corrente do feixe de } \\
\text { íons }\left(\boldsymbol{\mu} \mathbf{A} / \mathbf{c m}^{2}\right)\end{array}$ & $\begin{array}{c}\text { Aumento de } \\
\text { temperatura (K) }\end{array}$ \\
\hline 0 & 0,1 & 0 & 0 \\
200 & 0,1 & 37,6 & 2 \\
600 & 0,15 & 56,4 & 4 \\
1000 & 0,15 & 56,4 & 16 \\
\hline
\end{tabular}

\subsubsection{Principais dificuldades}

O uso do sistema de IBAD para produzir catodos de alumínio sobre filmes poliméricos nanoestruturados, visando a interface híbrida formada, enfrentou alguns problemas, descritos a seguir. 
Inicialmente utilizou-se o sistema exatamente como esquematizado na Figura 21, de forma que o copo de Faraday e o porta amostras estavam em posições opostas. Assim, primeiro colocava-se o copo de Faraday na posição de incidência do feixe de íons, posição em que o porta amostra ficava protegido tanto do feixe de íons quanto do material evaporado. Com a amostra na posição protegida, calibrava-se o feixe de íons e também fundia-se o alumínio para uma limpeza do mesmo e uma maior facilidade para começar a evaporação posteriormente. Os dois sistemas eram então desligados e o porta amostra era rapidamente colocado na posição onde estava o copo de Faraday anteriormente (sem necessidade de abertura da câmara). O evaporador era ligado e a taxa de evaporação pretendida era atingida rapidamente (devido ao pré aquecimento do material a ser evaporado). Assim que a taxa de evaporação atingia o valor determinado, o feixe de íons (calibrado anteriormente) era acionado. Este procedimento utilizado geralmente para IBAD, não tem maiores problemas, pois usualmente o IBAD é utilizado visando o bulk formado e não a interface. No caso do presente trabalho, este método se mostrou insuficiente, pois o interesse estava exatamente na formação da interface (as primeiras dezenas de segundos do processo). Para tanto desenvolveu-se junto à oficina do Departamento de Física Nuclear (DFN) um shutter acoplado a um copo de Faraday. Desta forma calibrou-se o feixe e também a taxa de deposição e uma vez com as duas ajustadas, e funcionando simultaneamente, abria-se o shutter, permitindo que íons e átomos evaporados incidissem simultaneamente sobre a amostra com as taxas programadas, de forma que se tinha um maior controle desde o primeiro segundo das condições do experimento, permitindo desta forma a utilização do IBAD para interfaces.

Outro problema enfrentado foi relativo à evaporação do alumínio, por feixe de elétrons, que é bem complicada devido à alta reatividade do alumínio quando fundido. Entre outros problemas, o alumínio apresenta um comportamento de "subir" pelas paredes do cadinho $^{24}$, fazendo com que vazamentos e conseqüente contato térmico do cadinho com o evaporador conduzam à sua quebra. Mesmo usando taxas de aquecimento e resfriamento bem lentas, e tomando o cuidado de colocar uma quantidade pequena de alumínio no cadinho, houve a perda de vários cadinhos por trincas.

Por fim, o monitoramento da temperatura do filme polimérico foi problemático. Aquecer o substrato é muito usual em processos IBAD. O porta amostras do sistema de IBAD utilizado possui uma resistência no seu interior, que quando ligada aquece o porta amostras e o substrato, que está em contato com ele. Um termopar localizado no interior desse porta 
amostras monitora a temperatura do mesmo e assim, de forma indireta, a do substrato. Utilizou-se este mesmo termopar, para monitorar a temperatura da amostra, entretanto não foi utilizado o sistema de aquecimento. Detectou-se uma variação muito pequena da temperatura, conforme pode ser vista na tabela 2 , porém uma análise detalhada mostra que a variação de temperatura sofrida pelo filme polimérico é muito maior que a registrada pelo termopar.

O processo de aquecimento da deposição ocorre essencialmente na superfície da amostra e da máscara utilizada, através da transformação da energia cinética dos íons em calor. A Figura 23 mostra um esquema do porta amostras (com a máscara e a amostra) e a localização do termopar. Para que o aquecimento seja detectado, ele deve passar da amostra (ou máscara) para o porta amostra e aquecer o porta amostra que é um bom condutor térmico, mas tem uma massa significativamente maior que a do filme polimérico. Outro problema é que o tempo de deposição é muito pequeno, sendo que não existe tempo suficiente para o sistema entrar em equilíbrio térmico. Desta forma, não foi possível medir a temperatura atingida pelo filme polimérico durante a deposição.

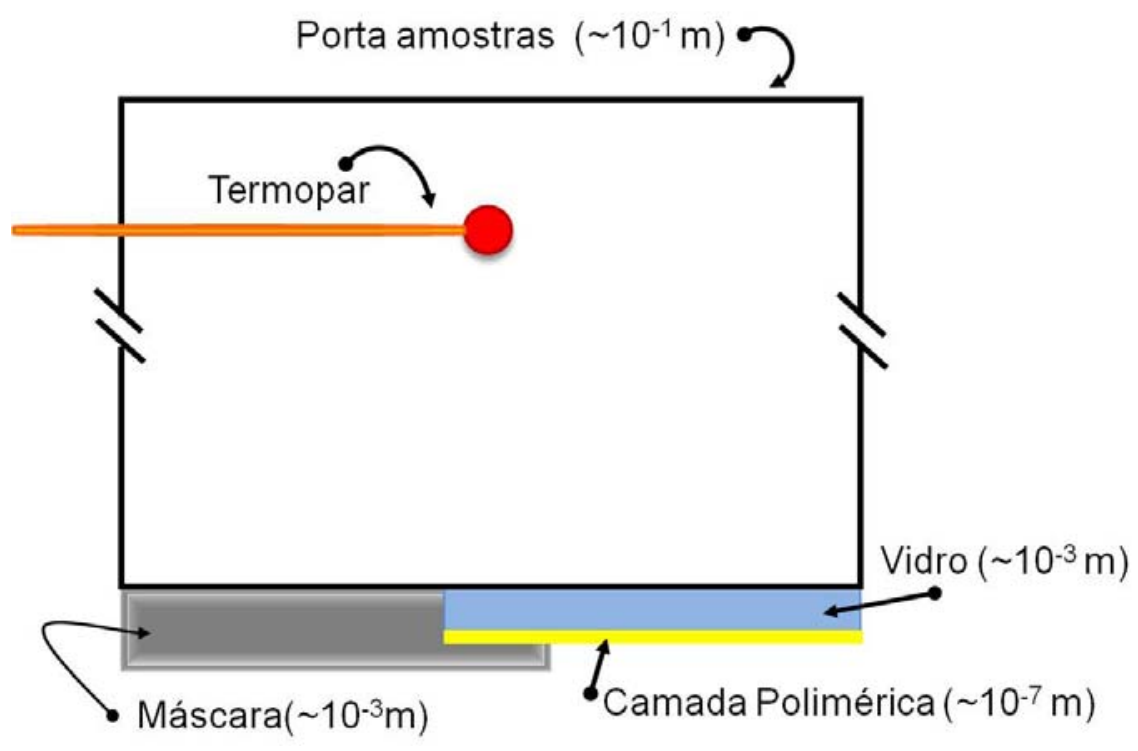

Figura 23 - Esquema do porta amostras (fora de escala). 


\subsubsection{Amostras preparadas}

Conforme já foi dito, os resultados apresentados nesta dissertação são das duas séries de amostras mais relevantes que foram preparadas. A tabela 3 e a Figura 24, mostram um resumo das principais características das amostras preparadas.

$\mathrm{Na} 1^{\mathrm{a}}$ série, foram preparadas amostras com a estrutura mais simples possível utilizando um espectro amplo para a energia dos íons, que correspondem às amostras PEDOT 60 + PFO 60, sendo que os números 60 correspondem à espessura do filme em nanômetro. A finalidade desta $1^{\text {a }}$ série foi obter uma idéia geral sobre os efeitos do uso do processo IBAD na produção de catodos de OLEDs. Destaca-se que na $1^{\mathrm{a}}$ série, o shutter não foi utilizado. Por outro lado, na $2^{\mathrm{a}}$ série, foram preparadas amostras com diferentes estruturas [(i) PEDOT $60+$ PFO 40, (ii) PEDOT 60 + PFO 150 e (iii) PEDOT 60 + PFO 40 + PDCA:PSS 16] e uma faixa mais restrita de energia foi utilizada no feixe. A Figura 24 apresenta de uma forma simples as amostras preparadas, sem diferenciar o uso do shutter e a energia dos íons.

Tabela 3 - Principais características das amostras preparadas.

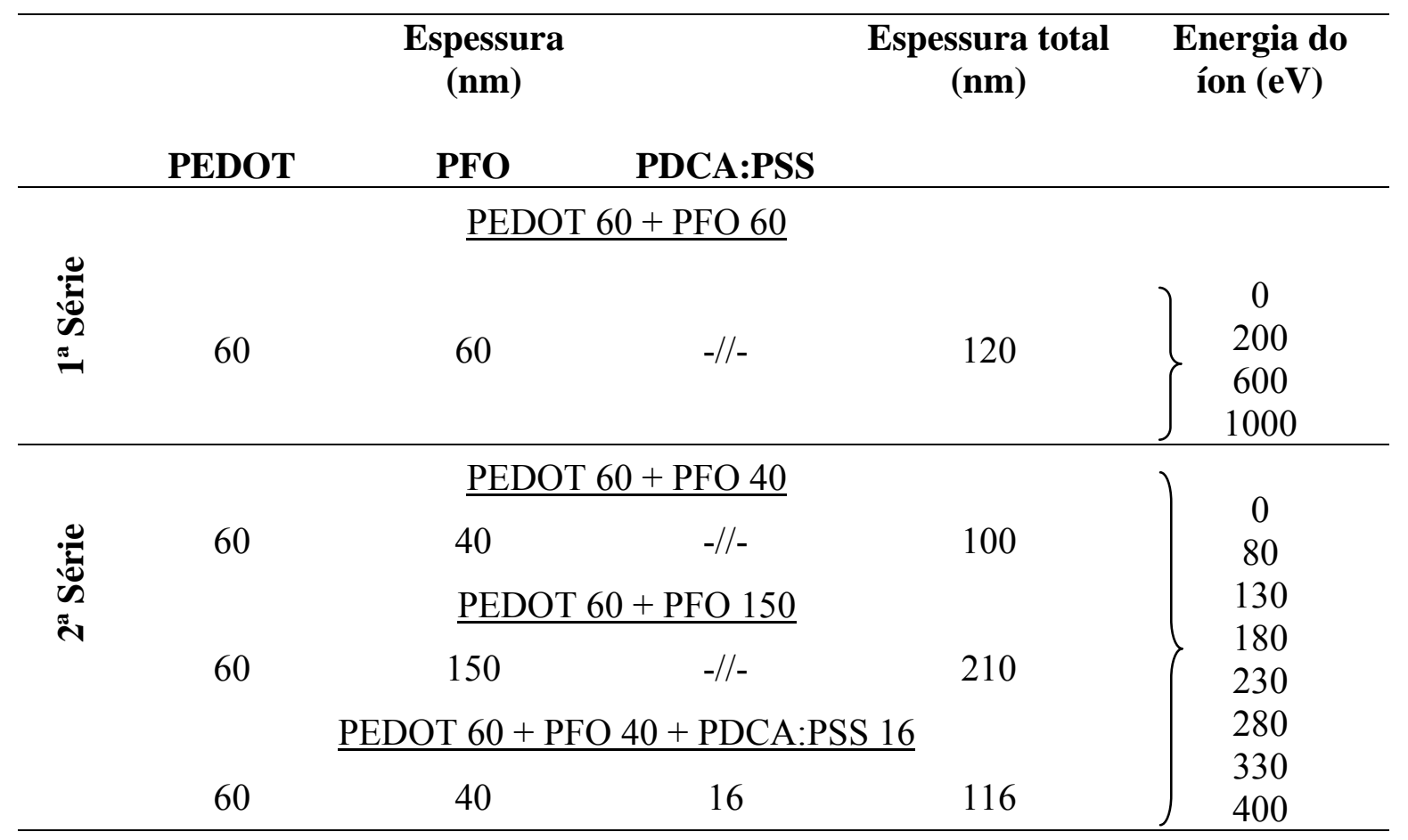






Figura 24 - Esquema das amostras preparadas.

\subsection{Técnicas de caracterização utilizadas}

\subsubsection{Perfilometria}

As medidas de espessura foram feitas por meio da perfilometria mecânica, utilizando um perfilômetro modelo Dektak 150, da marca Veeco. Para preparar a amostra, utilizou-se um substrato de vidro, sobre o qual os filmes poliméricos foram depositados, seguindo os parâmetros mencionados anteriormente. Uma vez obtido o filme, uma ponta de metal foi utilizada para remover o material, formando um risco na amostra, que atinge o substrato. Desta forma utilizou-se o perfil desta região para medir a espessura do filme. Em média três riscos eram feitos por amostra e o seu perfil foi medido em três pontos diferentes, assim as espessuras mencionadas são a média das nove medidas realizadas. 


\subsubsection{Espectroscopia de absorbância UV-VIS}

A espectroscopia de absorbância, conhecida por UV-vis, permite quantificar a luz absorvida por um material, tendo como fundamento a absorção de energia pelas moléculas nas regiões espectrais do visível e do ultravioleta. As medidas de absorção foram realizadas utilizando um espectrômetro U-2900 (UV-vis) de feixe duplo. Utilizou-se essa técnica para acompanhar o crescimento da camada espaçadora (PDAC:PSS), com o seguinte procedimento: Obteve-se primeiramente o espectro de absorbância para a amostra sem as bicamadas,vidro/ITO/ PFO, e a seguir mediu-se a absorbância com a adição seqüencial das bicamadas (amostra vidro/ITO/PFO/PDAC:PSS).

\subsubsection{Fotoluminescência}

O espectro de emissão espontânea de um material sob excitação ótica é a base da fotoluminescência (PL). Nesta técnica um feixe de luz é focalizado sobre a amostra e, uma vez que os fótons incidentes tenham energia suficiente, eles são absorvidos pelo material criando excitações eletrônicas. O relaxamento destas excitações pode acontecer radiativamente, dando origem à fotoluminescência. Utilizaram-se dois equipamentos diferentes para as medidas de PL. Um espectrofluorímetro modelo RF-5301 PC, da marca Shimadzu, com o comprimento de onda de excitação de $490 \mathrm{~nm}$ foi usado para a primeira série de amostras. Já para a segunda série de amostras, utilizou-se o sistema mostrado na Figura 25, com um laser de He-Cd (modelo 1K5652R-G, da marca Kimmon) que tem duas linhas de excitação (325 nm e $442 \mathrm{~nm}$ ) como fonte de luz. A luz laser é guiada através de um sistema de lentes, espelho e prisma, para que incida na amostra. A intensidade é controlada com o uso de filtros. A emissão da amostra é coletada por um conjunto de lentes e direcionada para um espectrofotômetro (modelo HR4000, da marca Ocean Optics). A câmara do criostato 
foi usada para manter a amostra em vácuo $\left(\sim 10^{-5}\right.$ Torr $)$ durante as medidas. As principais diferenças deste sistema em relação ao usado na primeira série de amostras são:

a) O feixe de excitação ilumina uma área bem menor, possibilitando a análise mais criteriosa das amostras;

b) A realização das medidas em vácuo também evita a degradação do PFO.

As medidas foram feitas de forma que a luz incidisse na área metalizada pelo lado do vidro.

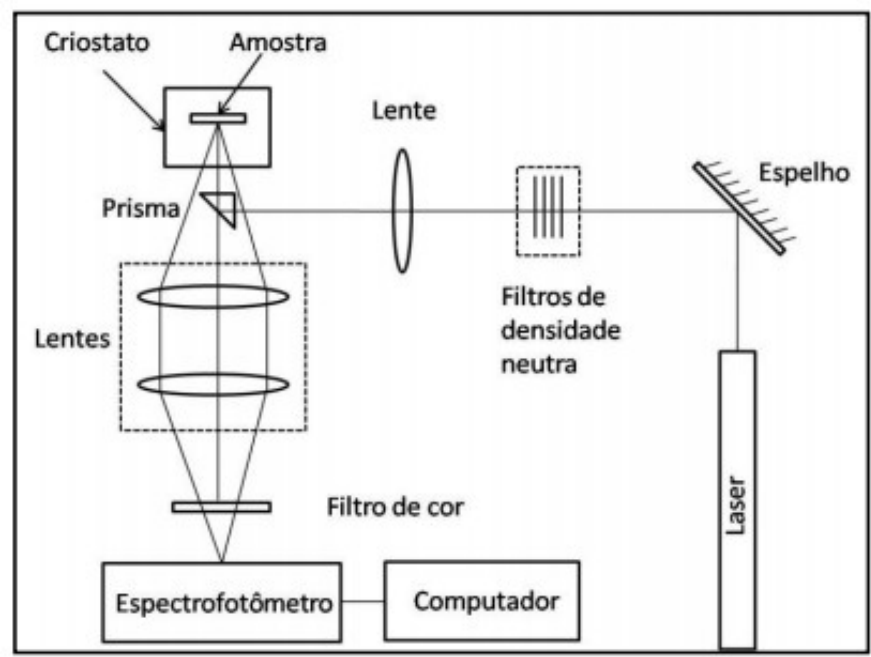

Figura 25 - Esquema do sistema de PL utilizado na segunda série de amostras.

\subsubsection{Eletroluminescência e caracterização elétrica}

Para analisar o funcionamento do dispositivo, ligou-se uma fonte de tensão ao catodo e ao anodo. Isto é feito removendo a camada polimérica de parte do dispositivo (conforme pode ser visto na Figura 22), assim o ITO, que é o anodo, fica exposto para que um contato elétrico de cobre seja colocado sobre ele. Um contato elétrico também é colocado sobre o alumínio. É necessário tomar cuidado para que não ocorra curto circuito, pois facilmente o contato elétrico colocado sobre o alumínio pode ultrapassar as camadas poliméricas e entrar em contato com o 
ITO, causando um curto circuito. Para que isto não ocorra, é necessário remover o ITO debaixo da região onde o contato elétrico entrará em contato com o alumínio. Uma vez feito isto, variou-se a tensão aplicada, medindo a corrente gerada e simultaneamente, com um fotodiodo, a luminosidade emitida pelo OLED. As medidas foram feitas utilizando uma fonte de tensão programável Keithley Source Meter 2400 e um eletrômetro Keitlhey 617 acoplado a um foto diodo. Para evitar a degradação causada pela presença de oxigênio, as medidas foram realizadas em vácuo.

\subsubsection{Espectroscopia de Impedância}

A espectroscopia de impedância eletroquímica (EIE) é uma técnica útil para a caracterização de propriedades elétricas de materiais, bem como de interfaces constituídas de materiais poliméricos. Essa técnica pode ser usada para investigar a dinâmica de ligações ou de cargas móveis no volume ou nas regiões interfaciais de qualquer conjunto de materiais, líquidos ou sólidos (por exemplo, iônicos, semicondutores, mistos eletrônico-iônicos e isolantes dielétricos).

Para a realização desses experimentos, o intervalo de freqüência variou de $10^{7} \mathrm{~Hz}$ a $1,0 \mathrm{~Hz}$, amplitude de voltagem de $0,1 \mathrm{~V}$, sem utilizar uma tensão contínua como Bias e foi utilizado um analisador de impedância/fase Solartron (modelo SI1260). Os contatos elétricos foram feitos da mesma forma que os utilizados para as medidas de caracterização elétrica, e as medidas foram realizadas em vácuo. 


\subsubsection{Microscopia de Fluorescência}

A microscopia de fluorescência é uma técnica de imagem que baseia-se no fenômeno de fotoluminescência. A amostra analisada é iluminada por uma luz e esta é absorvida e reemitida pela amostra em um comprimento de onda maior (no presente caso, foi utilizada luz ultravioleta na excitação e a luz na região do visível foi reemitida). Assim é realizada a análise de materiais fotoluminescentes. Neste trabalho, a microscopia de fluorescência foi empregada para investigação de efeitos da deposição IBAD, no sentido perpendicular ao feixe de íons, sobre a camada polimérica. Utilizou-se um microscópio de fluorescência modelo Olympus BX41, e uma lente de $40 \mathrm{x}$.

\subsubsection{Espectroscopia Raman}

A espectroscopia Raman é uma técnica analítica que fornece informações sobre a estrutura molecular de materiais, com base na observação do seu espectro de espalhamento de luz. Com grande freqüência, após interagir com a amostra, o espalhamento de luz ocorre sem que haja ganho ou perdido a energia e é conhecido como espalhamento Rayleigh. Apenas pequena fração de luz dispersa por uma molécula exibe uma mudança de freqüência constante em relação à luz incidente, indicando a ocorrência de transferência de energia para a molécula ou da molécula. Essa mudança de freqüência, que representa a diferença de energia entre um fóton incidente e outro espalhado, equivale à diferença entre dois estados vibracionais da molécula, que é o valor medido na espectroscopia Raman. Essa técnica foi utilizada para analisar as mudanças causadas pelo IBAD no polímero. Para as medidas Raman foi utilizado um equipamento Renishaw RM2000, utilizando-se um comprimento de onda de $632,8 \mathrm{~nm}$ de um laser de HeNe com um diâmetro da ordem de $1 \mu \mathrm{m}^{2}$, à temperatura ambiente e utilizando geometria de retroespalhamento. O equipamento utilizado pertence ao Grupo de Filme Finos do Instituto de Física de São Carlos. 


\subsubsection{Análise Computacional de imagem}

Uma análise da intensidade (que pode variar de 0 a 256) de cada uma das três cores (vermelho, verde e azul) que compõe cada pixel de um arquivo de imagem foi feita através de um programa computacional. Assim foi associado a cada pixel da imagem analisada um valor referente à sua intensidade luminosa, posicionado em uma matriz com as mesmas dimensões. Uma vez construída esta matriz, através de um tratamento simples de dados, pode ser feita a média de uma linha ou coluna (ou apenas parte das mesmas). Assim, através dessa análise de imagem representa-se uma imagem em um gráfico com duas dimensões (posição e intensidade).

\subsection{Simulações}

Foi realizada uma série de simulações dos processos envolvidos na formação dos filmes de alumínio e da interface híbrida durante a deposição assistida por feixe de íons. Esta seção tem o objetivo de mostrar como as simulações foram feitas, detalhando o procedimento.

Para essas simulações, o software SRIM (The Stopping and Range of Ions in Matter) ${ }^{72}$ foi usado. Esse software utiliza o código TRIM (Transport of Ions in Matter), baseado no trabalho original de J.P. Biersack ${ }^{73}$. Esse programa assume o íon como um átomo em movimento e todos os átomos do alvo como átomos em repouso e calcula a penetração dos íons dentro do alvo utilizando tratamento de mecânica quântica para as colisões entre os íons e átomos. Durante a colisão, é considerada uma colisão de Coulomb, incluindo trocas entre as camadas eletrônicas e também a interação destas mesmas camadas sobrepostas. As interações de longo alcance dos íons, criando plasmons e excitações eletrônicas no alvo são levadas em consideração utilizando uma descrição da estrutura eletrônica e das ligações interatômicas do alvo. O efeito cascata da colisão sobre todos os outros átomos do alvo é considerado e seguido em detalhes. O programa permite que alvos de material composto 
sejam utilizados e calcula tanto a distribuição tridimensional final dos átomos (íons e alvo) como fenômenos cinéticos associados ao processo: danos no alvo, sputtering, ionização e produção de fônons. Para a simulação foram utilizados íons de argônio, com valores de energia variando conforme explicado no item anterior. Selecionou-se ângulo de incidência normal ao substrato.

O software estima a densidade do substrato de acordo com a estequiometria dos dados de entrada. Devido à pequena espessura do filme, medir a densidade do mesmo só é possível utilizando várias camadas, porém a precisão do experimento seria alterada devido às várias interfaces criadas. $\mathrm{O}$ valor da densidade estimado pelo software, em função da estequiometria do polímero, foi de $0,9975 \mathrm{~g} / \mathrm{cm}^{3}$, para um polímero ADS 129BE (semelhante ao que foi utilizado, ADS 108GE) o valor medido para a densidade ${ }^{74}$ foi de $1,041 \mathrm{~g} / \mathrm{cm}^{3}$. A diferença de aproximadamente $4 \%$ pode ser negligenciada, conforme mostrado no gráfico da Figura 26, onde se vê a penetração média de um íon de argônio em função da energia para as duas diferentes densidades. A densidade estimada pelo software foi usada nas simulações feitas.

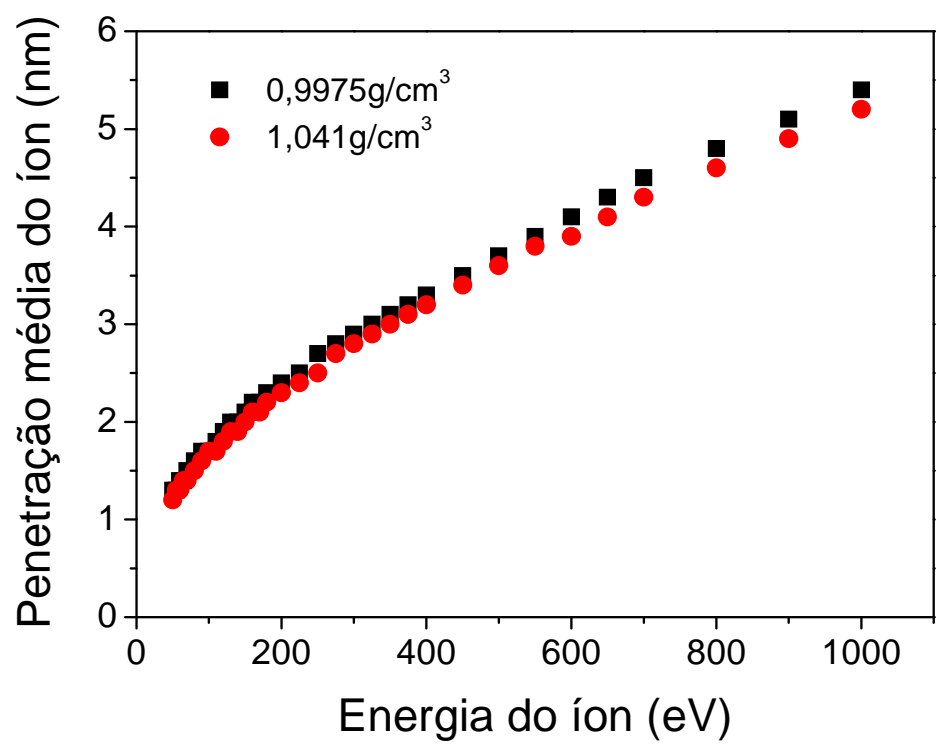

Figura 26 - Penetração média de um íon em função da energia, para alvos com duas densidades diferentes.

O software permite o uso de várias camadas, de forma que seria possível utilizar como alvo toda a estrutura vertical do dispositivo. Porém, conforme pode ser visto na Figura 26, mesmo para a energia mais alta que foi utilizada, a penetração do íon é pequena em relação à espessura da primeira camada. A densidade do polímero utilizado nas bicamadas (PDAC e PSS) é muito próxima à do PFO utilizado $\left(1,05\right.$ e $1,04 \mathrm{~g} / \mathrm{cm}^{3}$, respectivamente), de forma que 
optou-se por utilizar a mesma simulação para PFO e para as bicamadas, sem prejuízo do resultado final.

Como resultado final da simulação, tem-se a distribuição dos íons de argônio e também dos átomos do polímero que foram deslocados. Na Figura 27 tem-se este resultado para íons de Ar com uma energia de $200 \mathrm{eV}$. Conforme pode ser visto, devido ao baixo número de átomos de oxigênio, pode-se desprezar o seu deslocamento. Conforme visto na seção anterior, o argônio, sendo um gás nobre, não se liga ao polímero, abandonando-o, por difusão, após algum tempo. Assim os deslocamentos que mais interessam são o do carbono e do hidrogênio. Como o hidrogênio forma apenas uma ligação, a quebra da cadeia polimérica pode ser mais bem avaliada pelo deslocamento do átomo de carbono. Deste modo, apenas o deslocamento do carbono e do alumínio serão utilizados nas análises do trabalho.

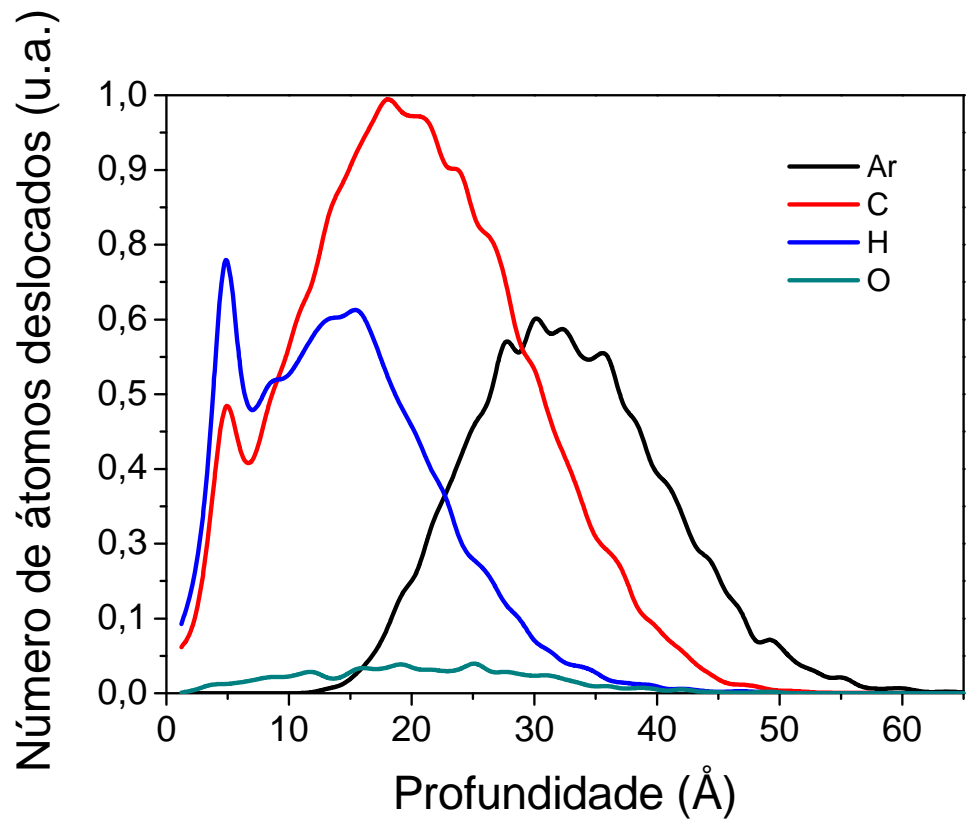

Figura 27 - Número de átomos deslocados em função da profundidade, para ions de argônio com $200 \mathrm{eV}$ incidindo sobre PFO. Incidência de ions da esquerda para a direita.

O software SRIM, foi desenvolvido para a incidência de íons em um alvo estático. No caso do IBAD, tem-se um processo de deposição do material evaporado simultâneo à incidência de íons. Para simular este processo, várias simulações consecutivas foram feitas, adicionando uma camada de alumínio na frente do polímero. Assim, aumentando a espessura desta camada lentamente e posteriormente somando todos os resultados, tem-se uma boa aproximação do processo de IBAD utilizado neste trabalho. A Figura 28 (a), apresenta várias 
simulações variando a espessura da camada de alumínio de $5 \AA$ a $30 \AA$. Já em (b), apresentase a somatória de todas as simulações. No presente trabalho, as simulações serão sempre apresentadas nesta forma, ou seja, a simulação do processo IBAD.
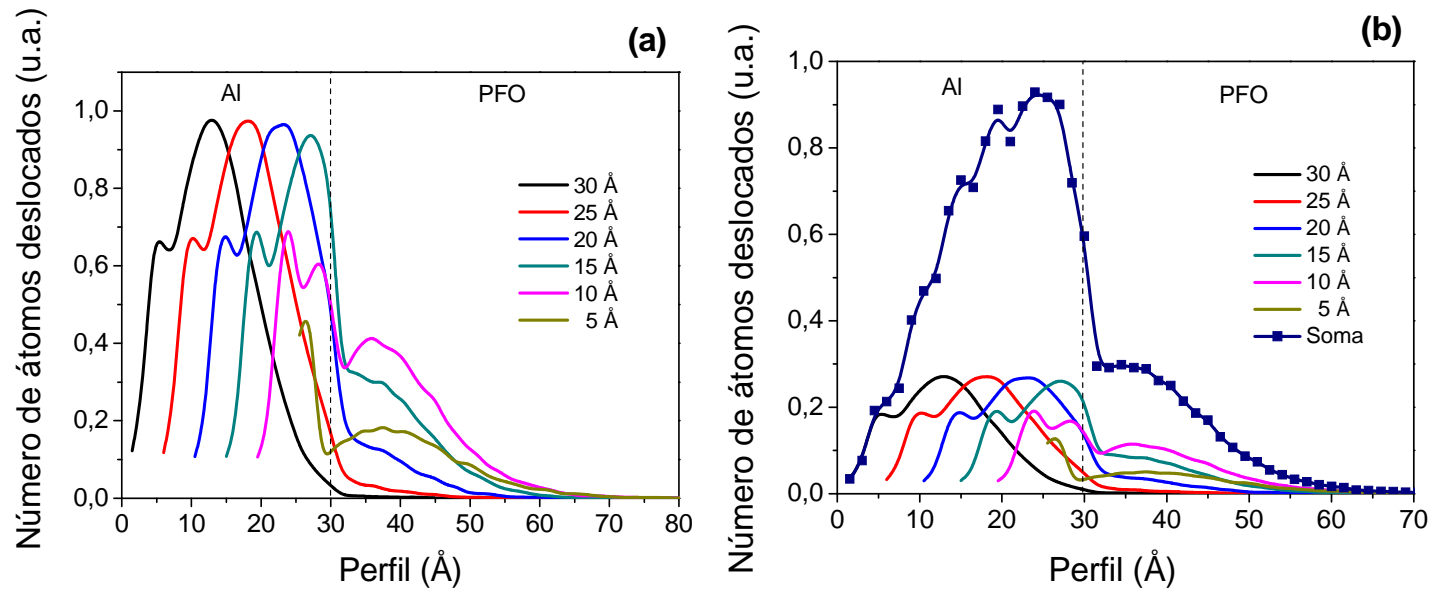

Figura 28 - Número de átomos de Al deslocados em função da profundidade para íons de argônio com $200 \mathrm{eV}$ incidindo sobre uma camada de Al (que varia de 5 a 30 A) sobre PFO (a) e a soma de todos deslocamentos, demonstrando o processo IBAD(b). À esquerda da linha tracejada, tem-se o Al e à direita, o PFO. A incidência de ions se dá da esquerda para a direita. 


\section{RESULTADOS E DISCUSSÕES}

Uma vez que a deposição utilizando IBAD em OLEDs é pouco explorada na literatura, primeiramente foi feita uma série de experimentos exploratórios onde os efeitos da deposição sobre a amostra foram analisados. Em primeiro lugar (seção 4.1), é apresentado o estudo da influência do IBAD sobre a camada metálica do catodo, desconsiderando a interface metal/polímero. Na seção 4.2, todo espectro de energia permitido pelo equipamento de IBAD para o feixe de íons foi explorado e o efeito da incidência dos íons diretamente sobre o polímero é mostrado. A análise optoeletrônica destas amostras também foi feita e os resultados levaram à algumas alterações nos processo de IBAD e na confecção das amostras. Os resultados desta primeira série de medidas levaram à delimitação de uma faixa mais restrita de energia para os íons, que foi aplicada na segunda série de amostras na seção 4.3. Nesta série, intervalos menores para a energia do íons foram utilizados e medidas de PL e caracterização elétrica foram feitas.

\subsection{Caracterização do Catodo metálico}

Mencionou-se que o uso do IBAD pode produzir efeitos de compactação e sputtering no filme metálico depositado (seção 3.4.3). Estes efeitos podem ser claramente observados na Figura 29, que mostra medidas da espessura do filme de Al depositado sobre substrato de $\mathrm{Si}$ para diferentes energias dos íons de argônio. A espessura nominal do filme de alumínio foi ajustada em $100 \mathrm{~nm}$ para esse experimento. 




Figura 29 - Gráfico da espessura da camada de alumínio em função da energia dos íons de argônio

O decréscimo linear da espessura mostrado para as energias de 0, 200 e $600 \mathrm{eV}$ pode ser explicado, em um primeiro momento, pela existência de uma densidade máxima, uma vez que o aumento da densidade se deve principalmente ao preenchimento das vacâncias e estas existem em número finito. ${ }^{25 ; 60 ; 61}$ Já o comportamento para a amostra com $1000 \mathrm{eV}$, encontra respaldo na remoção de átomos de alumínio por sputtering ${ }^{25}$, que consiste na remoção de um ou mais átomos após o choque do íon. Durante a deposição IBAD, minimizou-se este processo colocando o feixe de íons em um ângulo normal ao substrato. Porém, mesmo com o ângulo de incidência do feixe de íons normal ao alvo (substrato), sempre existe uma energia mínima (já que existe uma energia de ligação entre os átomos de alumínio) a partir da qual o sputtering ocorre (pode-se fazer uma analogia com o efeito fotoelétrico ${ }^{75}$, em uma primeira aproximação). Desta forma a redução da espessura observada, é dada pela combinação destes dois fatores, compactação e sputtering, onde a contribuição de cada um varia com a energia. A redução da espessura do alumínio da amostras de 1000 eV é visível, sendo que o catodo se torna semitransparente.

A influência que essa variação na espessura causa no funcionamento do dispositivo, foi analisada utilizando a técnica de espectroscopia de impedância, realizadas em vácuo, na qual freqüências de 1 a $10^{6} \mathrm{~Hz}$ foram utilizadas, com amplitude de voltagem de $0,1 \mathrm{~V}$ e com tensão $\mathrm{DC}=0$. A tabela 4 apresenta os resultados das resistências em série obtidas através dos ajustes das medidas de impedância. A resistência em série, refere-se aos contatos elétricos ${ }^{76}$ do dispositivo, o que inclui o ITO, o catodo, os contatos elétricos e os cabos elétricos. 
Tabela 4 - Valores de resistência em série obtidos para a segunda série de amostras.

\begin{tabular}{|c|c|c|c|}
\hline \multirow[t]{2}{*}{ Energia do íon (eV) } & \multicolumn{3}{|c|}{  } \\
\hline & PFO 40 & PFO 150 & PFO 40 + PDAC:PSS 16 \\
\hline 0 & 67 & 83 & 67 \\
\hline 80 & 74 & 80 & 81 \\
\hline 130 & 103 & 71 & 96 \\
\hline 180 & 100 & 114 & 81 \\
\hline 230 & 96 & 104 & 60 \\
\hline 280 & 62 & 70 & 108 \\
\hline 330 & 66 & 69 & 73 \\
\hline 400 & 62 & 41 & 47 \\
\hline
\end{tabular}

Os resultados mostram que não existe uma relação entre a energia dos íons e o valor da resistência. A diferença nos valores da resistência se deve às condições experimentais, tal como o contato elétrico entre os eletrodos e o ITO e o alumínio ${ }^{76}$. Desta forma, pode-se concluir que a alteração provocada no bulk do filme de alumínio pelo uso do processo IBAD não provoca nenhuma alteração significativa na condutividade do catodo.

\subsection{Interfaces Metal/Polímero semicondutor: altas energias}


O objetivo desta seção é apresentar os resultados da primeira série de amostras para as quais a energia dos ions de argônio foi utilizada no intervalo de 0 a $1000 \mathrm{eV}$. Visa-se com isso investigar os efeitos do processo IBAD na formação de interfaces não-abruptas no catodo em OLEDs e, consequentemente, investigar seu efeito no processo de injeção eletrônica dentro do espectro de energia permitido pela fonte de íons utilizada neste trabalho. Nestes primeiros ensaios, o shutter necessário para a estabilização das condições de deposição não foi utilizado. Após esta primeira série foi notada a necessidade desse dispositivo, e então, o mesmo foi desenvolvido. Os resultados desta primeira série se encontram publicados ${ }^{77}$.

\subsubsection{Simulações}

O software SRIM foi desenvolvido para a implantação de íons em sólidos e obtem resultados quantitativos consistentes para estes $\operatorname{casos}^{78}$, já para processos secundários tais como a alteração na densidade e o sputtering; os valores obtidos não são muito precisos. Os resultados obtidos para a simulação aplicada ao presente trabalho podem não representar fielmente estes processos secundários, porém servem para se ter uma idéia qualitativa dos mesmos.

As simulações foram realizadas considerando uma camada inicial de $10 \AA$ de $\mathrm{Al}$ depositada sobre a camada do polímero semicondutor já que, durante a preparação destas amostras, o feixe de íons foi acionado apenas após a taxa de evaporação atingir o valor nominal escolhido. Desta forma, a camada inicial de alumínio forneceu proteção parcial para a ação dos íons sobre o polímero. A Figura 30 (a), mostra o deslocamento dos átomos de Al em escala log para íons de argônio com a energia de 200, 600 e 1000 eV, até que o filme de alumínio atinja a espessura de 30,50 e $70 \AA$, respectivamente. No experimento, o filme de $\mathrm{Al}$ foi depositado até atingir $1000 \AA$ (maiores detalhes na seção 4.1.5.2), mas as simulações até as espessuras apresentadas fornecem dados suficientes para o entendimento das implicações da energia na formação da interface. Ao lado esquerdo da linha pontilhada na Figura 30 (a), 
tem-se o deslocamento dos átomos de alumínio dentro do filme (de alumínio), o que implica em uma compactação e conseqüente aumento da densidade do mesmo com a energia do íon, conforme discutido anteriormente. A medida que o filme cresce, esta alteração se mantém constante, conforme pode ser visto na Figura 28 (a). Assim tem-se uma alteração na densidade do filme uniforme ao longo do filme.

Ao lado direito da linha pontilhada na Figura 30 (a) tem-se o perfil em escala logarítmica dos átomos de Al que penetraram no polímero. Este perfil é praticamente gaussiano e a profundidade de penetração pouco altera em relação à interface (meia largura de aproximadamente $10 \AA$ ) com a energia. Por outro lado, a concentração de Al deslocado dentro da camada de polímero aumenta com o aumento da energia do ion.

(a)
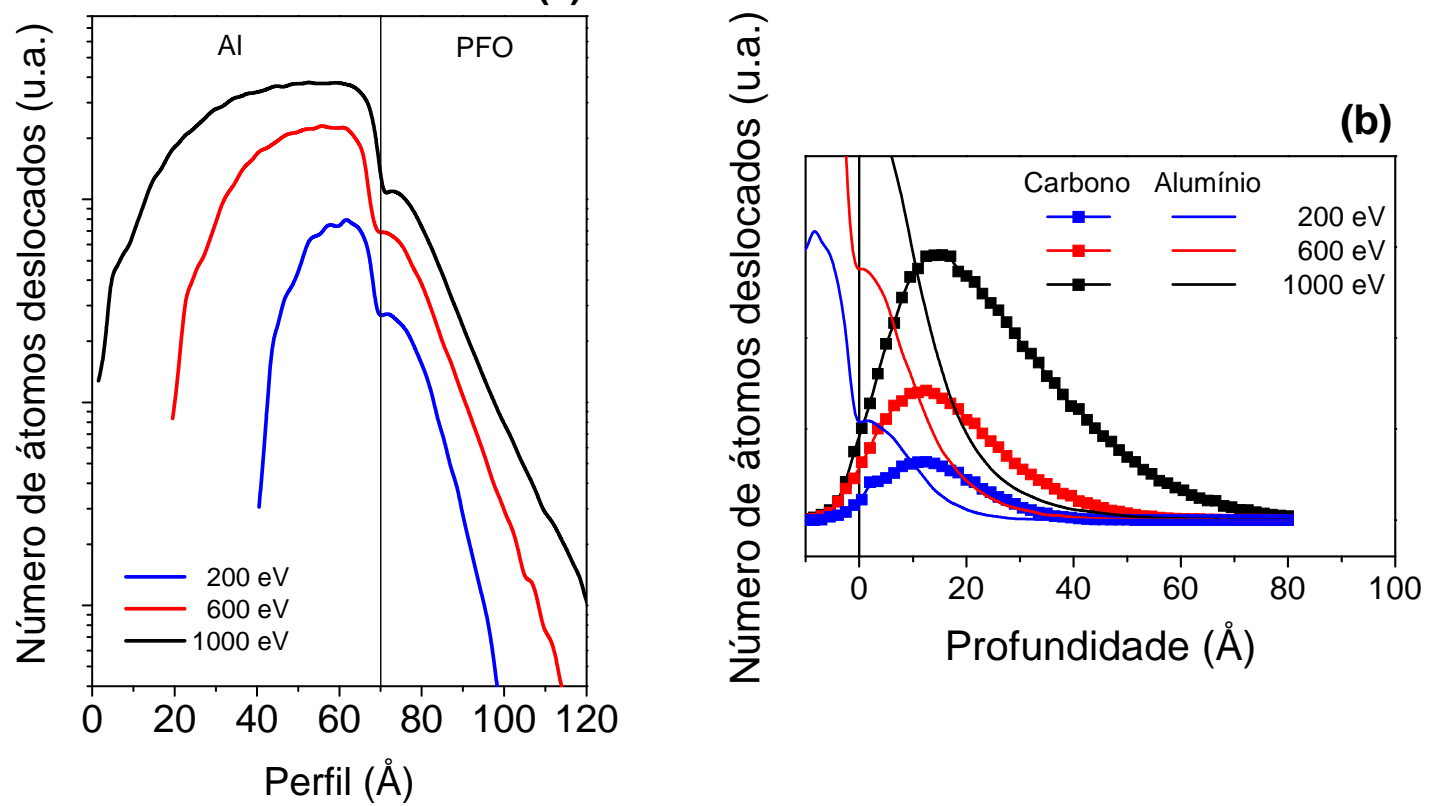

Figura 30 - Perfil da posição final dos átomos de Al, em escala monolog (a) e de AL e C superpostos em escala linear (b) deslocados no processo IBAD. À esquerda da linha vertical preta (em 70 A em (a) e em $0 \AA$ em (b) ), tem-se o Al e à direita, o PFO. A incidência de íons de argônio, com (200,600 e 1000eV), se dá da esquerda para a direita.

O deslocamento do carbono na região do filme próximo à interface possui o comportamento apresentado na Figura 30 (b) (quadrados). A figura também mostra o deslocamento do alumínio nessa região para comparação (linhas contínuas). Nota-se que uma pequena fração dos átomos de carbono se desloca no sentido contrário ao dos íons, penetrando no alumínio (átomo de carbono à esquerda da linha vertical em $0 \AA ̊$ ), o que apenas reforça o 
caráter híbrido da interface. Este resultado da simulação pode indicar que uma interface híbrida entre o metal e o polímero semicondutor pode ser formada com a técnica IBAD, conforme esquematizado na Figura 14 (b). É interessante notar que a simulação nos leva a quatro regiões distintas: a) a região em que prevalece o $\mathrm{Al}$ (metal ou catodo), b) uma região de aproximadamente $10 \AA$ em que frações de Al e polímero deslocado (onde houve o deslocamento do carbono) coexistem dentro da matriz polimérica (chamada de região híbrida), c) outra região polimérica de aproximadamente 30 a $70 \AA$, dependendo da energia do íon, contendo polímero deslocado e polímero no seu estado natural e, finalmente, d) uma região com o polímero no seu estado natural (bulk). Em uma interface abrupta estariam presentes apenas duas regiões, a região do catodo metálico e aquela com o polímero. É importante salientar que a região de interface contendo $\mathrm{C}$ deslocado pode apresentar degradação do material polimérico, como a quebra da cadeia, o que produziria uma redução no tamanho de conjugação do material na região. Efeitos outros, como aumento da temperatura, também podem alterar as características do polímero, todavia não são vistos nas simulações e serão discutidos nas próximas seções.

Apesar de não terem sido feitas medidas da penetração do alumínio no polímero, diversos resultados na literatura ${ }^{78 ; 79 ; 80}$ dão suporte ao uso das simulações utilizando o software SRIM e polímeros, apontando erros de no máximo 25\%. Assim é esperado que para íons com $1000 \mathrm{eV}$, a penetração máxima do catodo de alumínio seja da ordem de uma dezena de nanômetros $(6 \mathrm{~nm})$, enquanto a espessura do filme é da ordem de uma centena (60nm do $\mathrm{PFO}+60 \mathrm{~nm}$ do PEDOT).

\subsubsection{Caracterização por microscopia óptica de fluorescência}

Neste trabalho foram realizadas várias alterações no sistema IBAD que visaram o aprimoramento da deposição dos catodos metálicos assistida por íons. Verificamos, já nos 
primeiros experimentos realizados com a técnica, que as máscaras projetadas para a deposição dos catodos não estavam adequadas à configuração espacial entre a amostras e as fontes de ion e metal. Isso levou à formação de sombras nas bordas ou fronteira da área coberta pela máscara que, apesar de serem indesejadas, ajudaram na caracterização do material depositado e esclarecimentos de muitas questões referentes à ação dos íons sobre o material polimérico e também à qualidade do contato.

A Figura 31 ilustra estes efeitos. Apesar de o feixe iônico incidir com um ângulo normal à superfície do dispositivo, um pequeno desalinhamento cria a região de sombra, pois a máscara tem a espessura de $1 \mathrm{~mm}$. No esquema, o ângulo de incidência do íon foi desalinhado exageradamente para maior clareza da ilustração. $\mathrm{Na}$ fronteira superior da máscara, o metal foi depositado na região de sombra sem o auxilio de íons. Na região central a amostra foi protegida pela máscara e assim não foi bombardeado por íons e tampouco alumínio foi depositado sobre ela. Já a fronteira inferior, a máscara fez sombra para o metal e essa região foi alvo do feixe de íons apenas.

Figura 31 - (a) Esquema detalhado do processo de formação das três áreas. O ângulo de incidência do íon foi extrapolado para melhor visualização. (b) Esquema do resultado final.

A microscopia por fluorescência foi adequada para a caracterização local destas áreas distintas. A Figura 32 apresenta as imagens de microscopia de fluorescência (emissão total) de amostras preparadas por IBAD utilizando energias de 1000, 600 e $200 \mathrm{eV}$. A imagem foi feita pelo lado do anodo transparente de vidro/ITO, de modo que a luminescência abaixo do metal fosse detectada. Uma luz com comprimento de onda entre 350-390 nm foi utilizada para excitação e a imagem foi feita com uma objetiva com aumento de 20x. As três regiões visíveis 
em cada imagem correspondem a aquelas esquematizadas na Figura 31 (b). Espera-se que a intensidade da luminescência na parte coberta pela máscara seja igual para as três imagens. Porém, a intensidade da luz de excitação foi alterada em cada uma para que a parte atingida pelo íon ficasse visível. Pode-se observar o mesmo comportamento para cada amostra ou energia de íon: a intensidade da luminescência sob a região metalizada é muito maior que a região não metalizada protegida pela máscara (área central) e esta, por sua vez, é muito maior (dependendo da energia) que a emissão provinda da região não metalizada (área inferior mais escura) que sofreu apenas a ação dos íons.



Figura 32 - Imagens de microscopia de fluorescência para as amostras produzidas com ions de 200, 600 e $1000 \mathrm{eV}$.

A análise da Figura 32 mostra claramente como a intensidade da fotoluminescência sofre uma redução significativa, principalmente para energias altas do íon $(\geq 600 \mathrm{eV})$. A queda da intensidade de emissão nessa região pode estar associada à degradação do polímero luminescente e/ou na remoção do material polimérico. Na região do metal (não atingida pelo íon) processos de interferência ${ }^{32}$ e reflexão da luminescência na interface metálica fazem com que a intensidade seja significantemente maior que na região do polímero (ver seção 3.3.1).

A Figura 33 mostra o resultado de uma análise computacional de cada imagem da Figura 32. Esta análise levou em conta a integração da intensidade de cada pixel da imagem (que varia em uma escala de 0 a 256) feita ao longo de uma linha X para cada corte na coluna Y (identificados na parte inferior esquerda da Figura 32), de forma que representassem as três regiões apresentadas na Figura 31(b). As curvas foram normalizadas para cada amostra de forma que as regiões protegidas pela máscara (Região II) tivessem a mesma intensidade. As 
intensidades na região com metal (Região I) não servem para comparação, pois para 600 e 1000 eV o valor da intensidade saturou. Já para a região exposta ao feixe de íons (Região III), a intensidade diminui à medida que a energia do feixe de íons aumentou, o que indica uma degradação das propriedades luminescentes do polímero causado pela exposição ao feixe de íons. Um pequeno aumento da intensidade ocorre perto da fronteira entre a região II (protegida pela máscara) e a região III (exposta aos íons). Estes aspectos serão tratados a seguir.

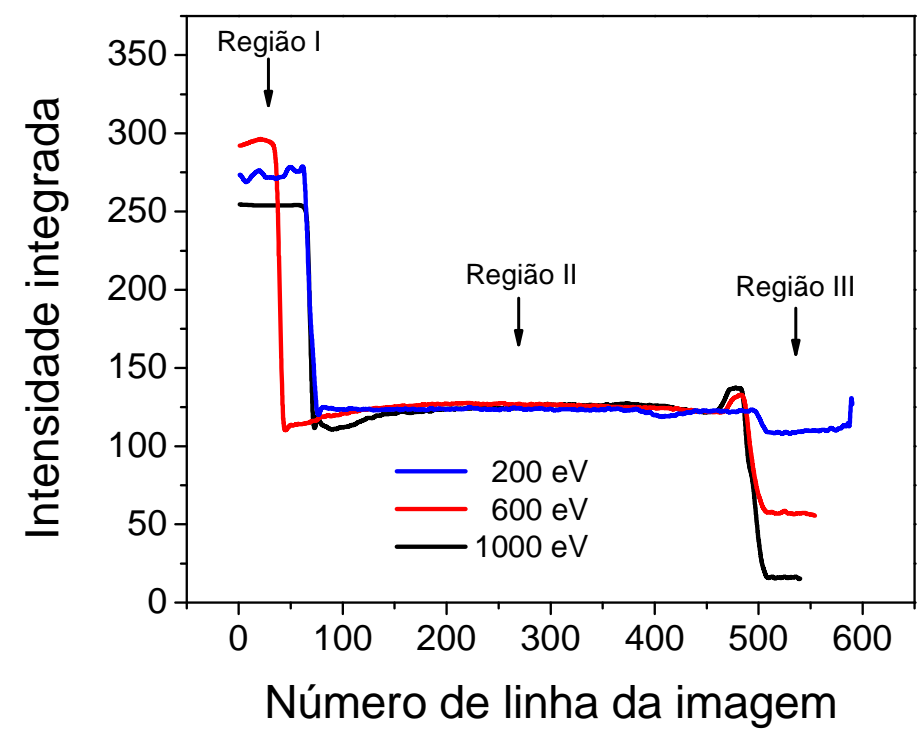

Figura 33 - Gráfico da intensidade de cada pixel integrada ao longo de uma linha em função da posição no eixo Y da imagem, para as três imagens da Figura 32. Região I > Polímero/Metal; Região II > Polímero ; Região III > Polímero/Íon

Do mesmo modo que foi feito na Figura 32, é interessante comparar os efeitos do bombardeamento dos íons sobre o metal, comparando as regiões com apenas deposição de metal com as regiões com deposição e assistência simultâneas. A Figura 34 mostra uma imagem de microscopia de fluorescência (emissão total) das três regiões da amostra preparada com o auxílio de íons com $1000 \mathrm{eV}$. À esquerda da imagem encontra-se a região protegida pela máscara (Região I), ao centro (região mais clara) tem-se a região de sombra que foi exposta somente à deposição de metal (Região II), conforme ilustrado na Figura 31 e por fim, à direita, está a região exposta à deposição IBAD do catodo (Região III), isto é, ao feixe de íons e à deposição de metal simultâneas. O gráfico sobreposto à imagem, em vermelho, é 
similar ao gráfico da Figura 33, e corresponde à intensidade integrada da emissão sob cada região em função da posição ao longo do eixo X.

Figura 34 - Imagem de microscopia de fluorescência para a amostra produzida com íons de $1000 \mathrm{eV}$. Gráfico sobreposto em vermelho corresponde à intensidade integrada em função da posição da linha X para as três regiões identificadas.

Pode-se ver pelo gráfico sobreposto a está figura (linha em vermelho) o perfil de intensidade para as três regiões. Conforme já visto acima, a maior intensidade sob a região II (de sombra), contendo apenas o metal, é explicada pelo efeito de cavidade sobre a emissão nessa região e depende da espessura da amostra. Este mesmo efeito ocorre na região III sob o metal que foi depositado por IBAD, porém a intensidade da luminescência é menor que na região II. A menor luminescência na região III indica que o material sofreu algum tipo de degradação ou foi parcialmente removido pelo bombardeamento com íons de Ar. Isso será discutido a seguir. Já a região I, protegida pela máscara possui intensidade de emissão 3,5 vezes menor que a da região II. Nota-se que entre a região II e a região III existe uma faixa estreita de maior intensidade de luminescência. Esta maior intensidade se deve à deposição de metal retroespalhado pelos íons, na fronteira com a região III. Estes átomos de metal podem ter uma energia maior que a energia térmica original dos átomos provindos da fonte. Veremos mais adiante que a intensidade da luminescência pode aumentar consideravelmente na faixa de energias dos ions de Ar entre 0 e 400 eV. Uma região intermediária análoga pode ser vista entre as regiões I e II. Nessa faixa de fronteira, os átomos do metal retroespalhados podem penetrar pelo espaço existente entre a máscara e a amostra e depositar nessa região. 
A imagem da Figura 34 mostra que a superfície do filme polimérico apresenta ondulações. Estas ondulações são variações de espessura do filme e podem ter como causa o efeito Marangoni ${ }^{81}$, que ocorre quando estruturas periódicas se formam durante a formação do filme de modo a minimizar sua tensão superficial. A principal causa é a rápida evaporação do solvente. Este efeito somado às forças oriundas das rotações que ocorrem durante o processo de sping coating, leva à formação destas ondulações. É interessante notar que estas estruturas estão mais definidas nas regiões II e III, cobertas com metal. Esta maior definição se deve ao aumento do contraste (maior diferença entre claro e escuro). Esta mudança no contraste pode ser entendida através do esquema apresentado na Figura 35 que, por sua vez, leva em consideração as variações da espessura e dos processos de emissão na presença de uma superfície ondulada metalizada. É importante lembrar que a emissão é coletada por uma objetiva posicionada do lado do substrato de vidro e, portanto, perpendicular à superfície do mesmo. Na região I não metalizada, o contraste é dado somente pela variação lateral da intensidade devido à variação do volume de filme, ou seja, maior (menor) espessura maior (menor) intensidade. Nesse caso, a variação de intensidade observada na Figura 35 segue o perfil de espessura do filme.



Figura 35 - Esquema em que a parte de cima ilustra o perfil morfológico das amostras e abaixo o perfil de luminescência esperado. À esquerda a região I( protegida pela máscara), ao centro a região II (onde ocorreu apenas metalização) e à direita a região III (onde metalização e incidência de ions ocorreram simultaneamente).

$\mathrm{Na}$ região II coberta apenas com metal, o efeito de interferência em uma cavidade ótica ocorre somente entre as superfícies paralelas do metal e do substrato. Assim, esse efeito só ocorrerá nas regiões de espessuras máximas e mínimas (derivada nula das ondulações com respeito à posição horizontal). Nesse caso a luz emitida será amplificada (ver seção 2.1.2) e coletada pela objetiva do microscópio (região clara). Nas outras posições, as superfícies do 
metal e do substrato não estão paralelas (a derivada das oscilações é diferente de zero) e o efeito de interferência é mínimo, sendo que apenas a luz propagando dentro do cone de coleta da objetiva é detectada. Nessas regiões a intensidade é mínima (região escura). O perfil de intensidade lateral aumenta o contraste através da variação entre uma região de máxima intensidade (maior espessura e interferência máxima), seguido por uma região intermediária de mínima intensidade (interferência mínima) e novamente por uma intensidade intermediária (menor espessura e máxima interferência).

A região III é metalizada e possui uma interface híbrida devido ao bombardeamento de íons durante a metalização. Além disso, a amostra da Figura 34 foi preparada com energia de $1000 \mathrm{eV}$ e, por isso, pode ocorrer redução da espessura total e degradação do filme (menor intensidade total). Isto aumenta ainda mais a razão claro/escuro, o que dá uma maior definição às ondulações superficiais, conforme mostra o perfil de intensidade esquematizado na Figura 35.

Este efeito de variação de contraste/resolução pode ser medido conforme mostra a Figura 36. Esta figura compara os perfis de intensidade ao longo da linha Y perpendicular às ondulações para as três regiões da Figura 34. Nesse caso, consideramos perfis próximos de regiões adjacentes, de modo a medir o perfil de intensidade de uma mesma ondulação. Podese ver que a variação da intensidade e da largura são bastante distintas para cada região. A variação da intensidade em relação à intensidade total é de $16 \%$ (menor contraste) para a região I, de 33 \% na região II e de 67 \% para a região III (maior contraste). O grande contrate da região III é reforçado pelo fato da largura das ondulações nessa área serem menores, conforme previsto no modelo esquematizado na Figura 35.

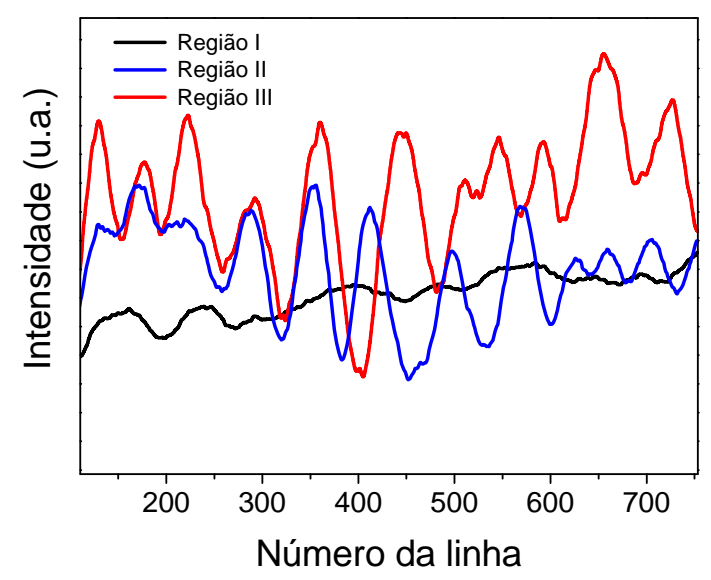

Figura 36 - Comparação entre os perfis de intensidade ao longo da linha Y (perpendicular às ondulações) para as três regiões da Figura 34. 
A possível remoção de polímero causada pelo feixe de íons foi analisada com o uso de perfilometria. O resultado dessas medidas mostram que para o feixe de íons de $1000 \mathrm{eV}$, aproximadamente $20 \mathrm{~nm}$ do polímero foram removidos na região atingida somente pelo íon. Como a espessura do PFO depositado foi de $60 \mathrm{~nm}$, tem-se uma redução de $1 / 3$ na quantidade da camada ativa nessa região. Porém, como vimos anteriormente, a redução de material é muito menor durante a deposição do metal. Portanto, a queda expressiva da luminescência na região III, mostrada no perfil inserido na imagem da Figura 32, indica que a remoção do material não é o único fator que promove a sua redução da intensidade. Degradação causada direta e indiretamente pelos íons com energia de $1000 \mathrm{eV}$ também produz a diminuição da luminescência. Isto mostra que não apenas os efeitos diretos do IBAD (implantação dos átomos de alumínio, deslocamento dos átomos do polímero e sputtering) são significativos, como também efeitos secundários. $\mathrm{O}$ aumento da temperatura do filme polimérico pode promover degradação do mesmo ${ }^{82}$, conforme já mencionado; no entanto, as alterações da temperatura causadas pela técnica IBAD em filmes poliméricos finos não foram estudadas (temperatura esta, provavelmente acima da temperatura normalmente estudada para a degradação de dispositivos ${ }^{44}$ ). Por outro lado, as medidas RAMAN do PFO em forma de filme e em forma vítrea não apresentam diferenças ${ }^{83}$.

\subsubsection{Caracterização por Fotoluminescência}

As medidas de microscopias por fluorescência, feitas na seção anterior, usaram a emissão total para fazer as imagens. É interessante analisar as amostras sob o ponto de vista espectral. $\mathrm{O}$ espectro de fotoluminescência da região sob o catodo de Al é mostrado na Figura 37 (a). Pode-se ver que a intensidade do espectro de luminescência cai com o aumento da energia do íon. A inserção na figura mostra que esta redução da fotoluminescência é de 17 vezes quando se comparam as intensidades das amostras cuja deposição foi feita sem $(0 \mathrm{eV})$ e com assistência de íons de argônio (1000 eV). Pode-se avaliar um desvio espectral para o azul de $5 \mathrm{~nm}$ do máximo de emissão na linha de fônon zero em função do aumento da energia dos 
íons (510 nm para $0 \mathrm{eV}$ e $505 \mathrm{~nm}$ para $1000 \mathrm{eV}$ ), o que sugere uma diminuição do comprimento de conjugação do $\mathrm{PFO}^{32}$. Este deslocamento espectral é desprezível para energias de $200 \mathrm{eV}$. Isto pode ser visto nos espectros de excitação normalizados mostrados na Figura 37(b) e que correspondem a aqueles de emissão da Figura 37(a). O deslocamento espectral para o azul para a amostra depositada com energias dos íons de argônio de $1000 \mathrm{eV}$ indica um forte rompimento das cadeias, produzindo a quebra de conjugação. Este deslocamento não é observado para energias menores ou iguais a $600 \mathrm{eV}$.

A redução da fotoluminescência com a energia dos íons de argônio não se deve a algum fenômeno de recombinação não radiativa, já que a criação de centros não radioativos daria origem a um deslocamento espectral para o vermelho ${ }^{32}$. O deslocamento espectral para o azul, da excitação, implica na diminuição do comprimento de conjugação.

Conforme vistona seção 2.1.2, a mudança da reflectância da interface metálica influencia o fenômeno de interferência, porém a diminuição de 16x na intensidade, não é contemplada por esta diminuição na reflectância, que pode promover uma diminuição em torno de 2 vezes $^{32}$. Conforme visto também, a remoção de polímero, o qual foi exposto exclusivamente ao feixe de íons, foi da ordem de 30\%. Para a área do catodo, que foi exposta simultaneamente aos íons e à metalização, com o atenuante da deposição de uma camada de aproximadamente $10 \mathrm{~nm}$ de alumínio antes de começar a incidência de íons, é esperado que a remoção da camada polimérica pelo feixe de íons (se ocorreu) seja mínima. Assim, a redução na intensidade, para as amostras produzidas com íons de altas energias, tem origem em um processo de degradação. A degradação causada diretamente pelo deslocamento de átomos do polímero pelos íons de argônio é da ordem de $5 \mathrm{~nm}$, ou seja aproximadamente $1 / 8$ da espessura do filme de PFO. Portanto um processo de degradação de maior alcance deve ser responsável por esta redução na intensidade. Conforme foi mostrado na seção 3.1.5.3, o sistema de IBAD utilizado não permitiu que a temperatura na superfície da amostra fosse mensurada durante o processo de deposição. Acredita-se que a causa da degradação para as altas energias seja devida às altas temperaturas alcançadas pelo filme polimérico, degradação está, que tem um alcance maior que a degradação causada pelo deslocamento dos átomos do polímero pelos íons. 
(a)
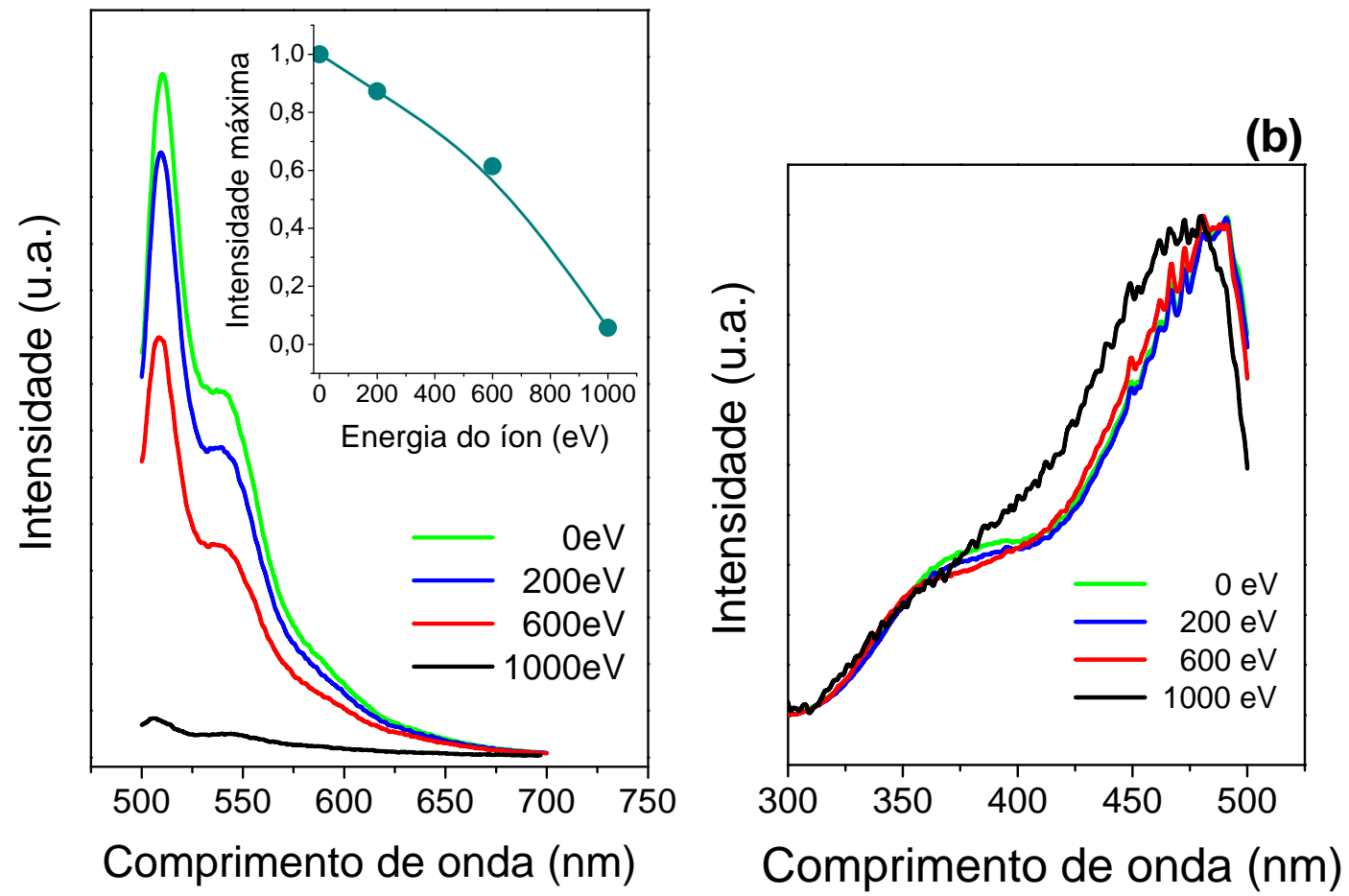

Figura 37 - Espectro de fotoluminescência das amostras de 0, 200, 600 e 1000 eV. Inserção: Gráfico do máximo da PL ( 510 nm) em função da energia do íon. (b) Espectro de excitação normalizado das amostras de 0, 200, 600 e $1000 \mathrm{eV}$.

\subsubsection{Caracterização por Espectroscopia Raman}

A Espectroscopia Raman é resultado da interação da luz com estados vibracionais da matéria e pode detectar modificações morfológicas (tensões), químicas (novas ligações), bem como no volume (intensidade) desse material. Nessa seção, resultados dessa espectroscopia são apresentados na tentativa de elucidar os efeitos da deposição dos catodos assistida por 
íons em OLED's. Estas medidas de Raman sob a região do catodo complementam as medidas de PL e excitação.

Nessa medida, a luz de excitação de um laser de He-Ne $(632 \mathrm{~nm})$ foi focalizada em uma área circular de aproximadamente de $1 \mu \mathrm{m}$ de diâmetro e a luz espalhada foi coletada pela mesma objetiva. A possibilidade de analisar uma área relativamente pequena, permitiu que não só a área sob o catodo (onde houve a incidência de íons e a deposição de $\mathrm{Al}$ ) fosse analisada como também as regiões especificadas na Figura 31, onde apenas ocorreu a deposição de metal ou houve apenas incidência de íons. A Figura 38 (a), mostra o espectro da área sob o catodo para as diferentes energias dos íons de argônio durante a deposição do catodo. O pico na região de $1593 \mathrm{~cm}^{-1}$ é relacionado aos anéis aromáticos ${ }^{83 ; 84}$ encontrados no PFO. Já a estrutura em torno de $1430 \mathrm{~cm}^{-1}$ é referente ao $\mathrm{PEDOT}^{85}$. Mais uma vez ocorre uma diminuição da intensidade espectral como um todo à medida que a energia aumenta. $\mathrm{O}$ espectro para $200 \mathrm{eV}$ apresenta uma intensidade maior que o de $0 \mathrm{eV}$, o que não é esperado, todavia dois fatores justificam este resultado. Em primeiro lugar, o comprimento de onda utilizado para a excitação também ocasiona excitações eletrônicas, assim o resultado final é a sobreposição dos espectros Raman e do espectro de PL. A separação dos espectros é feita diretamente no espectro final, e está sujeita a erros, pois é realizada visualmente. Um segundo problema é o efeito Marangoni (seção 4.2.2), que leva a uma distribuição não homogênea de material, pois a pequena área analisada é da mesma ordem de grandeza destas variações da quantidade de material, e a intensidade também está diretamente ligada à quantidade de material excitado.

(a)



(b)




Figura 38 - Espectro Raman sob a região metalizada (a) e sob a região não metalizada e a região onde ocorreu unicamente a incidência de ions(b) das amostras obtidas com ions de 0, 200, 600 e $1000 \mathrm{eV}$ e 0 e $1000 \mathrm{eV}$, respectivamente.

A Figura 38 (b) mostra os espectros sobre o metal sem incidência de íon para as amostras preparadas com $0 \mathrm{eV}$ e $1000 \mathrm{eV}$ (curvas preta e vermelha, respectivamente) e em verde o espectro da área em que houve exclusivamente a incidência de íons, para $1000 \mathrm{eV}$. Mais uma vez a diferença entre os dois espectros sob o metal se deve a fatores da medida e obtenção do espectro. Já para o espectro da área com incidência de íons é visível a queda na intensidade. Conforme mostrado anteriormente, a remoção de PFO por sputtering é da ordem de $1 / 3$, valor este insuficiente para explicar a queda da ordem de 10 vezes da intensidade. Assim o espectro apresentado na Figura 38 (b) evidencia que um processo de degradação é causado pelos íons. A degradação é exagerada nesta análise por se tratar de uma região que ficou exposta a uma alta dose de íons. Porém este resultado mostra que a incidência dos íons causa deslocamentos na cadeia polimérica que levam a uma degradação do mesmo. As técnicas espectroscópicas utilizadas medem todo o volume do polímero, assim uma alteração em um pequeno volume, pode ser mascarada pelo restante do volume, porém esta alteração, especialmente junto à interface, pode ser importante nos processos que ocorrem na interface metal/polímero do dispositivo.

\subsubsection{Caracterização elétrica e eletroluminescência}

Medidas de caracterização elétrica e eletroluminescência foram realizadas em vácuo nas amostras apresentadas acima. As curvas de corrente em função da voltagem são apresentadas na Figura 39 para diferentes energias dos íons de argônio. As altas correntes atingidas são explicadas pois nestas primeiras medidas ainda não havia se estabelecido uma rotina da preparação das amostras, como por exemplo, não utilizar o processo de decapagem do ITO inicialmente, fazendo-a de forma parcial (apenas sob a área do contato elétrico) após a primeira medida. Conforme apresentado na seção 3.1.1, a área efetiva do OLED (onde existe 
a presença de ITO e metal na estrutura vertical) foi muito maior nestes casos. As curvas do eletrodo depositado sem o auxilio de íons e com íons de $200 \mathrm{eV}$ tem um comportamento semelhante. A de $600 \mathrm{eV}$ apresenta uma injeção de corrente mais tardia e também um sobressalto em torno de 3 volts, o que poderia indicar alterações nas condições de injeção. Por fim um curto circuito é observado para o catodo formado com o auxílio de íons de $1000 \mathrm{eV}$, este curto circuito ocorreu na primeira amostra produzida, devido à baixa espessura da camada de alumínio e a não decapagem do ITO; assim o contato elétrico rompeu o polímero e atingiu o ITO, as amostras com $1000 \mathrm{eV}$ não foram produzidas novamente com a decapagem do ITO. Permitiu-se que a corrente atingisse valores considerados altos para um dispositivo orgânico, para observar o comportamento para altas correntes, mesmo sabendo que a deterioração do OLED ocorre em altas correntes.
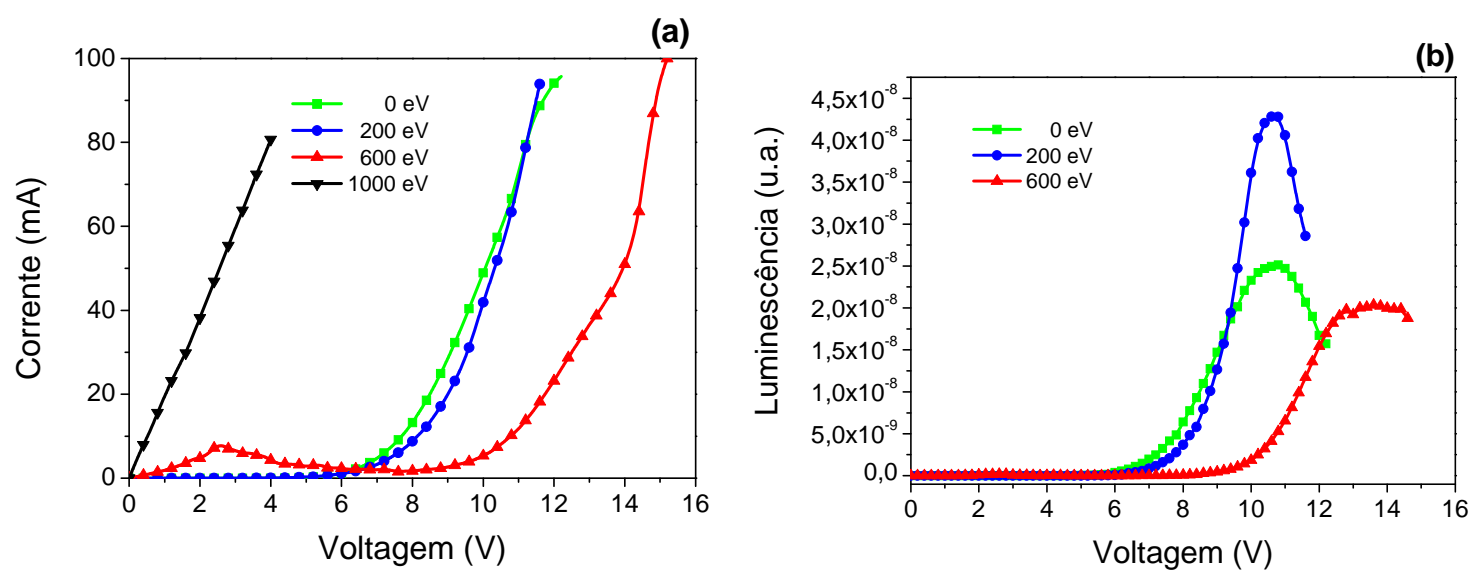

Figura 39 - Gráficos de corrente em função da voltagem (a) e eletroluminescência (b) para as amostras com 0, 200, 600 e $1000 \mathrm{eV}$.

A Figura 39(b) mostra variação da intensidade da eletroluminescência para os mesmos dispositivos, medidas simultaneamente à corrente. As altas correntes utilizadas provocam uma deterioração do dispositivo, o que é mostrado pela queda da luminescência a partir de um valor de voltagem (diferente para cada amostra). O comportamento para as amostras de 0 e $200 \mathrm{eV}$ é aproximadamente igual até aproximadamente 9 V. Porém, a amostra contendo catodo depositado a $200 \mathrm{eV}$ suporta correntes duas vezes maiores, indicando propriedades melhores de injeção para estes catodos. Isto pode ser explicado pela formação de uma interface mais homogênea pelo IBAD que pela evaporação não assistida. Esta homogeneização causa uma redução de caminhos preferenciais para os portadores, evitando 
assim que a corrente passe preferencialmente em alguns pontos, o que leva a uma diminuição da eficiência de eletroluminescência e a curtos-circuitos posteriormente ${ }^{44}$.

A piora na injeção de elétrons, não muito evidente para $200 \mathrm{eV}$, mas clara para 600 $\mathrm{eV}$, foi estudada por Terassi ${ }^{61}$ e é explicada pela exposição ao feixe de íons ${ }^{24}$. Gil e co-autores relatam um efeito semelhante causado pela incidência de íons e atribuíram à criação de armadilhas de cargas formadas próximas ao catodo ${ }^{24}$. Como resultado desta primeira série de experimentos, viu-se que para altas energias (1000 e $600 \mathrm{eV})$, tem-se uma descaracterização do OLED, uma piora generalizada das características fotofísicas do dispositivo (diminuição da PL) e também de injeção de elétrons. Assim os OLEDs produzidos com IBAD utilizando energias mais altas não são de interesse. A falta de um shutter influenciou a reprodutibilidade das amostras pois nos instantes iniciais da formação da interface, não existiam condições estáveis de evaporação do alumínio nem do feixe de íons. Dessa forma, o objetivo central do trabalho, de produzir uma camada deliberadamente híbrida, ficaria prejudicado pela ausência do shutter.

\subsection{Interfaces Metal/Polímero: baixas energias}

Com base nos dados da primeira série de amostras, optou-se por utilizar uma faixa de energia entre $0 \mathrm{eV}$ e $400 \mathrm{eV}$ para os íons de argônio. Diversos aprimoramentos foram realizados relativos à preparação de amostras e à deposição IBAD do catodo metálico. Um shutter foi projetado e instalado no equipamento de IBAD nesta segunda série de amostras. Este dispositivo propicia a regulagem dos feixes metálicos evaporados e de íons antes do 
início da deposição e incidência dos mesmos na amostra desde o início da deposição do catodo. Isto favorece um maior controle, formando uma camada híbrida (objetivo central do trabalho) mesmo para valores mais baixos de energia, eliminando-se assim a deposição da camada buffer do metal. Com isso foi possível preparar OLEDs com duas espessuras de camada ativa do polímero emissor de luz PFO (40 e $150 \mathrm{~nm}$ ) e também com a inclusão de uma camada espaçadora, entre esta camada ativa e o catodo, de forma que o dano causado pelo íon fosse controlado e a penetração do alumínio não atingisse a camada ativa.

Nesta seção serão apresentadas primeiramente as características das bicamadas espaçadoras e os efeitos dela no funcionamento dos OLEDs. Depois serão apresentadas as simulações para as energias utilizadas, com o uso do shutter, permitindo que os íons incidam sobre o polímero desde o início da simulação. Medidas de PL foram feitas para analisar o efeito das alterações causadas na interface pelo IBAD na interferência que ocorre quando se tem uma semicavidade. Por fim a caracterização elétrica e medidas de eletroluminescência são apresentadas e discutidas.

\subsubsection{Caracterização das camadas espaçadoras}

Na seção 3.1.4 detalhou-se o procedimento LbL assistido por spin para a montagem das bicamadas espaçadoras inertes de polieletrólitos sobre um filme polimérico semicondutor. Esta metodologia foi desenvolvida durante o presente trabalho.

A Figura 40 apresenta o acompanhamento por espectroscopia de absorbância do processo de automontagem $\mathrm{LbL}$ de bicamadas compostas dos polieletrólitos positivo PDAC e do negativo PSS sobre uma camada de $40 \mathrm{~nm}$ de PFO depositado sobre substrato de quartzo. A absorbância do PFO corresponde ao número de bicamadas zero. A banda entre 300 e 500 
nm corresponde a transições ópticas $\pi \rightarrow \pi^{*}$ entre estados conjugados $\pi$ ocupados e estados desocupados $\pi^{*}$ de mais alta energia. As transições ópticas no UV entre 190 e $250 \mathrm{~nm}$ correspondem a transições envolvendo estados localizados $\sigma$ de alta energia ${ }^{32}$. Esta região espectral se superpõe as transições ópticas no anel aromático do PSS.

Analisando a Figura 40 vê-se que a região do espectral correspondente aos polieletrólitos aumenta com a deposição das bicamadas. Na inserção, pode ser visto o máximo de absorção (para 197 nm) em função do número de bicamadas. O comportamento linear (reta vermelha) indica que o crescimento das camadas é uniforme no plano e na direção de deposição. Já a região do espectro referente ao PFO se mantém constante durante a adição das bicamadas, demonstrando que a camada de PFO abaixo não é removida com a deposição dos polieletrólitos, o que se deve ao uso de solventes com solubilidades distintas para o PFO (clorofórmio) e para os polieletrólitos (água). O uso destas bicamadas espaçadoras é recorrente no grupo ${ }^{32}$ e o valor da espessura apresentado para estes valores de absorbância é de $\sim 2 \mathrm{~nm}$ por bicamada.

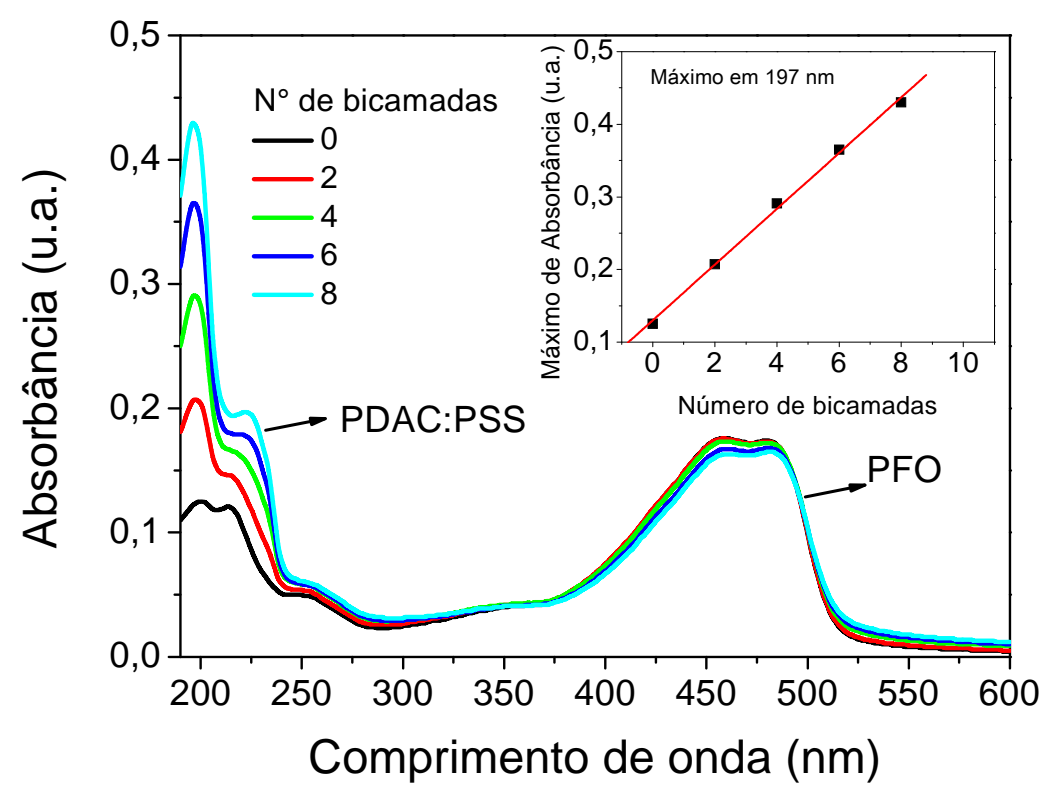

Figura 40 - Gráficos da absorbância para diferentes números de bicamadas; O detalhe corresponde ao valor da absorbância em 197nm em função do número de bicamadas.

Os efeitos da camada espaçadora sobre o funcionamento dos OLEDs, podem ser analisados nas curvas IxV apresentadas na Figura 41. Estes dispositivos possuem a mesma estrutura que os OLEDs apresentados acima, porém com espessura da camada ativa de $40 \mathrm{~nm}$. Esta figura apresenta a corrente em função da polarização direta (voltagens positivas 
responsáveis para injeção nas interfaces) para um OLED de referência (sem espaçador) e para três outros com camadas espaçadoras entre o metal e a camada ativa de PFO de quatro $(8 \mathrm{~nm})$, oito $(16 \mathrm{~nm})$ e doze $(24 \mathrm{~nm})$ bicamadas. É importante salientar que a deposição do catodo para estas amostras não foi assistida por íons de argônio. Pode-sever que, apesar do aumento da voltagem de funcionamento $\left(\mathrm{V}_{\text {on }}\right)$, há uma nítida melhora na injeção (menor resistência de contato, por exemplo) com o aumento da camada espaçadora. É interessante notar que a camada de polieletrólito é basicamente isolante. $\mathrm{O}$ aumento da $\mathrm{V}_{\text {on }}$ não se deve apenas à diminuição do campo interno do dispositivo com o aumento da espessura pela camada espaçadora. Isto seria esperado em uma situação ideal, com contatos ôhmicos e mobilidade semelhante para ambos os portadores ${ }^{48}$. No detalhe da Figura 41 (a), tem-se a dependência da tensão $\mathrm{V}_{\text {on }}$, obtida da simples extrapolação linear da curva $\mathrm{IxV}$ e o seu cruzamento com o eixo das ordenadas, em função do número de bicamadas. O comportamento é um crescimento linear dessa tensão com a espessura. A Figura 41 (b) mostra as mesmas curvas, mas agora em função do campo elétrico aplicado, calculado em função da espessura total (PEDOT + PFO + camada espaçadora) entre os eletrodos de alumínio e ITO. A não sobreposição das curvas características mostra que a camada espaçadora de polieletrólito não somente diminui o campo interno no dispositivo como também, altera as propriedades de injeção, pois estas camadas são não condutoras, o que afeta o tunelamento eletrônico. Além disso, esses dispositivos comportam duas vezes mais corrente do que aquele sem espaçador. A maior corrente suportada se deve à camada espaçadora que evita a formação de caminhos preferenciais para a injeção de elétrons fazendo com que a densidade superficial de corrente no PFO seja mais homogênea ${ }^{23}$.

(a)

Figura 41 - Gráfico da corrente em função da voltagem (a)e do campo elétrico (b) para amostras com diferentes números de bicamadas. Na inserção, o valor da voltagem $V_{\text {on }}$ em função do número de bicamadas.

\subsubsection{Simulações}

$\mathrm{Na}$ deposição do catodo das amostras desta seção foi utilizado o shutter assim a simulação foi feita conforme descrito na seção 3.3, primeiramente sem a camada de alumínio, com os íons incidindo diretamente sobre o PFO e depois adicionando sucessivamente uma camada de $5 \AA$ sobre o PFO. O resultado final é a soma de todas as simulações. Para evitar uma excessiva degradação do polímero nos primeiros estágios de deposição, utilizaram-se energias dos íons de argônio na faixa de 0 a $400 \mathrm{eV}$. A seguir compararam-se simulações feitas para os dois casos; sem o shutter, como feito na seção anterior, onde uma camada de 10 Å protege o PFO e com o shutter, onde os íons incidem diretamente sobre o PFO em um primeiro momento.

A Figura 42 compara os perfis de concentração dos íons de Ar implantados ao longo da interface da estrutura Metal/Polímero para os dois casos (com e sem shutter) utilizando íons com energia de $200 \mathrm{eV}$. Pode-se observar que a utilização do shutter permite uma maior penetração dos íons logo nos primeiros estágios da deposição, após a abertura desse dispositivo. Já no caso da ausência do shutter, a pré-camada de $10 \mathrm{~nm}$ de Al atua como barreira para o choque dos íons de Ar, o que resulta em um retroespalhamento dos mesmos produzido pelo choque com átomos de $\mathrm{Al}$ na pré-camada. 




Figura 42 - Perfil de concentração dos ions de Ar do processo IBAD (com e sem shutter). À esquerda da linha pontilhada, tem-se o Al e à direita, o PFO. A incidência de íons de argônio, com $200 \mathrm{eV}$, se dá da esquerda para a direita.

Já as Figura 43 (a) e (b) mostram o número de átomos de $\mathrm{Al}$ e C deslocados, respectivamente, para as mesmas condições simuladas acima, visando simular o efeito do shutter sobre a penetração e o deslocamento destes átomos na interface. Para o Al, uma pequena alteração ocorre no perfil de penetração na camada polimérica, pois os átomos de $\mathrm{Al}$ da pré-camada de $10 \mathrm{~nm}$ são eficientemente deslocados pelos íons de Ar com energia de 200 eV no início do processo IBAD. Além disso, a pequena espessura das camadas iniciais de Al não fornecem muitos átomos para serem deslocados. Já o deslocamento dos átomos de carbono é afetado de forma significativa pela presença do shutter devido à incidência direta dos íons de Ar e à presença de poucos átomos de Al que possam espalhar os íons, nos instantes iniciais, fazendo com que as interações iniciais (que envolvem mais energia) ocorram predominantemente com os átomos de carbono. 

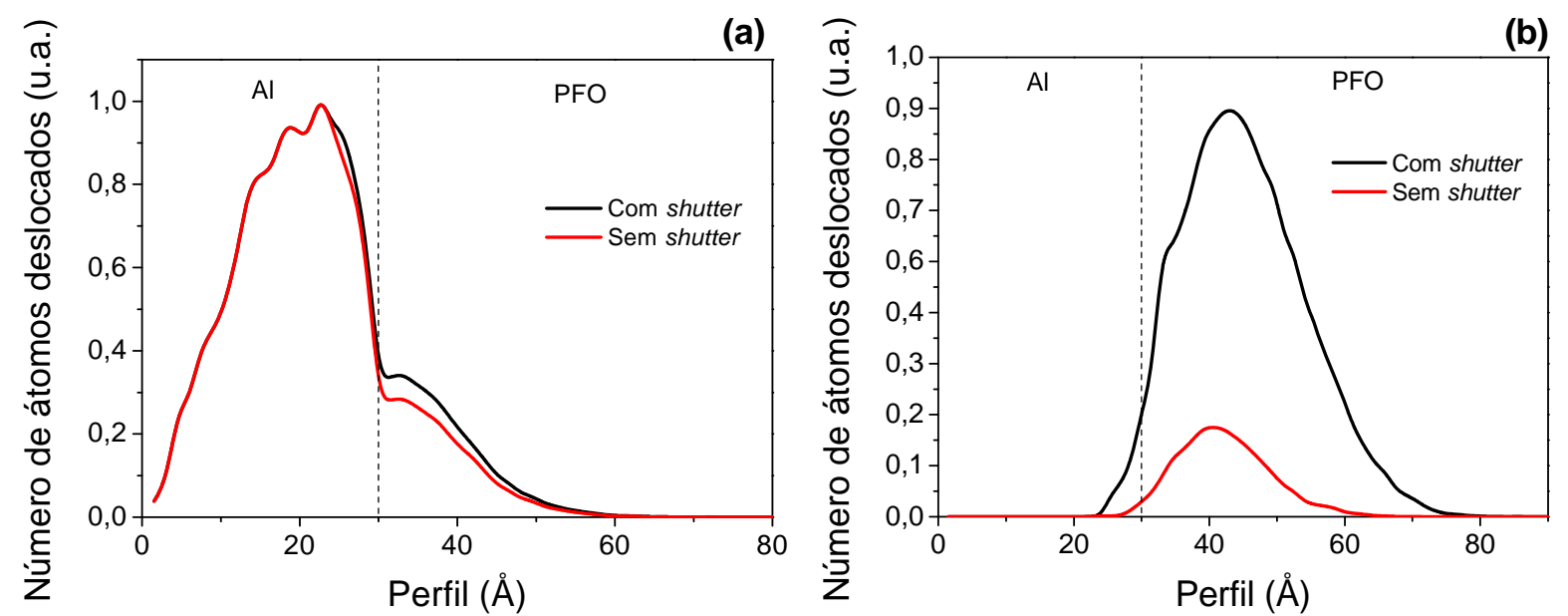

Figura 43 - (a) Perfil da posição final dos átomos de Al deslocados durante o processo IBAD (com e sem shutter). (b) Perfil da posição dos átomos de $C$ deslocados no processo IBAD (com e sem shutter). À esquerda da linha pontilhada, tem-se o Al e à direita, o PFO. A incidência de ions de argônio, com $200 \mathrm{eV}$, se dá da esquerda para a direita.

A seguir, a Figura 44 apresenta a sobreposição dos perfis dos átomos de alumínio implantados e dos átomos de carbono deslocados na região do polímero para diferentes energias do íon de Ar variando de 80 a $400 \mathrm{eV}$. É interessante notar que o máximo de átomos de alumínio deslocados para o interior do PFO fica em torno de $5 \AA$ de profundidade independentemente da energia do íon que assiste a deposição. Acredita-se que o maior efeito dos ions de Ar é deslocar os átomos de $\mathrm{C}$ logo nos primeiros estágios do processo IBAD e que os átomos de $\mathrm{Al}$ deslocados na deposição ocupariam as vacâncias de C. A nítida diferença está no aumento da concentração de $\mathrm{Al}$ em baixo desse perfil próximo à interface quando a energia varia de $80 \mathrm{eV}$ e $400 \mathrm{eV}$. O total de átomos de alumínio implantados aumenta em torno de 6 vezes, comparando a menor energia com a maior. Já o máximo do perfil dos átomos de $\mathrm{C}$ deslocados depende da energia, encontrando-se deslocado do perfil de $\mathrm{Al}$, o que permite uma alteração gradual das características da interface, com a formação das quatro regiões distintas discutidas para o caso de altas energias. Somando todos os átomos de carbono deslocados para íons com $80 \mathrm{eV}$ e $400 \mathrm{eV}$, o de maior energia desloca aproximadamente 19 vezes mais átomos que o de $80 \mathrm{eV}$. As alterações do PFO provocadas pela temperatura (dano térmico) não são obtidas através da simulação. 


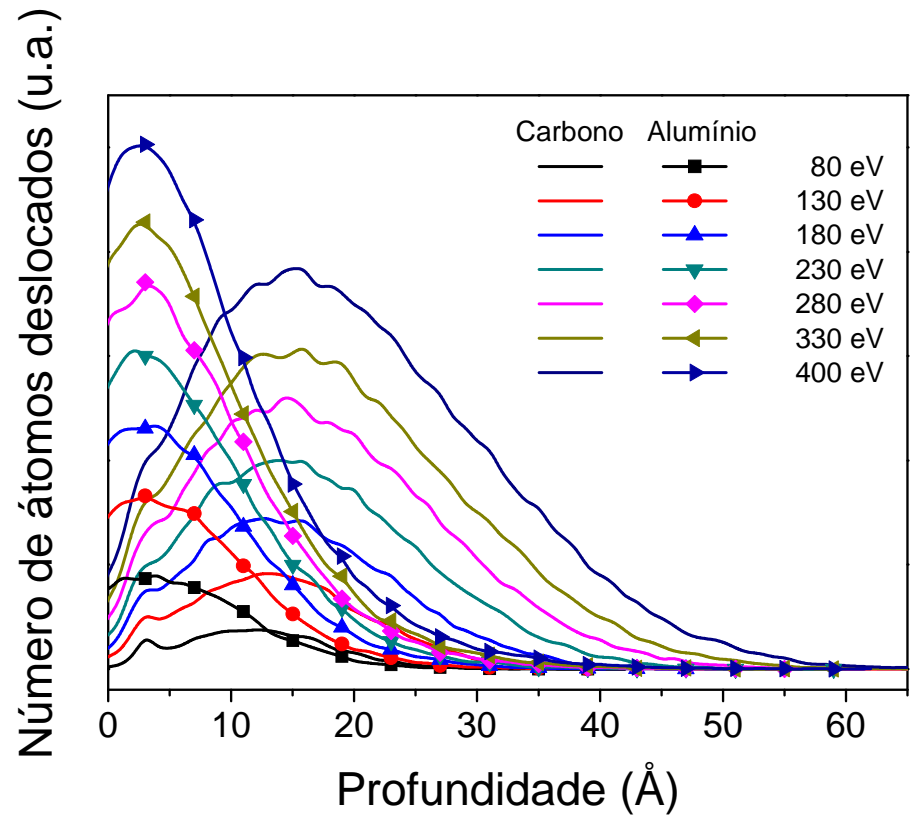

Figura 44 - Perfil dos átomos de alumínio implantados no polímero e dos átomos de carbono deslocados.

\subsubsection{Caracterização por Fotoluminescência}

Na seção 4.2.3 viu-se que a luminescência da camada ativa abaixo do catodo dos OLEDs é dependente da energia do íon de Argônio que assiste a deposição por IBAD. Nesta seção, são estudadas as propriedades de emissão da camada ativa de PFO em OLEDs preparados com energias variando de 0 a $400 \mathrm{eV}$, utilizando o shutter. Três tipos de amostras foram preparadas (seção 3.1.6). Dois consistem em OLEDs contendo PFO com espessuras de $40 \mathrm{~nm}$ e $150 \mathrm{~nm}$ e o outro, de amostras contendo camada espaçadora de 8 bicamadas de PDAC/PSS (16 nm) entre o catodo de Al preparado por IBAD e o filme de PFO (40nm).

A Figura 45 (a) ilustra os espectros de PL obtidos para a amostra com espaçador preparadas com energias variando de $0-400 \mathrm{eV}$. As medidas foram feitas com o feixe de excitação incidindo pelo lado do anodo transparente de vidro/ITO. Conforme pode ser visto na Figura 45 (b), duas regiões diferentes foram analisadas. Na região denominada Polímero, o feixe de excitação incidiu sobre o PFO emissor de luz que estava protegido pela máscara 
(região sem interface metálica). A região denominada Polímero/Metal, refere-se à região onde ocorreu a metalização (região com interface metálica). Conforme se pode observar, existe uma grande diferença entre as intensidades espectrais das duas regiões. Como é de se esperar, a intensidade e forma espectral mudam pouco para a região sem metal, enquanto que existe uma variação apreciável para a emissão abaixo do metal (de 8 a 11 vezes maior que a região sem metal), mas a forma espectral pouco se altera.

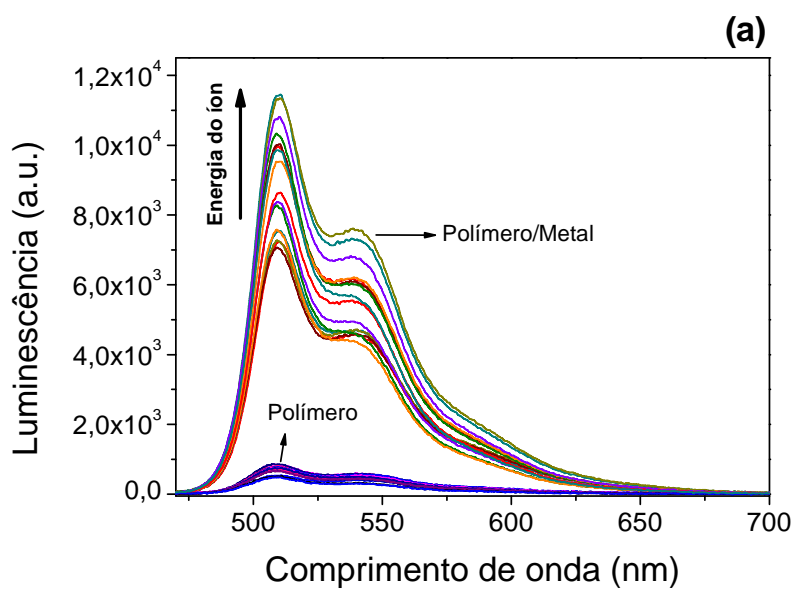

Figura 45 - (a) Espectro de luminescência da amostra com espaçador nas regiões Polímero e Polímero/Metal para as diferentes energias de ions. (b) Esquema representativo do experimento, mostrando as duas regiões.

A integral da PL na região sem metal pode ser vista na Figura 46 em função da energia dos íons para as três diferentes amostras (foram feitas duas medidas para cada energia). Notase que a intensidade de emissão é praticamente a mesma para cada série de amostras submetidas ao processo IBAD. A intensidade da amostra espessa é aproximadamente 3 vezes maior que a da amostra fina, o que está diretamente ligado ao valor aproximadamente três vezes maior de sua espessura em relação à espessura da camada ativa das outras duas séries de amostras. A intensidade um pouco menor para a amostra com espaçador em relação à amostra com mesma espessura da camada ativa $(40 \mathrm{~nm})$ se deve à presença da camada espaçadora de PDAC/PSS na sua superfície, o que altera seu índice de refração e as propriedades de reflexão interna da luminescência entre o PFO e o ar. O desvio padrão da integral da PL é de 13\%, 12\% e 6\% para, respectivamente, as amostras fina de $40 \mathrm{~nm}$, espessa de $150 \mathrm{~nm}$ e fina $(40 \mathrm{~nm})$ com espaçador. 




Figura 46 - Gráfico da integral da $P L_{P}$ em função da energia dos ions para as amostras contendo camada ativa de PFO de $40 \mathrm{~nm}$ e de $150 \mathrm{~nm}$ e de $40 \mathrm{~nm}$ com espaçador de PDAC/PSS de $16 \mathrm{~nm}$.

Como a emissão não se altera com a variação da energia (dos íons de argônio), na região sem metal, seu valor será tomado como referências para estudar as modificações sofridas pela PL da camada ativa abaixo do catodo. Assim, os resultados a seguir serão apresentados em termos da razão da intensidade integrada da emissão $\mathrm{PL}_{\mathrm{M}}$ na região Metal/Polímero pela intensidade integrada $\mathrm{PL}_{\mathrm{P}}$ da emissão na região logo adjacente sem metal da mesma amostra e podem ser vistos nas Figura 47 (a) e (b).

(a) (b)


Figura 47 - Razão da intensidade integrada $P L_{M} / P L_{P}$ em função da energia dos ions para (a) amostras fina e espessa. (b) amostras.finas, espessa e com espaçador. 
Na Figura 47 (a) vê-se a razão da $\mathrm{PL}_{\mathrm{M}} / \mathrm{PL}_{\mathrm{P}}$ em função da energia dos íons para OLEDs contendo camada ativa de PFO de $40 \mathrm{~nm}$ e de $150 \mathrm{~nm}$. Para a metalização sem o auxílio dos íons $(0 \mathrm{eV})$, vê-se que a intensidade de emissão sob o catodo é aproximadamente duas vezes maior que a aquela detectada na região sem metal. Este valor é esperado quando é considerado apenas o efeito de reflexão da emissão no metal ${ }^{32}$. Filmes de Al de $100 \mathrm{~nm}$, quando depositados sobre uma superfície lisa, produzem um espelho perfeito com reflexão de 96-98 \% de raios paralelos. Para a interface formada com a assistência de íons de Ar com energia de $80 \mathrm{eV}$, a razão $\mathrm{PL}_{\mathrm{M}} / \mathrm{PL}_{\mathrm{P}}$ cai, aumentando gradativamente para as energias até 280 eV. A razão apresenta quase o mesmo comportamento para as duas amostras. A queda abrupta para energias de $80 \mathrm{eV}$ pode ser uma consequência da alteração nas propriedades de reflexão da interface formada pelo metal pois como já demonstrado, essa faixa de energia não é suficiente para produzir degradação no material que justifique esta queda, hipótese esta, suportada pelo aumento da razão para íons com maiores energias. Além disso, a queda da razão $\mathrm{PL}_{\mathrm{M}} / \mathrm{PL}_{\mathrm{P}}$ é praticamente a mesma para a amostra espessa de $150 \mathrm{~nm}$, o que indica uma alteração das propriedades ópticas da interface. $\mathrm{O}$ aumento gradativo desta razão com o aumento da energia se deve provavelmente à melhora das propriedades de reflexão.

A Figura 47(b) compara as razões da $\mathrm{PL}_{\mathrm{M}} / \mathrm{PL}_{\mathrm{P}}$ para dos OLEDs contendo camada ativa de PFO de $40 \mathrm{~nm}$ (amostra fina) e $150 \mathrm{~nm}$ (amostra espessa) já mostradas na Figura 47 (a) com a mesma razão medida para a amostra fina contendo espaçador de PDAC/PSS de espessura de $16 \mathrm{~nm}$ entre o PFO (40nm) e o catodo. A amostra fina com espaçador, segue um comportamento semelhante ao da amostra espessa para a razão das PLs. Após uma queda para $80 \mathrm{eV}$, ela aumenta monotonamente até a energia de $400 \mathrm{eV}$. Porém, os valores de $\mathrm{PL}_{\mathrm{M}} / \mathrm{PL}_{\mathrm{P}}$ são muito maiores para essa amostra, ou seja, são 4 a 7 vezes maiores que as amostras sem espaçador. Trabalhos recentes ${ }^{32 ; 86}$ mostram que $\mathrm{PL}_{\mathrm{M}} / \mathrm{PL}_{\mathrm{P}}$ depende da espessura da camada ativa e de sua distância até a interface metálica. A seção 2.1.2, mostra os efeitos esperados de interferência em uma cavidade óptica formadas por um filme emissor de luz entre uma interface metálica e o vácuo. Acredita-se que o acréscimo da camada espaçadora produz uma suavização da interface metal/polímero, permitindo uma reflexão paralela do feixe incidente. Além disso, o espaçador evita a supressão da emissão próxima a interface metálica e a penetração do metal na camada ativa, evitando que o PFO sofra algum dano, com as energias utilizadas.

Recentemente, Salvadori e co-autores ${ }^{87 ;} 88$ demonstraram a autoformação de nanoagregados de ouro implantadas a baixas energias $(\sim 50 \mathrm{eV})$ em polímero 
polimetilmetacrillato (PMMA). O resultado é uma camada fina de nanopartículas de Au muito próxima à superfície. A densidade destas nanopartículas nessa região depende da fluência e/ou da dose dos íons de Au implantados. As Figura 48 (c) e (d) mostram a formação desta camada de nanopartículas, de ouro, para doses de $0,8 \times 10^{16} \mathrm{~cm}^{-2}$ e $1,5 \times 10^{16} \mathrm{~cm}^{-2}$, respectivamente, obtidas através de imagens de Microscopia Eletronica de Transmissão de alta resolução (HRTEM). Já a simulação do perfil de concentração das nanopartículas, em função da profundidade no PMMA tomada em relação à superfície do filme, é mostrada nas Figura 48 (a) e (b) para doses de $0,8 \times 10^{16} \mathrm{~cm}^{-2}$ e $1,5 \times 10^{16} \mathrm{~cm}^{-2}$, respectivamente. Acredita-se que o mesmo processo de autoformação está ocorrendo no presente sistema, formando uma camada de nanoagregados de $\mathrm{Al}$, próximo à superfície do metal. Conforme demonstrado pelas simulações TRIM (seção 4.3.2), a concentração de Al aumenta com a energia, o que favorece o aumento do diâmetro das nanoparticulas e a coalescência das mesmas, próximo à superfície do PFO. Como o IBAD é um processo dinâmico, a formação dos nanoagregados se daria até a superfície do metal. A comparação das simulações da Figura 44 e da Figura 48 (a) e (b) ilustra esta hipótese.
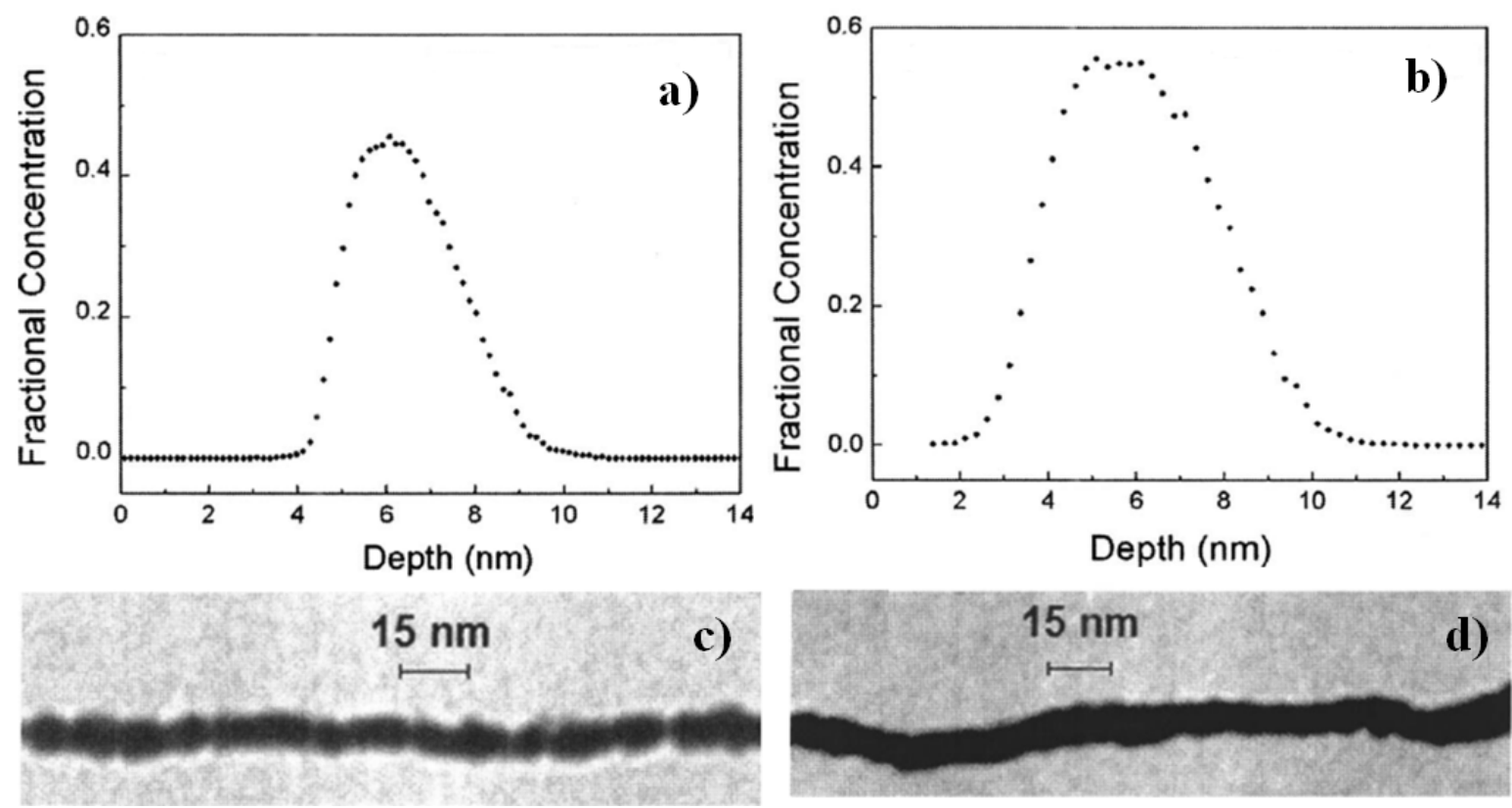

Figura 48 - Simulação do perfil de concentração das nanopartículas em função da profundidade, para doses de. $0,8 \times 10^{16} \mathrm{~cm}^{-2}$ (a) e $1,5 \times 10^{16} \mathrm{~cm}^{-2}$ (b). Imagem de microscopia de transmissão de ouro implantado em PMMA com doses de $0,8 \times 10^{16} \mathrm{~cm}^{-2}$ (c) e $1,5 \times 10^{16} \mathrm{~cm}^{-2}(d)$. Figuras retiradas das referências. ${ }^{87 ; 88}$

A dependência da razão da $\mathrm{PL}_{\mathrm{M}} / \mathrm{PL}_{\mathrm{P}}$ com a energia do íon de Ar mostrada na Figura 47 pode ser explicada de acordo com o modelo que foi apresentado e discutido no parágrafo 
anterior. A Figura 49 ilustra este modelo. Um segmento conjugado pode ser considerado em primeira aproximação, como um dipolo emissor (seção 2.1.2), representado pela seta vermelha. Este, estando paralelo à interface (formada por um metal (espelho plano)), emite duas ondas eletromagnéticas, uma delas na direção do metal, a qual é refletida na direção oposta (direção do substrato de vidro) e a outra, na direção do substrato de vidro (segundo esquema de feixes a partir da esquerda na figura). Sem considerar efeitos de interferência e reflexões na interface vidro/polímero, os dois feixes se somam de modo que a intensidade medida para esse caso pelo lado do vidro é ao menos duas vezes maior que aquela medida pelo dipolo sem o metal refletor. Com o uso da deposição IBAD, existe o deslocamento do Al para a camada do PFO adjacente e, provavelmente, a autoformação de nanoagregados de $\mathrm{Al}$ próximos à interface Metal/Polímero. Para baixas energias $(80 \mathrm{eV})$, a densidade de $\mathrm{Al}$ é pequena (veja simulação TRIM mostrada na seção 4.3.2), o que favorece a formação de uma baixa densidade de nanopartículas. Nestas condições, a luz é fortemente espalhada por partículas de Al isoladas, o que reduz a intensidade da luminescência recolhida através do vidro (esquema central na figura). Com o aumento da energia, a densidade de aglomerados metálicos aumenta, favorecendo a coalescência dos mesmos (à direita na figura), o que reduz o espalhamento da luz incidente, aumentando, conseqüentemente, a razão $\mathrm{PL}_{\mathrm{M}} / \mathrm{PL}_{\mathrm{P}}$. É importante salientar que a luz emitida não é reabsorvida ao propagar pelo filme de PFO devido à forte migração e relaxações energéticas do estado excitado em polímeros conjugados desordenados e, em consequência, do processo de emissão sempre ocorrer nos segmentos conjugados de menor energia nesses materiais.

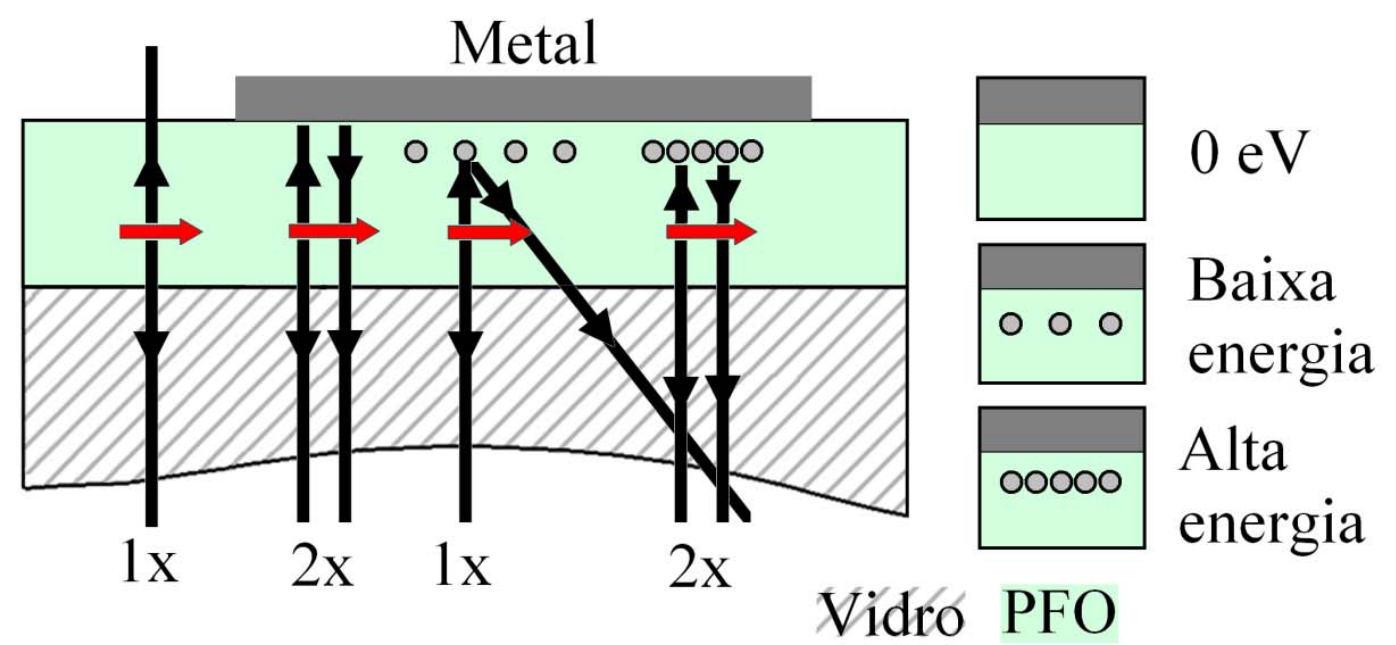

Figura 49 - Esquema do efeito da formação de aglomerados sobre a intensidade da PL para interfaces metálicas formadas com íons de diferentes energias. 
Em um primeiro momento a equivalência dos resultados para o caso de $0 \mathrm{eV}$ e alta energia, na Figura 49 é surpreendente, porém a idealização da superfície formada sem o auxílio de íons por um espelho não é real. A migração de átomos de metal, durante a

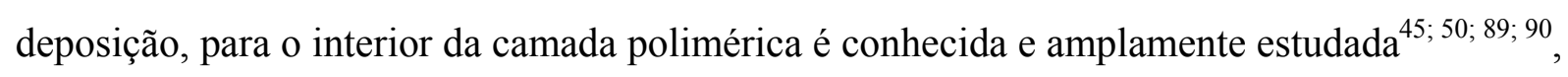
assim a interface formada possui uma distribuição de átomos de metal em uma região próxima à superfície, como ilustra a Figura 13 (b). Assim é possível que a nova superfície metálica formada pela coalescência das nanopartículas de metal tenha uma reflectância superior à superfície formada sem o auxílio de íons. Outro fator que contribui para a formação de uma interface mais definida é a reatividade do polímero, pois um polímero mais reativo com o metal possibilita uma maior densidade superficial de centros de nucleação e conseqüentemente uma interface mais definida ${ }^{23}$ (seção 2.2.2). A reatividade do polímero pode ser aumentada pela exposição a um feixe de íons, conforme demonstrado por Liao e coautores $^{51}$. No caso do catodo formado com o auxílio de íons, tem-se a exposição da superfície do PFO ao feixe de íons, o que causa danos na estrutura molecular do polímero e o deixa mais reativo. Assim a concentração dos átomos de Al, que favorece a formação de nanopartículas que podem vir a coalescer e o aumento da reatividade do polímero, possibilita a formação de uma superfície que pode ter a refletividade pior, igual ou melhor que a da interface formada sem o auxílio de íons.

A Figura 50 apresenta a simulação da variação da intensidade, provocada pela presença de uma semicavidade com diferentes valores de reflectância (que representam as mudanças na interface metal/polímero causada pelo IBAD), cujos detalhes foram explicitados na seção 2.1.2. Na parte superior da Figura 7 estão representadas as três amostras utilizadas. As variações da razão $\mathrm{PL}_{\mathrm{M}} / \mathrm{PL}_{\mathrm{P}}$ das amostras com 40 e $150 \mathrm{~nm}$ de $\mathrm{PFO}$ são contempladas de maneira satisfatória pela variação na reflectância na interface, uma vez que analisando a Figura 50 vê-se que a variação da simulação para estas duas amostras é de aproximadamente duas vezes. Já para a amostra com espaçador, a variação da razão entre $\mathrm{PL}_{\mathrm{M}} / \mathrm{PL}_{\mathrm{P}}$ (de 7 a 14) também está dentro do fator 2 . 




Figura 50 - Simulação da alteração na intensidade, para as três amostras, causada por uma semicavidade para diferentes valores de reflectância.

O experimento óptico de luminescência acima mostra claramente que as interfaces Metal/Polímero estão sendo modificadas com o processo IBAD. Em acordo com trabalhos recentes $^{87 ;} 88$, nanopartículas e aglomerados das mesmas estão sendo formadas na região da interface de maior deslocamento do $\mathrm{Al}$, dentro do polímero emissor de luz. Isto, aliado à modificação da reatividade do polímero devido à exposição ao feixe de íons, causa modificações na interface metálica, que são suficientes para alterar a reflexão da luz emitida nessa interface. As simulações da seção 4.3.2, mostram que possivelmente a camada de PFO não é degradada de forma significativa, pois o deslocamento dos átomos de carbono ocorre em uma pequena região, comparada ao volume total do polímero. Assim, o efeito de diminuição da refletividade prevalece à degradação, causando uma diminuição da PL para energias mais baixas. Já para energias maiores, a maior concentração de átomos de Al (influenciado também pela maior reatividade do polímero) leva ao aumento do tamanho das nanoparticulas e sua coalescência, reduzindo assim o espalhamento de luz e conseqüentemente aumentando a refletância da interface. Deste modo tem-se o aumento da PL sob o catodo. A queda da PL a partir dos $280 \mathrm{eV}$ para a amostra mais fina (40 $\mathrm{nm}$ ), pode ser associada à degradação do PFO pelo bombardeamento com íons. Já o dano causado por esse efeito não pode ser notado na amostra mais espessa $(150 \mathrm{~nm})$, porém pode ser notada uma tendência de estabilização da razão das PLs na Figura 47 (a). Já para a amostra fina com espaçador, após uma queda para $80 \mathrm{eV}$, a razão das PLs segue um comportamento de aumento 
até a energia de $400 \mathrm{eV}$. Este comportamento explica-se pela proteção oferecida pela camada espaçadora, evitando que o PFO sofra algum dano, com as energias utilizadas.

\subsubsection{Caracterização elétrica}

$\mathrm{Na}$ seção 4.2, na qual os dispositivos foram preparados utilizando íons com um espectro amplo de energia, nota-se que o uso de íons com alta energia $>600 \mathrm{eV}$ provoca uma degradação nas características elétricas dos dispositivos OLEDs, o que foi caracterizado pelo aumento da voltagem de funcionamento $\left(\mathrm{V}_{\text {on }}\right)$. A comparação entre os dispositivos preparados com 0 eV e $200 \mathrm{eV}$ não foi conclusiva em termos da $V_{\text {on }}$, porém foi notado que o dispositivo suporta densidades de correntes maiores quando a metalização é assistida por íons de Ar. Isto foi relacionado à interface híbrida que, de certa forma modifica o potencial de interface e promove uma injeção mais homogênea sob a área do catodo, minimizando campos não uniformes e efeitos de formação de caminhos de percolação preferenciais para a injeção de elétrons.

Esta seção trata da série de amostras, em que uma nova máscara foi utilizada para deposição do catodo e também a área do ITO foi reduzida a uma faixa estreita no centro da amostra. Essa configuração minimizou influência de fatores ligados à deposição dos filmes poliméricos nas proximidades das bordas da amostra e às alterações causadas pelas regiões de sombra durante o processo de deposição. As ondulações produzidas pelo efeito Marangoni também foram minimizadas. Para esta configuração do OLED, tem-se para $10 \mathrm{~mA}$, densidade de corrente de $\sim 11 \mathrm{~mA} / \mathrm{cm}^{2}$ e campos de $1,0.10^{8}, 4,8.10^{7}$ e $7,1.10^{7} \mathrm{~V} / \mathrm{m}$ para uma voltagem de $10 \mathrm{~V}$ aplicada nos OLEDs contendo, respectivamente, espessuras de camada ativa de PFO de $40 \mathrm{~nm}$ (amostra fina), 150nm (amostra espessa) e 40nm incluindo a camada espaçadora de $16 \mathrm{~nm}$. Todas elas foram depositadas sobre $60 \mathrm{~nm}$ de PEDOT. Como nas medidas ópticas mostradas na Seção 4.3.3, será mostrado que a injeção dos portadores é modificada pelo processo IBAD. 
A Figura 51 (a) compara curvas de densidade de corrente versus campo elétrico J x E (pontos) na região de polarização direta $(\mathrm{V}>0)$ de OLEDs contendo camada ativa de PFO de 40nm de espessura preparados com energias de íons de Ar de 0, 80, 180, 280 e 400 eV durante a deposição do catodo de Al. A figura também apresenta os ajustes dos dados experimentais (linhas vermelhas) pelo modelo de Fowler-Nordheim (eq. 2.7). As curvas JxE apresentam o comportamento esperado de retificação para um $\mathrm{OLED}^{48}$. É interessante notar que o processo IBAD não modifica de forma significativa as características da curva JxE, para a faixa de energia utilizada, sendo que os melhores ajustes foram obtidos para OLEDs nos quais a deposição foi assistida por feixe de íons. No entanto, o aumento da energia dos íons produz um deslocamento da voltagem de injeção de portadores $\mathrm{V}_{\text {on }}$ para altas voltagens. Este deslocamento pode ser melhor acompanhado na Figura 51 (b), que mostra a tensão necessária para atingir determinada corrente $(1,2,4,6$ e $8 \mathrm{~mA})$ em função da energia dos íons. Pode-se estimar uma variação de aproximadamente $40 \%$ em $\mathrm{V}_{\text {on }}$ na região de energias utilizadas no experimento. De acordo com o modelo Fowler-Nordheim, o aumento de $\mathrm{V}_{\text {on }}$ pode representar um crescimento do potencial de interface, o que limita a injeção para os catodos depositados assistidos por IBAD. $\mathrm{O}$ aumento de $\mathrm{V}_{\text {on }}$ segue o sentido contrário para a redução da espessura devido ao processo sputtering ou a penetração do metal ao longo da camada ativa. Isto pode indicar que o deslocamento de $\mathrm{V}_{\text {on }}$ pode estar associado a mudanças da barreira para injeção de elétrons $\Delta_{\mathrm{E}}$ na interface catodo/polímero.
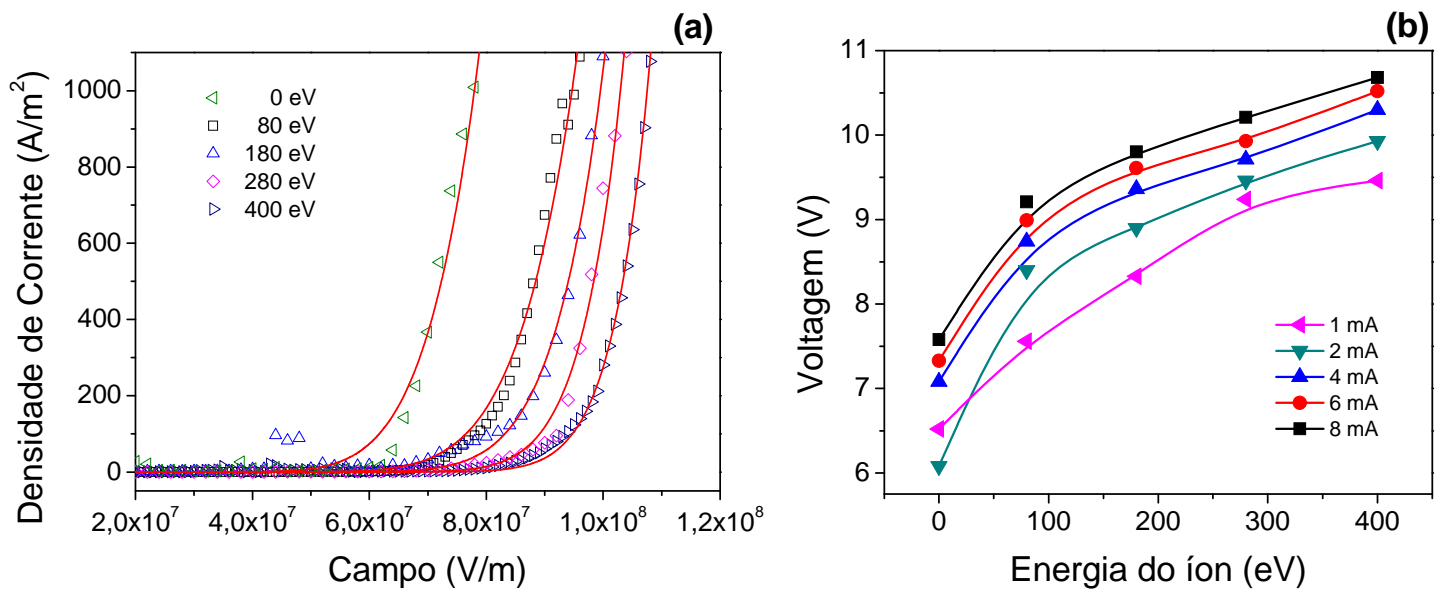

Figura 51 - Amostra fina: (a) Gráfico de corrente em função da voltagem para diferentes energias de ions e; (b) Voltagem necessária para atingir uma determinada corrente em função da energia dos ions. 
Cho e colaboradores ${ }^{91}$, e outros também ${ }^{92 ;}{ }^{93}$, mostram que a formação de uma interface mais definida entre o metal e o polímero é responsável por uma melhora na injeção de elétrons devida à difusão menor dos átomos de metal para o interior do polímero. Porém, já foi visto na seção anterior, para a amostra com $40 \mathrm{~nm}$ de PFO, que o auxílio de íons de $80 \mathrm{eV}$ causa a variação nas propriedades ópticas do dispositivo, o que pode estar associado a espalhamentos da emissão na interface. Todavia, estas propriedades ópticas voltam aos valores esperados com o aumento da energia utilizada. O comportamento da curva JxE apresenta apenas um aumento da voltagem de injeção com o aumento da energia. Estes aspectos serão comparados e discutidos com aqueles das outras amostras mais abaixo. No entanto, a exposição da superfície polimérica a um feixe de íons causa uma piora na injeção de elétrons ${ }^{24 ;} 94$, que está relacionada à criação de estados que atuam como armadilhas de elétrons $^{51 ;}$. . O resultado para a amostra com $40 \mathrm{~nm}$ de PFO pode sugerir que efeitos de degradação produzida pelo íon na interface pode ser o efeito dominante, que leva a uma mudança significativa de suas características elétricas.

A Figura 52(a) compara curvas J x E (pontos) na região de polarização direta ( $\mathrm{V}>0$ ) dos OLEDs, contendo agora camada ativa de PFO de espessura de $150 \mathrm{~nm}$ preparados com energias de íons de Ar de 0,130, 180,230, 280 e 330 eV durante a deposição do catodo de Al. A figura apresenta também os ajustes dos dados experimentais (linhas vermelhas) pelo modelo de Fowler-Nordheim (eq. 3.2). Para essa amostra, as curvas JxE ajustam-se bem aos valores esperados pela teoria. No entanto, é interessante notar um comportamento diferente para a voltagem de injeção $\mathrm{V}_{\text {on }}$ em relação ao que foi apresentado acima para a amostra com camada ativa de $40 \mathrm{~nm}$. Na Figura 52 (b), a $\mathrm{V}_{\text {on }}$ diminui aproximadamente $12 \%$ para íons com energia até $230 \mathrm{eV}$ e depois volta a aumentar para energias maiores. 
(a)
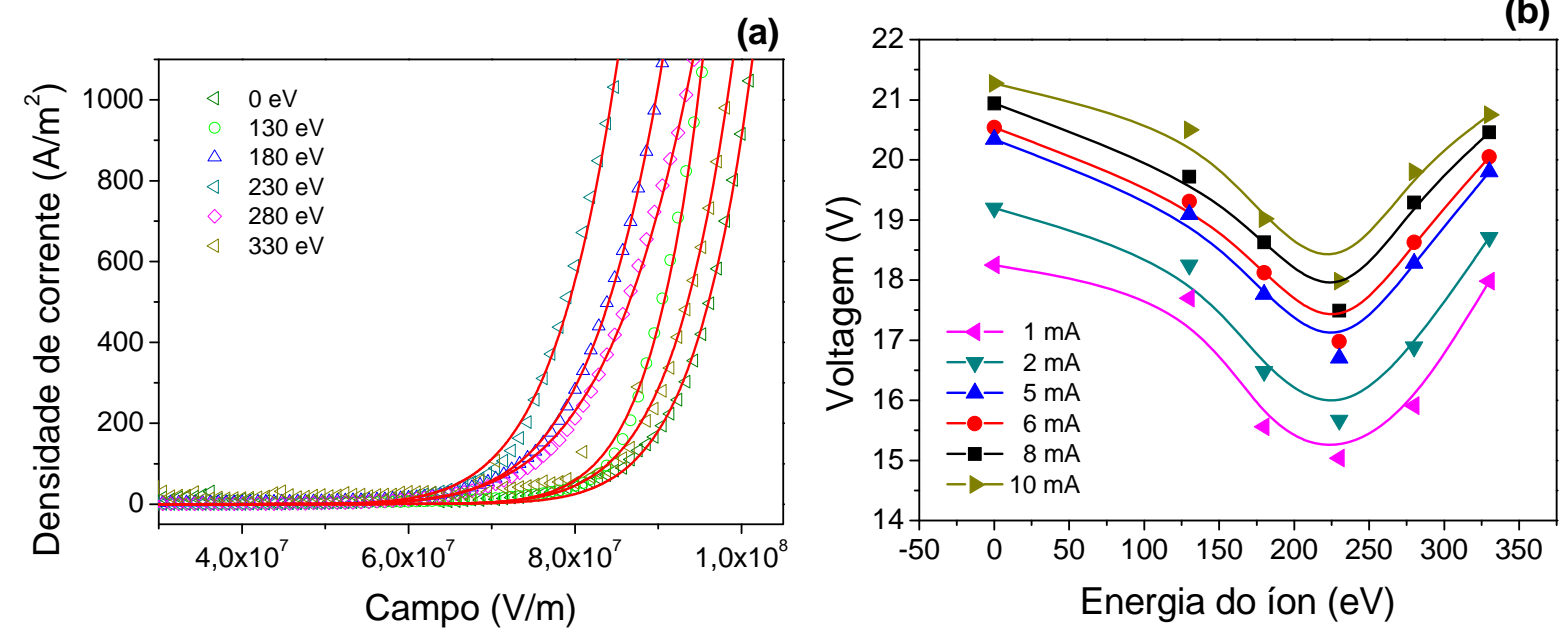

Figura 52 - Amostra espessa: (a) Gráfico de corrente em função da voltagem para diferentes energias de ions e; (b) Voltagem necessária para atingir uma determinada corrente em função da energia dos ions .

As alterações na interface metal/polímero são supostamente as mesmas para as duas amostras. Porém, a amostra com camada ativa de $150 \mathrm{~nm}$ utiliza uma solução mais concentrada durante a deposição do filme. Assim, devido ao efeito Marangoni ${ }^{81 ;}$ 96, a superfície desta amostra pode estar mais rugosa. Considerando apenas alterações nas interfaces, a diferença de comportamento apresentado pelas amostras com 40 e $150 \mathrm{~nm}$ de PFO, pode ser devida à diferença do efeito da deposição IBAD em polímeros com rugosidades diferentes. No entanto, os campos elétricos $\left(\sim 8 \times 10^{7} \mathrm{~V} / \mathrm{cm}\right)$, para os quais ocorre a injeção de portadores, é praticamente o mesmo para as duas amostras quando o catodo é depositado sem o auxílio de íons. Isto indica que variações de rugosidade, devido ao efeito Marangoni, podem ter um efeito secundário na injeção de portadores nas interfaces e não devem ser responsáveis pela diferença de comportamento apresentada.

Na Figura 53 os valores da espessura das amostras, utilizados para calcular o campo, foram alterados (virtualmente) para que houvesse a sobreposição das curvas JxE. Assumiramse variações de espessura para amostras com o catodo depositado com o auxílio de íons e a camada ativa nominal de PFO de $150 \mathrm{~nm}$ para a amostra sem assistência foi mantida. Vê-se então que, em relação às amostras preparadas sem assistência por íon $(0 \mathrm{eV}$ e espessura total de $210 \mathrm{~nm}$ incluindo PDOT), as espessuras devem diminuir até $165 \mathrm{~nm}$ para a energia de 230 eV e depois aumentar para $195 \mathrm{~nm}$ para $330 \mathrm{eV}$ para ocorrer a superposição. Assim a suposição de que o IBAD esteja provocando uma alteração na espessura efetiva do PFO não encontra suporte, uma vez que a profundidade de penetração do alumínio apenas aumenta 
com a energia dos íons, conforme visto nas simulações. Um outro ponto que desqualifica esta suposição, é que os valores de penetração dos átomos de alumínio são da ordem de 10 vezes maior que os obtidos nas simulações.

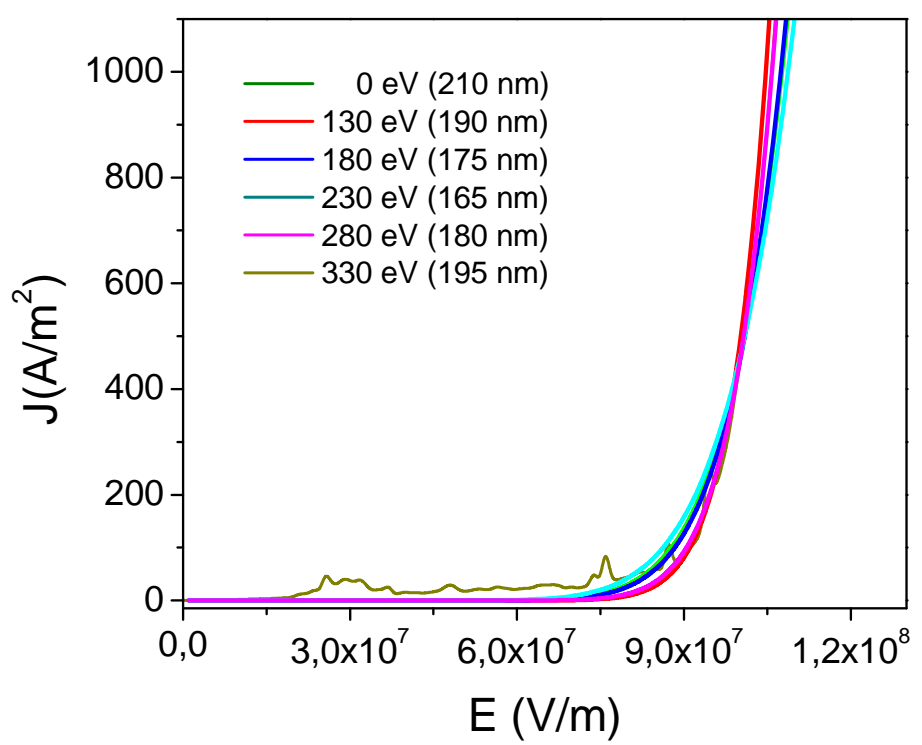

Figura 53 - Gráfico da densidade de corrente em função do campo,para as amostras com 150nm de PFO, onde a distância entre os eletrodos foi alterada para que todas as curvas se sobrepusessem. Entre parêntese o valor da distância utilizado.

Para as amostras com camada espaçadora de $16 \mathrm{~nm}$ e camada ativa de $40 \mathrm{~nm}$, o comportamento da curva JxE é mostrado na Figura 54(a). A figura apresenta também os ajustes dos dados experimentais (curvas em vermelho) pelo modelo de Fowler-Nordheim (eq. 3.2). Os campos, para os quais ocorrem a injeção, variam de $1.1 \times 10^{8}$ a $1.6 \times 10^{8} \mathrm{~V} / \mathrm{m}$, sendo mais altos que as amostras com espessuras da camada ativa de $40 \mathrm{~nm}$ e $150 \mathrm{~nm}$. É interessante notar que o modelo descreve bem o comportamento das curva JxE e que a introdução do espaçador isolante de $16 \mathrm{~nm}$ melhora o processo de injeção. A Figura 54(b) apresenta a variação de $\mathrm{V}_{\text {on }}$ através das voltagens para se atingirem correntes no intervalo de 1 a $10 \mathrm{~mA}$, em função da energia do íon de Ar. Pode-se ver que, para uma dada corrente, a voltagem $V_{\text {on }}$ cai aproximadamente $30 \%$ no intervalo de energias de 0 a $180 \mathrm{eV}$ e aumenta novamente até uma saturação para energias maiores. Este comportamento é similar ao da amostra com camada ativa espessa de $150 \mathrm{~nm}$, ou seja, pode-se dizer que dois efeitos podem estar atuando para que $\mathrm{V}_{\text {on }}$ diminua a baixas energias e aumente a altas energias. 
(a)
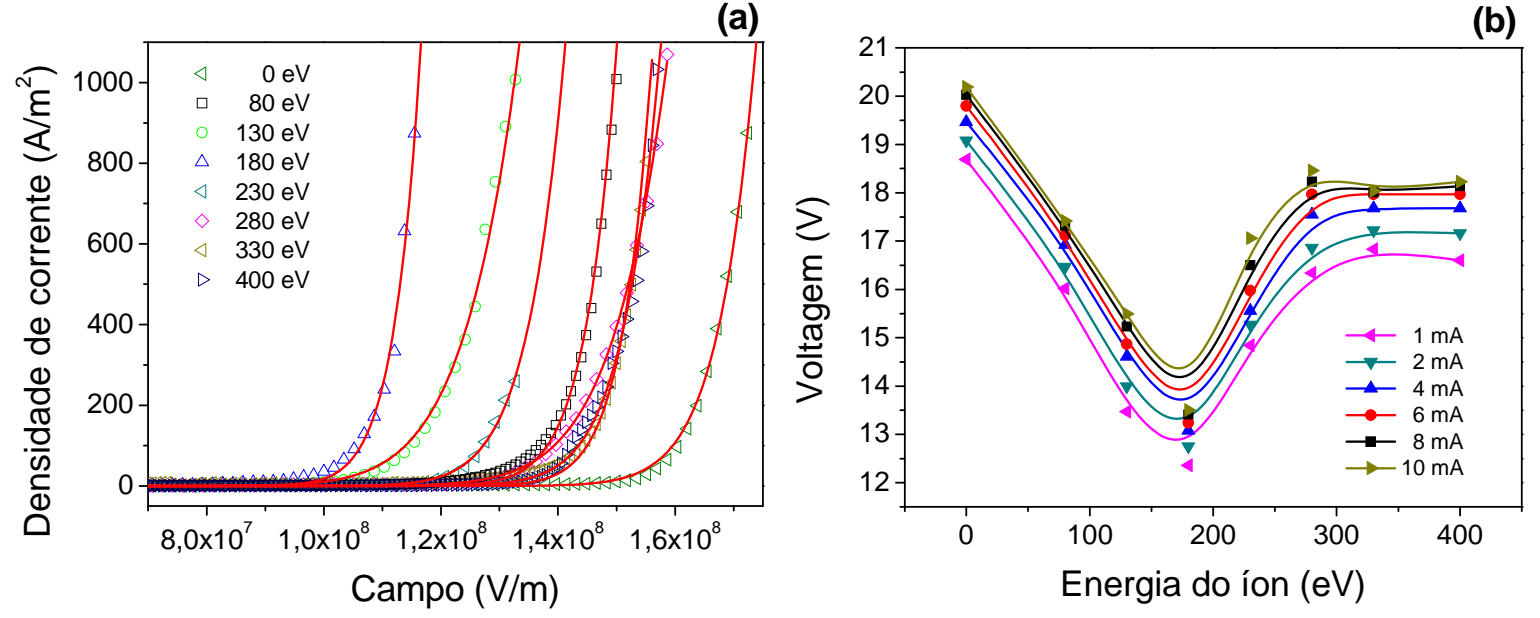

Figura 54 - Amostra com espaçador: (a) Gráfico de corrente em função da voltagem para diferentes energias de ions e; (b) Voltagem necessária para atingir uma determinada corrente em função da energia dos íons.

O espaçador dos polieletrólitos PDAC/PSS de $16 \mathrm{~nm}$ pode atuar como proteção ao bombardeamento dos íons e, portanto, evitar que os mesmos atinjam a camada ativa PFO. Assim, o comportamento apresentado se deve unicamente às alterações provocadas na injeção de elétrons através da interface espaçador/metal. Para um maior entendimento deste efeito, outros estudos seriam necessários. Porém, esta análise mais detalhada foge do tempo útil desta dissertação.

Analisando o comportamento da PL na Figura 47 (b) pode-se supor que as mudanças nas propriedades de emissão, observadas para a região de baixas energias, que foram associadas à presença de uma interface híbrida possam estar relacionadas com o decréscimo de $\mathrm{V}_{\text {on }}$, e a mudança no potencial de interface. A barreira energética para um contato ideal entre o $\mathrm{Al}$ e o $\mathrm{PFO}$ é $\Delta \sim 2,1 \mathrm{eV}^{17}$ e a injeção é dominada por processos de tunelamento à temperatura ambiente e que podem ser mediados por estados profundos na lacuna de energia $^{17}$. A formação de nanopartíiculas metálicas na interface poderia aumentar significantemente os campos elétricos locais (efeito de ponta, por exemplo), facilitando a injeção eletrônica (menor $\mathrm{V}_{\mathrm{on}}$ ). A coalescência destas nanopartículas (maior refletividade detectada para emissão) com o aumento da energia dos íons de Ar reduziria estes campos e aumentaria a voltagem de injeção $V_{\text {on }}$ até uma saturação. Acredita-se que aspectos geométricos, podem estar atuando no comportamento da injeção para os OLEDs estudados acima. Pode ser que o potencial de interface tenha sofrido modificações com a proximidade do segundo eletrodo (o anodo de ITO) para a amostra com camada ativa fina (40 nm) e que a 
formação de nanoparticulas e a coalescência das mesmas pode ter papel secundário em relação ao tunelamento na interface metálica das mesmas. Esta hipótese será verificada em trabalhos futuros.

A Figura 55 (a) compara o campo elétrico de injeção necessário para injetar uma corrente de $6 \mathrm{~mA}$ para OLEDs com espessura de camada ativa de $40 \mathrm{~nm}$ (fina) , $150 \mathrm{~nm}$ (espessa) e de $40 \mathrm{~nm}$ com $16 \mathrm{~nm}$ de espaçador entre o PFO e o metal. O comportamento com a energia do íon de Ar é o mesmo apresentado acima. Como já vimos, o valor do campo elétrico na figura é praticamente o mesmo para os dispositivos preparados sem assistência de ions $(0 \mathrm{eV})$ com camadas ativas fina e espessa. $\mathrm{O}$ comportamento com a energia ion de Ar é o mesmo apresentado acima. A introdução da camada espaçadora de polieletrólito aumenta consideravelmente este campo de injeção para elétrons. Isto pode ser explicado pela presença de bicamadas formadas por cargas opostas (dipolares) do espaçador, que podem estar modificando o potencial de interface, ou transferência de carga na interface ${ }^{97}$. No caso, é esperado um aumento da largura da barreira (campos elétricos de interface menores) dificultando o tunelamento eletrônico. Recentemente, foi demonstrado em nossos laboratórios (em trabalho ainda não publicado) que a injeção eletrônica é modulada em torno da $\mathrm{V}_{\text {on }}$ para um OLED sem espaçador, dependendo da camada espaçadora terminar com o polieletrólito positivo (PDAC) ou com o polieletrólito negativo (PSS) junto ao metal. Isto demonstra que o efeito da camada espaçadora na injeção de elétrons não é causado apenas pela separação entre o catodo e a camada ativa, mas também pelas cargas (dipolos) presentes na interface.

(a)


Figura 55 - Voltagem necessária para atingir $6 \mathrm{~mA}$ em função da energia dos ions para as amostras fina, espessa e com espaçador. 
A Figura 55 (b), por sua vez, compara a energia da barreira $\Delta$ em função da energia do ion de Ar. Este parâmetro foi obtido dos ajustes das curvas JxE pela equação 2.7. para os mesmos OLEDs com espessura de camada ativa de $40 \mathrm{~nm}$ (fina), $150 \mathrm{~nm}$ (espessa) e de 40 $\mathrm{nm}$ com $16 \mathrm{~nm}$ de espaçador entre o PFO e o metal. Pode-se ver que a altura da barreira $\Delta$ possui comportamento semelhante a aquele do campo necessário para iniciar a injeção (Figura 55 (a)). É interessante notar que $\Delta$ possui valores da ordem da altura da barreira energética $\Delta_{\text {ITO }}$ entre o ITO e o PDOT $^{48}$. Isto significa que buracos transpõem preferencialmente a barreira de $\Delta_{\mathrm{ITO}} \sim 0.2 \mathrm{eV}$ por hopping ao serem injetados no anodo ${ }^{47 ; 48}$. Já os elétrons tunelam a barreira formada no catodo. Este tunelamento depende preferencialmente da largura da barreira, que é uma função do campo elétrico. Existem diversos modelos que tentam explicar os processos exatos que promovem modificações da barreira e a Figura 56 expõe um modelo simples que ilustra o possível efeito que a presença das nanopartículas de alumínio exercem sobre a barreira. Em (a), tem-se uma interface normal, sem a presença das nanopartículas, em (b) a presença das nanopartículas provoca um estreitamento da barreira e em (c), por fím, é ilustrado como a presença da camada espaçadora de $16 \mathrm{~nm}$ provoca um aumento da barreira.

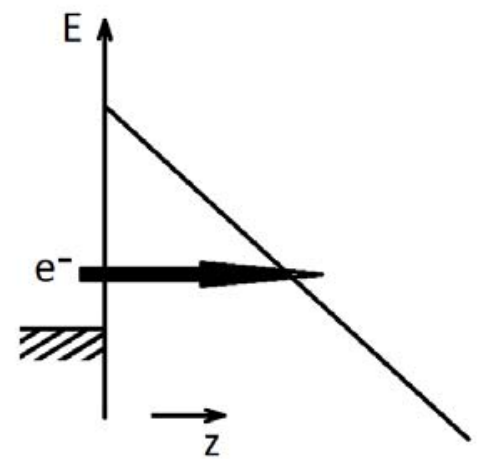

(a)

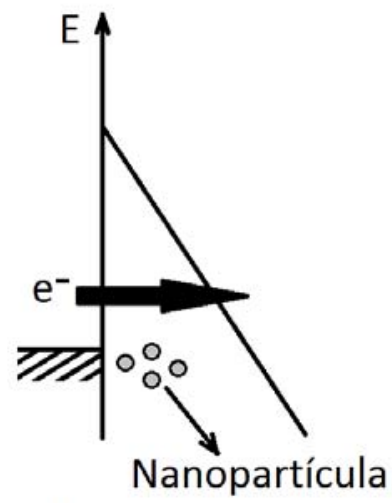

(b)

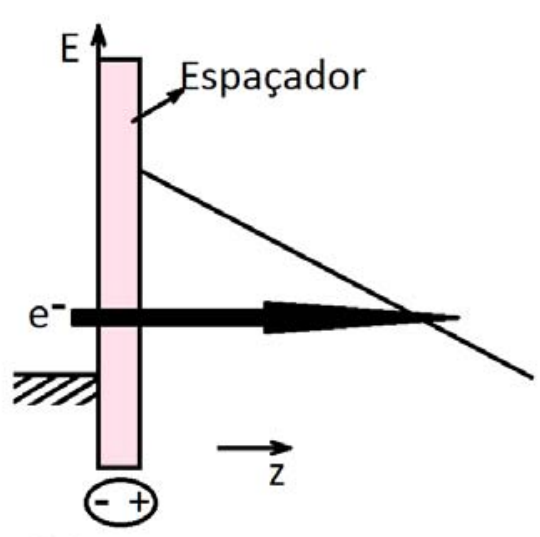

(c)

Figura 56 - Ilustração das barreiras de energia (segundo o modelo de tunelamento) para uma amostra com uma interface padrão (a), com a implantação de nanopartículas (b) e com um espaçador entre o catodo e a camada ativa(c). Do lado esquerdo o metal e seu respectivo nível de Fermi e do lado direito o polímero. Dispositivo sob polarização direta.

Conforme mencionado anteriormente, a exposição da superfície polimérica a um feixe de íons causa uma "piora" na injeção de elétrons ${ }^{24 ;}{ }^{94}$, que está relacionada à criação de

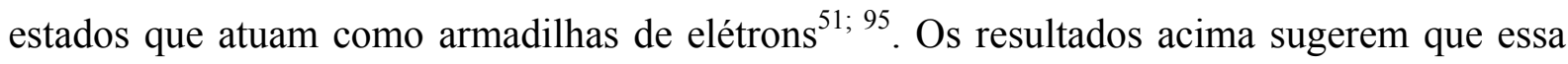
interpretação não é válida quando se tem simultaneamente a deposição de metal, já que a degradação não é o efeito dominante, pelo menos para energias entre 0 e $250 \mathrm{eV}$. 


\subsubsection{Eletroluminescência}

Conforme visto na seção 2.2.2, as correntes de elétrons $I_{e}$ e de buracos $I_{h}$ não são equilibradas na grande maioria das vezes. Na seção anterior, havia interesse na corrente total $\left(\mathrm{I}=\mathrm{I}_{\mathrm{e}}+\mathrm{I}_{\mathrm{h}}\right.$ ) de portadores de carga e não houve preocupação com o seu caráter (positivo e negativo) e nem com o balanço ou fração da corrente total (que corresponde à corrente de elétrons $\left(\mathrm{I}_{\mathrm{e}}\right)$ injetados pelo catodo metálico e a de buracos $\left(\mathrm{I}_{\mathrm{h}}\right)$ injetados pelo anodo de ITO). $\mathrm{O}$ ideal seria que elétrons e buracos fossem injetados com mesma densidade de corrente para o mesmo campo aplicado. Esta situação dificilmente é satisfeita, já que os contatos e as mobilidades para elétrons e buracos são distintos. A busca de condições ideais de injeção significa aumentar a eficiência dos dispositivos OLEDs. Medidas da intensidade de electroluminescência em função da voltagem dão uma indicação indireta da contribuição de $I_{e}$ e $I_{h}$ na corrente total $I$, uma vez que a eletroluminescência é proporcional ao produto das densidades de carga $n_{e}$ e $n_{h}$ de elétrons e buracos que estão sendo transportados ao longo do dispositivo. No presente trabalho, a injeção de elétrons no catodo está sendo modificada por IBAD. Nesta seção, tentaremos correlacionar estas alterações no catodo com a corrente de elétrons. Porém, as medidas de eletroluminescência realizadas até o momento estão longe de serem satisfatórias, pois o caminho óptico de coleta da luz emitida (entre o OLED e o detector) não foi mantido constante. Portanto, somente evidências qualitativas das alterações sofridas pela injeção de elétrons com da deposição do catodo por IBAD serão conseideradas.

O comportamento de eletroluminescência para a amostra com 40nm de PFO é mostrado na Figura 57 (a). O gráfico mostra a intensidade da luminescência em escala arbitrária em função da voltagem para a polarização direta dos dispositivos vistos na seção anterior. As medidas de JxE e de eletroluminescência foram feitas simultaneamente. Nota-se que a amostra com o catodo formado sem a assistência dos íons de argônio tem um desempenho bem melhor, não só acendendo antes, como também com a eficiência de recombinação muito maior, conforme será visto adiante. Além disso, as curvas de eletroluminescência versus voltagem seguem o mesmo comportamento que aquele visto para as curvas IxV na Figura 51(a) da seção anterior. É interessante notar que a faixa de voltagens entre 5 e $10 \mathrm{~V}$ para as quais ocorrem as emissões corresponde à faixa de injeção de portadores (Figura 51(b)). 
(a)

(b)
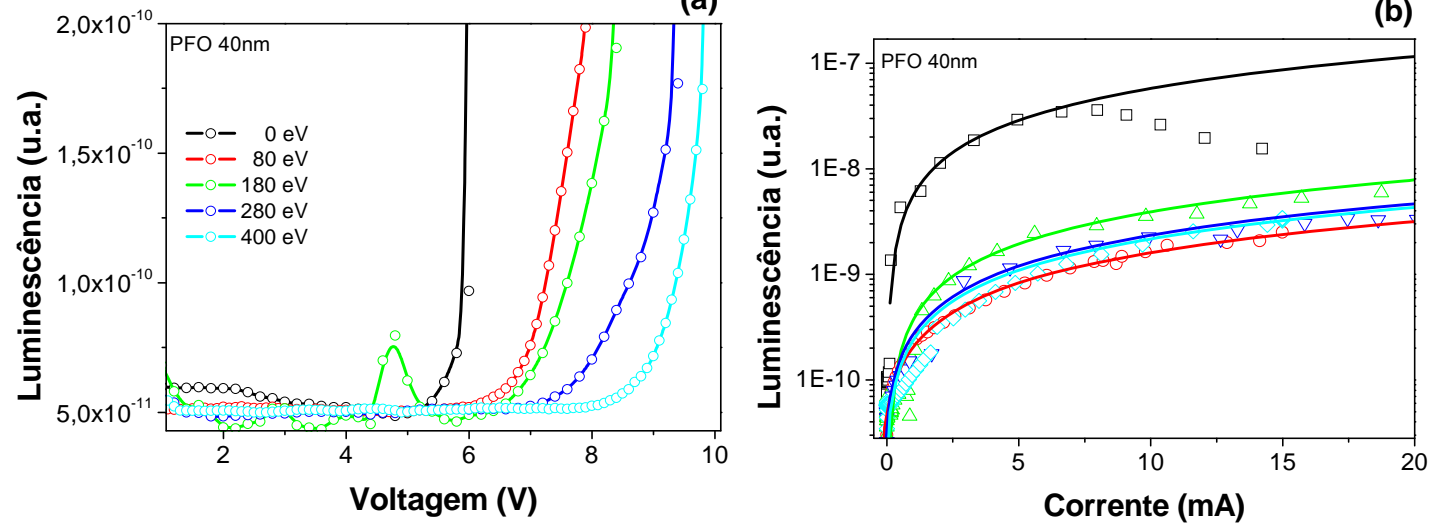

(c)
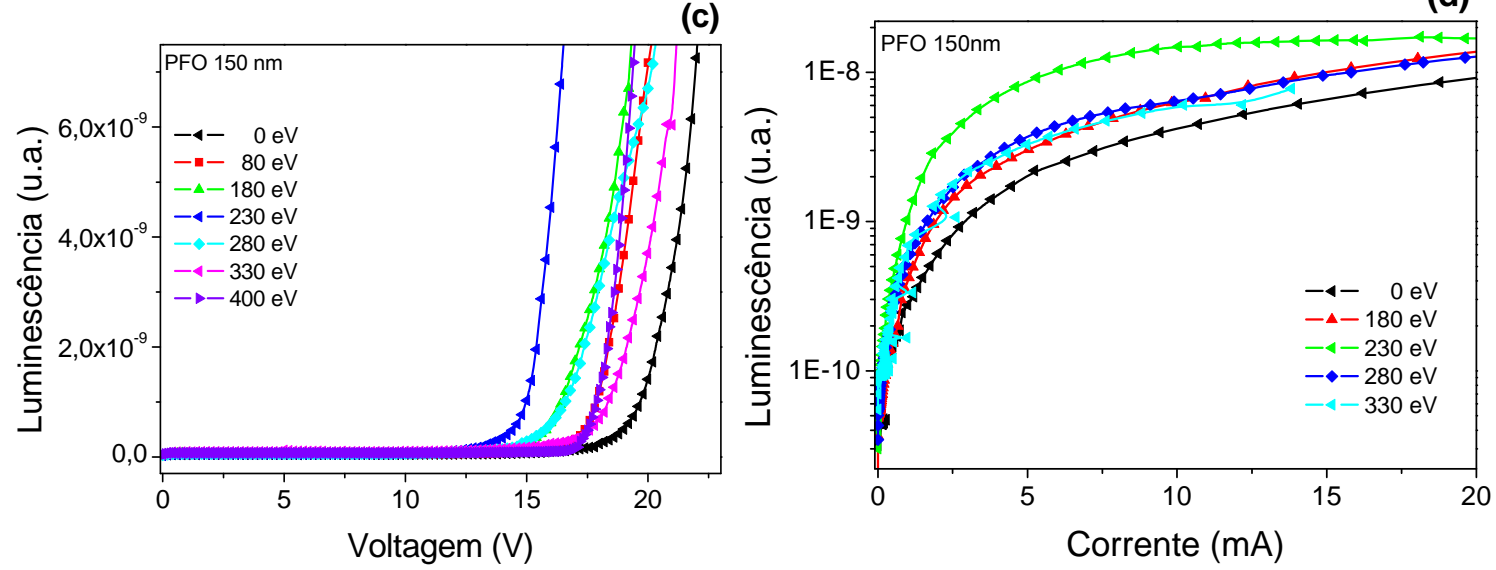

(e)
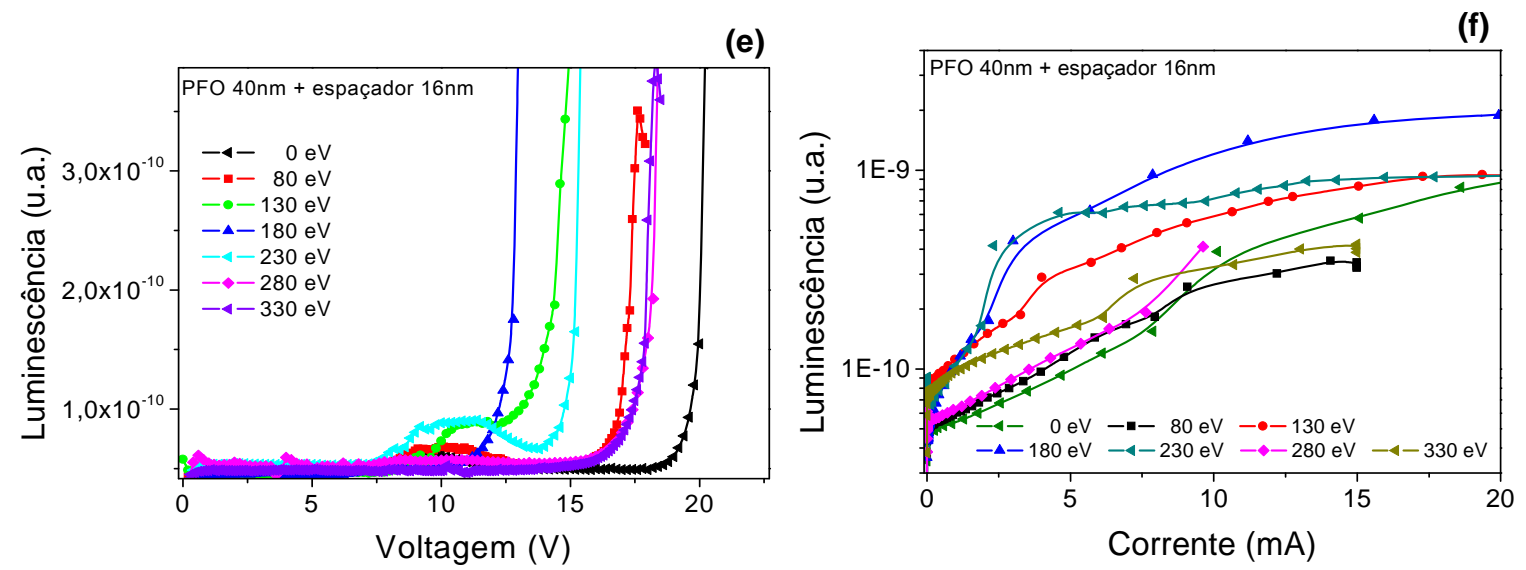

Figura 57 - Amostras com $40 \mathrm{~nm}$ de PFO, (a) e (b), com $150 \mathrm{~nm}$ de PFO,(c) e (d) e para amostras com espaçador de $16 \mathrm{~nm}$ e $40 \mathrm{~nm}$ de PFO, (e) e (f). À esquerda, gráficos da luminescência em função da voltagem. $\grave{A}$ direita, gráficos da luminescência em função da corrente, mostrando a eficiência de eletroluminescência.

É interessante ver o comportamento da intensidade da eletroluminescência em função da corrente, pois existe uma correlação direta entre as duas grandezas quando as mesmas são medidas simultaneamente. Basicamente dois efeitos estão ligados à eficiência de 
recombinação radiativa que leva a eletroluminescência: o balanço na injeção de portadores (buracos e elétrons) e os processos não radiativos concorrentes que desativam os elétrons injetados através do catodo na banda $\pi^{*}$ e os buracos injetados na banda $\pi$ através do anodo. Estes dois processos podem ser observados num gráfico de eletroluminescência versus corrente. A relação entre intensidade da eletroluminescência e corrente é linear se existe uma relação unívoca entre elas. Processos outros que aparecem na aplicação da corrente ou que estão presentes na amostra podem ser detectados como um desvio dessa linearidade.

A Figura 57 (b) apresenta a intensidade da eletroluminescência (pontos) em escala logarítmica em função da corrente para a mesma amostra da Figura 57 (a). A curvas contínuas são ajustes lineares feitos para baixas correntes. Uma luminescência maior para uma dada corrente dá a eficiência relativa do processo de eletroluminescência nos dispositivos. A amostra contendo catodo depositado sem assistência de íons de $\operatorname{Ar}(0 \mathrm{eV})$ possui maior eletroluminescência que as amostras com eletrodo depositado com a assistência de íons. Porém, essa amostra sofre um desvio da linearidade para altas correntes, indicando uma degradação das características do dispositivo. As amostras tratadas por IBAD, apesar do menor rendimento, possuem melhor comportamento a altas correntes. A amostra preparada com energia de $180 \mathrm{eV}$ possui melhor eficiência relativa de emissão.

O OLED fabricado com camada ativa de $150 \mathrm{~nm}$ possui propriedades eletroluminescentes melhores que o dispositivo com camada ativa de $40 \mathrm{~nm}$. As Figura 57 (c) e (d) comparam, respectivamente, as curvas de intensidade da eletroluminescência em função da voltagem de polarização e da corrente para vários valores de energia do íon de $\mathrm{Ar}$. $\mathrm{Na}$ Figura 57 (d), a intensidade da eletroluminescência é apresentada em escala logarítmica. $\mathrm{O}$ comportamento da eletroluminescência e a região para a qual a injeção ocorre são semelhantes aos das curvas IxV apresentadas na seção anterior (Figura 52). A análise conjunta da intensidade da eletroluminescência e da corrente (Figura 57 (d)) indica que há uma maior injeção de elétrons no catodo para as amostras preparadas por IBAD, aumentando o balanceamento de portadores durante o funcionamento do dispositivo. Em outras palavras, todas as amostras (150 nm de PFO) com o catodo preparado com o auxilio de íons apresentam uma melhora da eficiência em relação à amostra preparada sem o auxilio de íons. O OLED preparado com energia de $230 \mathrm{eV}$ possui maior eficiência quando comparado com os outros dispositivos dessa série. É interessante notar que os outros OLED com catodos preparados por IBAD apresentam a mesma eficiência em altas correntes, ou seja, eles têm a mesma relação linear com a corrente. Além disso, é uma evidência que amostras com maior eficiência de 
emissão degradam suas características mais acentuadamente em correstes menores. Isto pode indicar que centros não radiativos estão sendo gerados a partir do estado excitado molecular, contribuindo para a degradação do dispositivo. Estas amostras não foram encapsuladas e, apesar de estarem no vácuo, elas podem estar sofrendo os efeitos de serem preparadas em contato com a atmosfera ambiente. Dos resultados acima fica evidente que o comportamento de injeção não depende exclusivamente da interface polímero metal, uma vez que a interface, formada nas amostras com camadas ativas de espessuras de 40 e $150 \mathrm{~nm}$, é essencialmente a mesma, porém com processos de injeção de elétrons distintos.

O comportamento da intensidade da eletroluminescência em função da voltagem e da corrente para a amostra com espaçador de $16 \mathrm{~nm}$ entre a camada ativa e o catodo é apresentado nas Figura 57 (e) e Figura 57 (f) para as mesmas energias de bombardeamento utilizadas acima. Pode-se ver que a região de voltagens para as quais ocorre a eletroluminescência é praticamente igual a aquela observada para a injeção de elétrons no catodo. Porém, os dispositivos com o espaçador não apresentaram boas característica de eletroluminescência, como pode ser visto nas curvas da Figura 57 (f). Nessa figura, a eletroluminescência não segue o comportamento linear, o que indica que a injeção de elétrons no catodo contendo espaçador não é homogênea com o aumento da corrente. Acreditamos que isso pode estar associado à qualidade do filme automontado de polieletrólitos. Estes aspectos envolvendo otimização das propriedades dos espaçadores serão tratados futuramente.

A Figura 58 (a) apresenta a comparação das eletroluminescências pela corrente dos OLEDs estudados acima para a condição de maior eficiência relativa, ou seja, amostras com $40 \mathrm{~nm}$ de PFO, $150 \mathrm{~nm}$ de PFO e com espaçador e $40 \mathrm{~nm}$ de PFO produzidas com íons de 0, 230 e $180 \mathrm{eV}$, respectivamente. Se compararmos as intensidades da eletroluminescência notamos que a amostra com o espaçador tem uma eficiência bem menor que as amostras com camada ativa de 40 e $150 \mathrm{~nm}$. O motivo para este comportamento não pode ser inferido do fato de que a camada espaçadora limita a injeção por emissão de campo para os elétrons na interface e estes passam a ter uma menor participação na corrente total medida, o que explica a baixa eficiência. Pode-se notar ainda que a amostra com $40 \mathrm{~nm}$ de PFO sem a assistência de íons apresenta a melhor eficiência. 
(a)

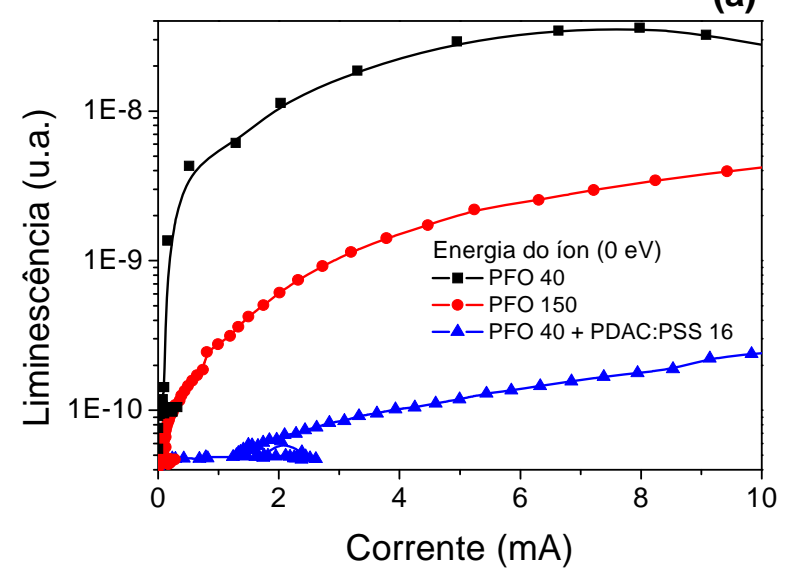

(b)

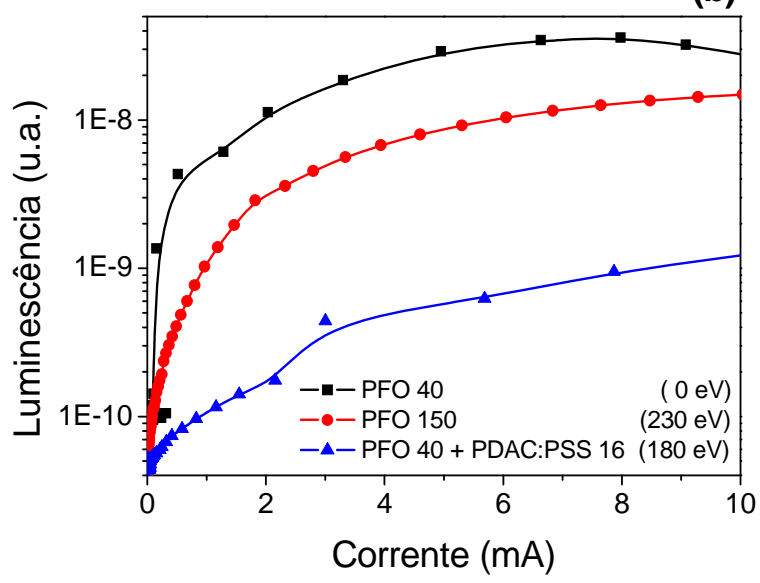

Figura 58 - Gráfico da luminescência em função da corrente, mostrando a eficiência de eletroluminescência para: (a) Amostras fina, espessa e com espaçador como catodo produzido sem o auxilio de ions; (b) Amostra com maior eficiência de cada tipo(fina, espessa e com espaçador).

Por fim, a Figura 58 (b) apresenta a comparação da eficiência para as melhores amostras produzidas de cada tipo (40 nm de PFO, $150 \mathrm{~nm}$ de PFO e com espaçador e $40 \mathrm{~nm}$ de PFO, nas quais os catodos foram produzidos com íons de 0, 230 e $180 \mathrm{eV}$, respectivamente) Nota-se que a amostra com $40 \mathrm{~nm}$ de PFO sem a assistência de íons apresenta a melhor eficiência. As medidas de eletroluminescência e de eficiência mostram claramente que o IBAD afeta principalmente a injeção de elétrons, de forma que o potencial entre o metal e o PFO é modificado. 


\section{CONCLUSÕES E PERSPECTIVAS FUTURAS}

Um dos maiores problemas em OLEDs é a obtenção de contatos que garantam a injeção homogênea e uniforme dos portadores de carga nos contatos. Interfaces metal/polímero podem apresentar campos elétricos não uniformes, o que gera caminhos de percolação favoráveis à corrente elétrica em pequenas áreas e, portanto, densidades de correntes altas que levam à fadiga e a degradação do material. Este trabalho teve o objetivo de estudar a deposição do catodo por IBAD em OLEDs através de medidas de PL e caracterização elétrica. Uma vez que a utilização do IBAD com este objetivo é praticamente inédita, uma etapa do trabalho esteve voltada à caracterização do processo e sua posterior otimização. Conseguiu-se assim estabelecer uma metodologia, ainda sujeita a aperfeiçoamentos, para a deposição de catodos em OLED utilizando IBAD.

A alteração, no catodo (bulk) (não na interface metal/polímero) provocada pela deposição IBAD não apresentou relação com a injeção de portadores. Como o contato entre o polímero e o metal não é um contato ôhmico, o comportamento é dominado pela injeção através da interface. Foi observado que para a incidência de uma alta dose de íons (íons/área) sobre o polímero, ocorre degradação, que leva a uma redução drástica das propriedades de conjugação do polímero. As simulações feitas mostraram que o deslocamento dos átomos do polímero ocorrem em uma pequena profundidade, que não justifica tamanha queda na luminescência, o que mostra que a incidência dos íons gera danos não só pelo deslocamento dos átomos (ocasionado pelos íons) como também uma degradação de longo alcance, que foi relacionada ao aumento da temperatura. Não foi possível caracterizar a degradação sobre o catodo, porém durante o processo IBAD ela ocorre exatamente na proximidade da área da interface, assim, mesmo que a exposição ao feixe de íons ocorra por um tempo pequeno (o que leva a uma menor dose) ela ocorre exatamente na área mais sensível. $O$ efeito da deposição com íons de alta energia $(600 \mathrm{e} 1000 \mathrm{eV})$ sobre as características elétricas do OLED foi de retardar a $\mathrm{V}_{\text {on }}$, provavelmente devido à criação de armadilhas de cargas formadas próximas ao catodo, o que mostra que íons com energias muito altas não são indicadas para a preparação de OLEDs. Já os OLEDs preparados com $200 \mathrm{eV}$ alcançaram uma maior corrente antes de deteriorar, o que se deve à formação de um contato mais 
homogêneo e com menor propensão à formação de caminhos preferenciais para a injeção de elétrons.

Para íons com energia entre 80 e $400 \mathrm{eV}$, a utilização de três tipos diferentes de amostras permitiu através da PL identificar que a reflectividade da interface metal/polímero é afetada diretamente pela energia dos íons utilizados. Esta mudança foi associada à presença de nanopartículas de metal na interface. As simulações do processo IBAD permitiram associar o aumento da concentração do Al com o aumento da energia do íon, com um possível aumento da reatividade química do polímero, diminuindo a mobilidade desses átomos. Estes dois fatores propiciam uma maior coalescência dos átomos de alumínio, o que leva a uma interface mais definida e com maior reflectividade. Assim surpreendentemente a utilização do IBAD leva à formação de uma interface mais definida para energias variando de $80 \mathrm{eV}$ a 400 $\mathrm{eV}$.

As medidas elétricas para catodos depositados com íons entre 80 e 400 eV mostram que dois efeitos podem estar atuando para que $V_{\text {on }}$ diminua a baixas energias e aumente a altas energias. Além do mais um destes efeitos está ligado à espessura da amostra, uma vez que apenas a alteração na interface não sustenta a diferença entre a amostra com 40 e $150 \mathrm{~nm}$ de PFO. O exato papel dos efeitos da formação das nanopartículas (e posterior coalescência) e da incidência do feixe de íons não pode ser identificado. O modelo de Fowler- Nordheim foi utilizado para analisar os resultados e mostraram que uma variação na barreira entre o metal e o polímero é provocada pelo uso do IBAD. O mecanismo exato pelo qual o IBAD afeta a barreira não pode ser determinado, porém os resultados de eletroluminescência mostram que a injeção de elétrons é afetada pelo uso do IBAD.

Uma vez que este trabalho teve por objetivo explorar a potencialidade do uso do IBAD em eletrônica orgânica, praticamente pela primeira vez, várias questões ficaram em aberto. Um estudo mais aprofundado demandaria tempo e novos experimentos, o que seria impraticável dentro dos objetivos deste trabalho de mestrado. Assim várias perspectivas para trabalhos futuros surgiram. Algumas estão listadas a seguir:

$>$ Estudo detalhado da interface formada, através de técnicas destrutivas ou não, permitirá entender as alterações provocadas para cada energia e, através da relação entre a interface formada e as alterações funcionais no dispositivo, definir o papel da estrutura da interface nos processos de injeção. 
$>$ O papel que a concentração de alumínio e a maior reatividade química causada pelos íons têm no processo de formação da interface também é uma lacuna em aberto.

Estudo do efeito que os danos causados direta e indiretamente pelo feixe de íons produz, sobre os estados eletrônicos da interface e possivelmente sobre a mobilidade dos portadores

Estudo dos processos de injeção utilizando medidas IxV variando a temperatura, para que a contribuição térmica possa ser entendida e a partir daí produzir dispositivos que favoreçam os elétrons como portadores.

Análise do efeito que um contato mais homogêneo e com menor propensão à formação de caminhos preferenciais para a injeção de elétrons (que leva a uma densidade superficial de corrente mais homogênea), possa ter sobre o tempo de vida do OLED. 


\section{REFERÊNCIAS}

1 POPE, M.; MAGNANTE, P.; KALLMANN, H. P. Electroluminescence in organic crystals. Journal of Chemical Physics, v. 38, n. 8, p. 2042, 1963.

2 TANG, C. W.; VANSLYKE, S. A. Organic electroluminescent diodes. Applied Physics Letters, v. 51, n. 12, p. 913-915, 1987.

3 TOBJORK, D.; OSTERBACKA, R. Paper electronics. Advanced Materials, v. 23, n. 17, p. 1935-1961, 2011.

4 SCHEINERT, S. et al. Low-cost submicrometer organic field-effect transistors. Organic Electronics, v.223, n.1,p.155-188, 2010.

5 TANG, W. H. et al. Recent development of conjugated oligomers for high-efficiency bulkheterojunction solar cells. Solar Energy Materials and Solar Cells, v. 94, n. 12, p. 1963 1979, 2010.

$6 \mathrm{KOCH}, \mathrm{N}$. Organic electronic devices and their functional interfaces. Chemphyschem, v. 8, n. 10, p. 1438-1455, 2007.

7 MCMAHON, D. P.; TROISI, A. Organic semiconductors: impact of disorder at different timescales. Chemphyschem, v. 11, n. 10, p. 2067-2074, 2010.

8 MCCREERY, R. L.; BERGREN, A. J. Progress with molecular electronic junctions: meeting experimental challenges in design and fabrication. Advanced Materials, v. 21, n. 43, p. 4303-4322, 2009.

9 BHARATHAN, J. M.; YANG, Y. Polymer/metal interfaces and the performance of polymer light-emitting diodes. Journal of Applied Physics, v. 84, n. 6, p. 3207-3211, 1998.

10 SCOTT, J. C. Metal-organic interface and charge injection in organic electronic devices. Journal of Vacuum Science \& Technology A, v. 21, n. 3, p. 521-531, 2003.

11 ITO, E.; HARA, M. Characterization of organic/metal interfaces using angle-resolved Xray photoelectron spectroscopy. Japanese Journal of Applied Physics, v. 47, n. 2, p. 13931396, 2008. 
12 BRAUN, S.; SALANECK, W. R.; FAHLMAN, M. Energy-level alignment at organic/metal and organic/organic interfaces. Advanced Materials, v. 21, n. 14-15, p. 1450$1472,2009$.

13 CAZATI, T. et al. Analysis of the Al-PANI interfaces by complex impedance spectroscopy. Journal of Physics D-Applied Physics, v. 44, n. 16, p. 6, 2011.

14 PARK, J. W.; SHIN, D. C.; PARK, S. H. Large-area OLED lightings and their applications. Semiconductor Science and Technology, v. 26, n. 3, p. 9, 2011

15 TSENG, S. R. et al. Electron transport and electroluminescent efficiency of conjugated polymers. Synthetic Metals, v. 159, n. 1-2, p. 137-141, 2009.

16 ZHANG, X. W. et al. Electron injection property at the organic-metal interface in organic light-emitting devices revealed by current-voltage characteristics. Physica B-Condensed Matter, v. 404, n. 8-11, p. 1247-1250, 2009.

17 SHINAR, J. Organic light emitting devices. New York: Springer-Verlag, 2004.

18 SCOTT, J. C. et al. Degradation and failure of MEH-PPV light-emitting diodes. Journal of Applied Physics, v. 79, n. 5, p. 2745-2751, 1996.

19 AZIZ, H.; XU, G. A degradation mechanism of organic light-emitting devices. Synthetic Metals, v. 80, n. 1, p. 7-10, 1996.

20 BROWN, T. M. et al. The influence of LiF thickness on the built-in potential of blue polymer light-emitting diodes with LiF/Al cathodes. Synthetic Metals, v. 124, n. 1, p. 15-17, 2001.

21 GRECZYNSKI, G.; FAHLMAN, M.; SALANECK, W. R. An experimental study of poly(9,9-dioctyl-fluorene) and its interfaces with $\mathrm{Li}, \mathrm{Al}$, and $\mathrm{LiF}$. Journal of Chemical Physics, v. 113, n. 6, p. 2407-2412, 2000.

22 LI, F. et al. Fabrication and electroluminescence of double-layered organic light-emitting diodes with the A12O3/Al cathode. Applied Physics Letters, v. 70, n. 10, p. 1233-1235, 1997. 
23 DEMIRKAN, K. et al. Reactivity and morphology of vapor-deposited Al/polymer interfaces for organic semiconductor devices. Journal of Applied Physics, v. 103, n. 3, p. 7, 2008 .

24 GIL, T. H. et al. Origin of damages in OLED from Al top electrode deposition by DC magnetron sputtering. Organic Electronics, v. 11, n. 2, p. 322-331, 2010.

25 SIKOLA, T. et al. Ion beam assisted deposition of metallic and ceramic thin films. Nuclear Instruments \& Methods in Physics Research Section B-Beam Interactions with Materials and Atoms, v. 127, p. 673-676, 1997.

26 BRÜTTING, W. Physics of organic semiconductors. Weinheim: WILEY-VCH, 2005.

27 SARICIFTCI, N. S. Primary photoexcitations in conjugated polymers: molecular excitation versus semiconductor band model. Singapore: River Edge, 1997.

28 FRIEND, R. H. et al. Electronic excitations in luminescent conjugated polymers. Solid State Communications, v. 102, n. 2-3, p. 249-258, 1997.

29 WONG, K. F.; BAGCHI, B.; ROSSKY, P. J. Distance and orientation dependence of excitation transfer rates in conjugated systems: Beyond the Forster theory. Journal of Physical Chemistry A, v. 108, n. 27, p. 5752-5763, 2004.

$30 \mathrm{KUHN}, \mathrm{H}$. Interaction of chromophores in monolayers assemblies. Pure and Applied Chemistry, v. 27,n. 1, p.421-438, 1971.

31 TSUTSUI, T. et al. Effect of confined radiation-field on spontaneous-emission lifetime in vacuum-deposited fluorescent dye films. Chemical Physics Letters, v. 182, n. 2, p. 143-146, 1991.

32 BORGES, C. A. Efeitos de interface sobre as propriedades ópticas de polímeros conjugados. 2005. p.142 Tese (Doutorado) - Instituto de Física de São Carlos, Universidade de São Paulo,São Carlos, 2005.

33 CHANCE, R. R.; PROCK, A.; SILBEY, R. Comments on classical theory of energytransfer. Journal of Chemical Physics, v. 62, n. 6, p. 2245-2253, 1975.

34 FORSTER, T. Zwischenmolekulare energiewanderung und fluoreszenz. Annalen Der Physik, v. 2, n. 1-2, p. 55-75, 1948. 
35 DEPPE, D. G. et al. Spontaneous emission from planar microstructures. Journal of Modern Optics, v. 41, n. 2, p. 325-344, 1994.

36 MOTT, N. F. Electrons in disordered structures. Advances in Physics, v. 16, n. 61, p. 49, 1967.

37 SUGIYAMA, K. et al. Dependence of indium-tin-oxide work function on surface cleaning method as studied by ultraviolet and x-ray photoemission spectroscopies. Journal of Applied Physics, v. 87, n. 1, p. 295-298, 2000.

$38 \mathrm{KIM}, \mathrm{S}$. Y. et al. Effect of ultraviolet-ozone treatment of indium-tin-oxide on electrical properties of organic light emitting diodes. Journal of Applied Physics, v. 95, n. 5, p. 25602563, 2004.

39 BROWN, T. M.; CACIALLI, F. Contact optimization in polymer light-emitting diodes. Journal of Polymer Science Part B-Polymer Physics, v. 41, n. 21, p. 2649-2664, 2003.

40 JANIETZ, S. et al. Electrochemical determination of the ionization potential and electron affinity of poly(9,9-dioctylfluorene). Applied Physics Letters, v. 73, n. 17, p. 2453-2455, 1998.

41 LIAO, L. S. et al. Electronic structure and energy band gap of poly (9,9-dioctylfluorene) investigated by photoelectron spectroscopy. Applied Physics Letters, v. 76, n. 24, p. 35823584, 2000.

42 CAMPBELL, A. J. et al. Transient and steady-state space-charge-limited currents in polyfluorene copolymer diode structures with ohmic hole injecting contacts. Applied Physics Letters, v. 76, n. 13, p. 1734-1736, 2000.

43 SATO, Y.; ICHINOSAWA, S.; KANAI, H. Operation characteristics and degradation of organic electroluminescent devices. IEEE Journal of Selected Topics in Quantum Electronics, v. 4, n. 1, p. 40-48, 1998.

44 ZHOU, X. et al. Real-time observation of temperature rise and thermal breakdown processes in organic LEDs using an IR imaging and analysis system. Advanced Materials, v. 12 , n. 4, p. 265-269, 2000.

45 CUMPSTON, B. H.; JENSEN, K. F. Electromigration of aluminum cathodes in polymerbased electroluminescent devices. Applied Physics Letters, v. 69, n. 25, p. 3941-3943, 1996. 
46 CAMPBELL, I. H. et al. The Schottky energy barrier dependence of charge injection in organic light-emitting diodes. Applied Physics Letters, v. 72, n. 15, p. 1863-1865, 1998.

47 PARKER, I. D. Carrier tunneling and device characteristics in polymer light-emittingdiodes. Journal of Applied Physics, v. 75, n. 3, p. 1656-1666, 1994.

48 HEEGER, A. J.; PARKER, I. D.; YANG, Y. Carrier injection into semiconducting polymers - fowler-nordheim field-emission tunneling.Synthetic Metals, v.67, n.1-3, p. 23-29, 1994.

49 ARKHIPOV, V. I. et al. Charge injection into light-emitting diodes: theory and experiment. Journal of Applied Physics, v. 84, n. 2, p. 848-856, 1998.

50 PARK, Y. et al. Electron spectroscopy studies of interface formation between metal electrodes and luminescent organic materials. Journal of Vacuum Science \& Technology aVacuum Surfaces and Films, v. 15, n. 5, p. 2574-2578, 1997.

51 LIAO, L. S. et al. Improvement of interface formation between metal electrode and polymer film by polymer surface modification using ion sputtering. Applied Physics Letters, v. 77, n. 20, p. 3191-3193, 2000.

52 ANDOH, Y. et al. A new machine for film formation by ion and vapor-deposition. Nuclear Instruments \& Methods in Physics Research Section B-Beam Interactions with Materials and Atoms, v. 6, n. 1-2, p. 111-115, 1985.

53 CHUBACI, J. F. D. Formação e caracterização de filmes finos de nitretos de carbono. 1996. p. 72 Tese (Doutorado) - Instituto de Física, Universidade de São Paulo, São Paulo, 1996.

54 OHRING, M. The material science of thin film. London: Academic Press, 1992.

55 JAIN, I. P.; AGARWAL, G. Ion beam induced surface and interface engineering. Surface Science Reports, v. 66, n. 3-4, p. 77-172, 2011.

56 MOLITON, A. et al. Ion-implantation in conjugated polymers - mechanisms for generation of charge-carriers. Philosophical Magazine B-Physics of Condensed Matter Statistical Mechanics Electronic Optical and Magnetic Properties, v. 69, n. 6, p. 11551171, 1994. 
57 WINTERSGILL, M. C. Ion-implantation in polymers. Nuclear Instruments \& Methods in Physics Research Section B-Beam Interactions with Materials and Atoms, v. 1, n. 2-3, p. 595-598, 1984.

58 LIFSHITZ, Y. et al. Subplantation model for film growth from hyperthermal species. Physical Review B, v. 41, n. 15, p. 10468-10480, 1990.

59 ENSINGER, W. Ion bombardment effects during deposition of nitride and metal films. Surface \& Coatings Technology, v. 99, n. 1-2, p. 1-13, 1998.

$60 \mathrm{MAO}, \mathrm{S}$. D. et al. Corrosion properties of aluminium coatings deposited on sintered $\mathrm{NdFeB}$ by ion-beam-assisted deposition. Applied Surface Science, v. 257, n. 13, p. 5581$5585,2011$.

61 TERRASI, A. et al. Ion-beam-assisted deposition of Al films on Si. Journal of Vacuum Science \& Technology a-Vacuum Surfaces and Films, v. 13, n. 6, p. 2827-2831, 1995.

62 ANTONY, R. et al. Ion beam assisted deposition of organic light emitting devices: enhanced optoelectronic properties. European Physical Journal-Applied Physics, v. 4, n. 1, p. 45-51, 1998.

63 . Ions size dependent characteristics of organic light-emitting diodes realized by ion beam assisted deposition. In: INTERNATIONAL CONFERENCE ON SCIENCE AND TECHNOLOGY OF SYNTHETIC METALS, ICSM 98. Montpellier, France, July 12-18, 1998. Abstracts... Montpellier: ICSM, 1998.p.908-909.

64 ANTONY, R.; MOLITON, A.; RATIER, B. Effect of various ions on organic lightemitting diodes obtained by ion-beam-assisted deposition. Applied Physics B-Lasers and Optics, v. 71, n. 1, p. 33-41, 2000.

65 ANTONY, R.; MOLITON, A.; TROADEC, D. Optimized organic light-emitting diodes according to deposition processes. Synthetic Metals, v.121, n.1-3, p 1749-1750, 2001.

66 ANTONY, R.; MOLITON, A.; LUCAS, B. Organic light-emitting devices obtained with helium-ion-beam-assisted deposition process. Applied Physics a-Materials Science \& Processing, v. 70, n. 2, p. 185-195, 2000. 
67 CHAKAROUN, M. et al. Lifetime obtained by ion beam assisted deposition. Materials Science \& Engineering C, v. 27, n. 5-8, p. 1043-1045, 2007.

68 KIM, W. J. et al. Passivation effects on the stability of pentacene thin-film transistors with $\mathrm{SnO} 2$ prepared by ion-beam-assisted deposition. Journal of Vacuum Science \& Technology B, v. 23, n. 6, p. 2357-2362, 2005.

69 CHANG, C. C. et al. Spin coating of conjugated polymers for electronic and optoelectronic applications. Thin Solid Films, v. 479, n. 1-2, p. 254-260, 2005.

$70 \mathrm{CHO}$, J. et al. Fabrication of highly ordered multilayer films using a spin self-assembly method. Advanced Materials, v. 13, n. 14, p. 1076, 2001.

71 LOPES, K. C. Fabricação e caracterização de filmes semicondutores de InN depositados com o método de deposição assistida por feixe de íons. 2008. p.99 Dissertação (Mestrado) - Instituto de Física, Universidade de São Paulo, São Paulo, 2008.

72 ZIEGLER, J. F.; ZIEGLER, M. D.; BIERSACK, J. P. SRIM - The stopping and range of ions in matter (2010). Nuclear Instruments \& Methods in Physics Research Section BBeam Interactions with Materials and Atoms, v. 268, n. 11-12, p. 1818-1823, 2010.

73 BIERSACK, J. P.; HAGGMARK, L. G. A monte-carlo computer-program for the transport of energetic ions in amorphous targets. Nuclear Instruments \& Methods, v. 174, n. 1-2, p. 257-269, 1980.

74 CHEN, S. H. et al. Molecular packing in crystalline poly(9,9-di-n-octyl-2,7-fluorlene). Macromolecules, v. 37, n. 18, p. 6833-6838, 2004.

75 EINSTEIN, A. Generation and conversion of light with regard to a heuristic point of view. Annalen Der Physik, v. 17, n. 6, p. 132-148, 1905.

76 JONDA, C.; MAYER, A. B. R. Investigation of the electronic properties of organic lightemitting devices by impedance spectroscopy. Chemistry of Materials, v. 11, n. 9, p. 2429$2435,1999$.

77 OLZON-DIONYSIO, D. et al. Ion beam assisted deposition of an organic light emitting diode electrode. Surface \& Coatings Technology, v. 204, n. 18-19, p. 3096-3099, 2010. 
78 WILSON, R. G. Ion-implantation ranges and range straggles in organic polymers and comparison with calculations. Journal of Applied Physics, v. 73, n. 5, p. 2215-2219, 1993.

79 FEKETE, Z. A. et al. Ion beam irradiation of conjugated polymers for preparing new membrane materials - a theoretical study. Separation and Purification Technology, v. 57, n. 3, p. 440-443, 2007.

80 TEIXEIRA, F. S. et al. Gold-implanted shallow conducting layers in polymethylmethacrylate. Journal of Applied Physics, v. 105, n. 6, p.64313, 2009.

$81 \mathrm{WEH}, \mathrm{L}$. Self-organized structures at the surface of thin polymer films. Materials Science \& Engineering C-Biomimetic and Supramolecular Systems, v. 8-9, p. 463-467, 1999.

82 NENNA, G. et al. Insights into thermal degradation of organic light emitting diodes induced by glass transition through impedance spectroscopy. Journal of Applied Physics, v. 105, n. 12, p. 6, 2009.

83 ARIU, M.; LIDZEY, D. G.; BRADLEY, D. D. C. Influence of film morphology on the vibrational spectra of dioctyl substituted polyfluorene (PFO). Synthetic Metals, v. 111, p. 607-610, 2000.

84 BUISSON, J. P. et al. Comparative-study of the vibrational properties of polymers with phenyl ring. Synthetic Metals, v. 41, n. 1-2, p. 287-290, 1991.

85 DE KOK, M. M. et al. Modification of PEDOT: PSS as hole injection layer in polymer LEDs. Physica Status Solidi a-Applied Research, v. 201, n. 6, p. 1342-1359, 2004.

86 BORGES, C. A. M. et al. Strong luminescence intensity modulation near a metal-organic interface. Synthetic Metals, v. 154, n. 1-3, p. 133-136, 2005.

87 TEIXEIRA, F. S. et al. Surface plasmon resonance of gold nanoparticles formed by cathodic arc plasma ion implantation into polymer. Journal of Vacuum Science \& Technology B, v. 27, n. 5, p. 2242-2247, 2009.

88 Electrical, optical, and structural studies of shallow-buried Aupolymethylmethacrylate composite films formed by very low energy ion implantation. Journal of Vacuum Science \& Technology A, v. 28, n. 4, p. 818-823, 2010. 
89 GAO, Y.; PARK, K. T.; HSIEH, B. R. Interface formation of Ca with poly(p-phenylene vinylene). Journal of Applied Physics, v. 73, n. 11, p. 7894-7899, 1993.

90 LEE, J. H.; YI, Y. J.; MOON, D. W. Direct evidence of Al diffusion into tris-(8hydroquinoline) aluminum layer: medium energy ion scattering analysis. Applied Physics Letters, v. 93, n. 15, p. 3, 2008.

$91 \mathrm{CHO}, \mathrm{J} . \mathrm{H}$. et al. Effects of metal penetration into organic semiconductors on the electrical properties of organic thin film transistors. Applied Physics Letters, v. 89, n. 13, p.132101, 2006.

92 KIM, Y.; JEON, D. Effect of deposition temperature on the morphology and contact resistance of Au on pentacene. Journal of Applied Physics, v. 108, n. 1, p. 3, 2010.

93 ZHANG, X. H.; DOMERCQ, B.; KIPPELEN, B. Effect of Au deposition rate on the performance of top-contact pentacene organic field-effect transistors. Synthetic Metals, v. 159, n. 21-22, p. 2371-2374, 2009.

94 JEONG, S. M. et al. Charge injection and transport model in organic light-emitting diodes with aluminum cathodes prepared by ion beam assisted deposition. Solid-State Electronics, v. 49, n. 2, p. 205-212, 2005.

95 LIAO, L. S. et al. Ion-beam-induced surface damages on tris-(8-hydroxyquinoline) aluminum. Applied Physics Letters, v. 75, n. 11, p. 1619-1621, 1999.

96 POULARD, C.; DAMMAN, P. Control of spreading and drying of a polymer solution from Marangoni flows. EPL, v. 80, n. 6, p. 64001, 2007.

97 HEIMEL, G. et al. Organic/metal interfaces in self-assembled monolayers of conjugated thiols: A first-principles benchmark study. Surface Science, v. 600, n. 19, p. 4548-4562, 2006. 